\title{
EMPREGO DA TÉCNICA DE ANÁLISE DE IMAGENS NA DETERMINAÇÃO DO COMPRIMENTO E DA LARGURA DE SEMENTES DE MILHO
}

\author{
PEDRO ABEL VIEIRA JUNIOR \\ Engenheiro Agrônomo
}

Orientador: Prof. Dr. SILVIO MOURE CICERO

Dissertação apresentada à Escola Superior de Agricultura "Luiz de Queiroz", da Universidade de São Paulo, para a obtenção do título de Mestre em Agronomia. Área de concentração: Fitotecnia.

PIRACICABA

Estado de São Paulo - Brasil

Fevereiro - 1998 
Dados Internacionais de Catalogação na Publicação (CIP) DIVISÃo DE BIBLIOTECA E DOCUMENTAÇÃo - Campus "Luiz de Queiroz"/USP

Vieira Junior, Pedro Abel

Emprego da técnica de análise de imagens na determinação do comprimento e da largura de sementes de milho / Pedro Abel Vieira Junior. - - Piracicaba, 1998.

153 p. : il.

Dissertação (mestrado) - - Escola Superior de Agricultura Luiz de Queiroz, 1998. Bibliografia. Titulo

1. Informática agricola 2. Processamento de imagem 3. Semente de milho I.

CDD 633.15 


\section{EMPREGO DA TÉCNICA DE ANÁLISE DE IMAGENS \\ NA DETERMINAÇÃO DO COMPRIMENTO E DA \\ LARGURA DE SEMENTES DE MILHO}

Pedro Abel Vieira Junior

Aprovada em: 20/02/98

Comissão julgadora:

Prof. Dr. Silvio Moure Cicero

Prof. Dr. Durval Dourado Neto

Dr. Luiz Carlos Miranda
ESALQ/USP

ESALQ/USP

EMBRAPA-Soja

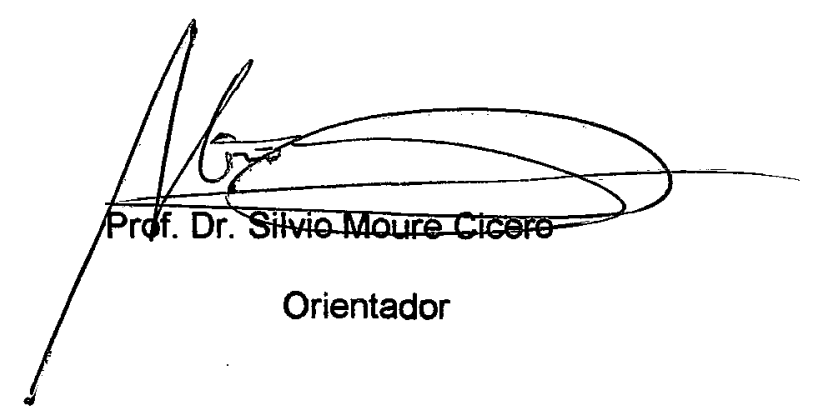


Ao meu pai Pedro Abel (in memorian), pelo exemplo de vida e minha formação

\author{
À minha esposa, Adriana, \\ pela compreensão, apoio, \\ dedicação à família e \\ o amor que nos une
}

Aos meus filhos Nicolle, Gabriella e

Lucas, e que esta fase de nossas

vidas contribua para suas

formações 


\section{AGRADECIMENTOS}

Ao Prof. Dr. Silvio Moure Cicero, pelo apoio, orientação, tempo e esforço dispensado para a realização desta dissertação.

À EMBRAPA, através do Serviço de Produção de Sementes Básicas, pela oportunidade de realização do curso e pelo suporte financeiro.

À EMBRAPA - Instrumentação Agropecuária, nas pessoas de seus Chefes, Dr. Silvio Crestana e Dr. Ladislau Martin Neto, por ceder as dependências do Laboratório de Análise de Imagens, equipamentos e o sistema SIARCS $3.0^{\circledast}$.

Ao SENAI, através da Escola Mário Dedini, na pessoa de seu Diretor Sr. Orlando Cristofoletti, por ceder as dependências do Laboratório de Metrologia e instrumentos de medição.

Ao corpo docente da ESALQ/USP, especialmente aos Professores Doutores Paulo Roberto de Camargo e Castro, Durval Dourado Neto, Walter Rodrigues da Silva, Julio Marcos Filho, Ricardo Ferraz de Oliveira, Francisco Ferraz de Toledo, Antônio Luiz Fancelli, Nilson Augusto Villa Nova e José Otávio Machado Menten pela atenção e apoio. 
Ao Prof. Dr. Carlos Tadeu dos Santos Dias, do Departamento de Matemática e Estatística da ESALQ/USP, pelas suas sugestões e colaboração nas análises estatísticas.

Ao Engenheiro Agrônomo Dr. José Rozalvo Andrigueto, pelo apoio e incentivo a minha carreira profissional.

Ao Engenheiro Agrônomo Dr. Luiz Carlos Miranda, pelo valoroso apoio na execução do trabalho e estimado exemplo de amizade.

Ao Engenheiro Elétrico Lúcio de Castro Jorge, pelas valiosas sugestões expontâneas e colaboração na análise das imagens.

Aos Engenheiros Agrônomos, Helena Maria C. P. Chamma, Maria Heloisa D. Moraes, Edson Teramoto, em especial a Ciro Scaranari e Ana Dionisia L. C. Novembre, pelo apoio e colaboração.

Ao supervisor Edison Bolson, pelo auxílio e suporte na condução do trabalho e pela amizade.

Ao Técnico Ednaldo José Ferreira, pela colaboração na análise das imagens.

Aos colegas de curso, em especial aos amigos Leila Martins, Renata Maschietto, Mariane Victorio de Carvalho, Oscar José Smiderle e Dioger Teruel, pelo incentivo e bons momentos compartilhados, e a Marluce Cortez, Cristina Maria Ribeiro, Luiz Ferraro, Marcelo Miguel, Carlos Moure 
Cicero, Mônica Martins, Maria Cristina Spinola, Clóvis Peixoto e Maristela Panobianco.

Aos funcionários da ESALQ/USP, Ilze Helena C. G. das Neves, Hodair Banzatto Junior, Maria Aparecida Soledade, Antonio Arruda, Osvaldo de Jesus, Osmair Neves, Edson Moraes, pelo apoio e colaboração.

A todos que, direta ou indiretamente, colaboraram para a realização do curso. 


\section{SUMÁRIO}

Página

RESUMO

$\mathbf{x}$

SUMMARY xii

1. INTRODUÇÃO 001

2. REVISÃO DE LITERATURA 004

2.1. Semeadura e rendimento da cultura 004

2.2. Metrologia 008

2.2.1. Incerteza de medida 010

2.2.2. Instrumentos de medida 017

2.3. Beneficiamento de sementes 021

2.3.1. Classificação quanto à largura e à espessura 022

2.3.2. Classificação quanto ao comprimento 024

2.3.3. Avaliação da classificação 026

2.4. Processamento de imagens digitais 031 2.4.1. Imagem e imagem digital 035 
2.4.2. Digitalização de imagens

039

2.4.3. Técnicas de pré-processamento da imagem digital ........... 042

2.4.4. Análise da imagem .......................................................... 044

3. MATERIAL E MÉTODOS .................................................................. 048

3.1. Localização ................................................................................. 048

3.2. Obtenção das sementes ........................................................... 048

3.3. Estimativa do tamanho da amostra .......................................... 049

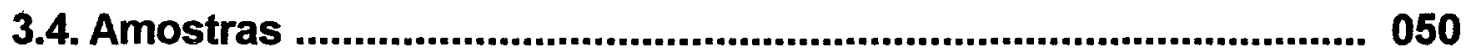

3.5. Determinação das medidas de referência .................................... 051

3.6. Determinação das medidas com o paquímetro ............................. 052

3.7. Digitalização das imagens ....................................................... 052

3.8. Pré-processamento das imagens ............................................... 058

3.9. Análise das imagens ................................................................ 060

3.10.Identificação das sementes nas imagens ................................. 063

3.11.Estimativas das medidas em milímetros .................................. 063

3.12. Estimativa da incerteza de medida ............................................. 065 
3.13.Estimativa do tamanho da amostra

4. RESULTADOS E DISCUSSÃO 069

4.1. Estimativa do tamanho da amostra 069

4.2. Eliminação dos momentos referentes aos resíduos 072

4.3. Análise das imagens 072

4.4. Medidas determinadas 082

4.5. Medidas estimadas 084

4.6. Incerteza de medida 089

4.6.1. Medidas determinadas 089

4.6.2. Medidas estimadas 094

4.7. Tamanho da amostra 132

4.8. Considerações finais 139

4.8.1. Adequação dos parâmetros e dos procedimentos 139 4.8.2. Sistema de classificação 140

5. CONCLUSÃO 142

6. REFERÊNCIAS BIBLIOGRÁFICAS 143 


\title{
EMPREGO DA TÉCNICA DE ANÁLISE DE IMAGENS NA DETERMINAÇÃO DO COMPRIMENTO E DA LARGURA DE SEMENTES DE MILHO
}

\author{
Autor: Pedro Abel Vieira Junior \\ Orientador: Prof. Dr. Silvio Moure Cicero
}

\section{RESUMO}

A classificação de sementes de milho pelas dimensões de comprimento e largura é importante para um bom desempenho de semeadoras de precisão, contribuindo em muito para a obtenção da adequada distribuição espacial e população de plantas, com reflexos sobre o rendimento da cultura.

No Brasil, uma das limitações enfrentadas pelas empresas produtoras de sementes de milho é a falta de padrões oficiais mais específicos para a classificação, principalmente em relação ao comprimento das sementes. Provavelmente a carência de padrões oficiais advêm da inexistência de métodos práticos, exatos e repetitivos para medir as sementes.

Por esta razão, amostras de lotes de sementes classificados em $18 \mathrm{C}, 18 \mathrm{~L}, 20 \mathrm{C}, 20 \mathrm{~L}, 22 \mathrm{C}, 22 \mathrm{~L}, 24 \mathrm{C}, 24 \mathrm{~L}$ foram submetidas ao teste de 
retenção de peneiras e longuímetro. Em amostras de sementes retidas pelas peneiras e determinadas pelo longuímetro, foram determinadas as dimensões de comprimento e largura empregando-se o projetor de perfil. A seguir, foram comparadas às medidas determinadas com o projetor de perfil, com e entre si, as medidas determinadas pelos métodos tradicionais e as medidas estimadas com emprego do sistema SIARCS $3.0^{\circledR}$ (métodos do retângulo circunscrito e da elipse que melhor representa o objeto) em imagens digitalizadas com um scanner de mesa nas resoluções de 100, 150, 200 e 250 ppi com as sementes em várias ordenações.

Foram estudados os seguintes parâmetros e procedimentos: resolução de digitalização da imagem, tamanho da amostra em função da precisão requerida, procedimento computacional (método do retângulo circunscrito e da elipse que melhor representa o objeto, disponiveis no sistema SIARCS $3.0^{\circledR}$ ) e disposição das sementes durante a digitalização das imagens (posição dorsal e ventral, e disposiçăo).

Em função da adequação dos parâmetros e dos procedimentos estudados, conclui-se que o emprego da técnica de análise de imagens é viável para determinar o comprimento e a largura de sementes de milho, apresentando alta precisão e exatidão satisfatória, bem como vantagens adicionais em relação aos métodos tradicionais. 


\section{UTILIZATION OF IMAGE ANALYSIS TECHNIQUE TO ESTIMATE THE \\ LENGHT AND THE WIDTH IN CORN SEEDS}

Author: Pedro Abel Vieira Junior

Adviser: Prof. Dr. Silvio Moure Cicero

\section{SUMMARY}

Corn seeds classification by their length and width is important for a good performance of precision drills, in order to obtain an adequate arrangement of the plant population, with reflex on the yield.

One of the limitations found in Brazilian seed industries is the lack of an specific official pattern for seed classification, specially for its length. Probably the lack of an official pattern is due to an absence of a practical, precise and accurate method for this evaluation, which encourages seed industries to develop their own tests.

For that reason, samples of eight corn seed lots, classified by their length and width as $18 \mathrm{C}, 18 \mathrm{~L}, 20 \mathrm{C}, 20 \mathrm{~L}, 22 \mathrm{C}, 22 \mathrm{~L}, 24 \mathrm{C}$ and $24 \mathrm{~L}$, were submitted to retention sieve and to a practical test used to measure seed 
length; those are some methods usually used to evaluate the classification of corn seeds. In the seeds retained by the sieves and classified by length, their length and width were measured using an overhead projector, a measuring instrument known by its precision and accuracy. The measures determined with overhead were compared, with and among themselves, to the respectives measures determined with methods traditionally utilized to evaluate the classification of corn seeds and to the measures estimated applying the SIARCS $3.0^{\circledast}$ software in images of seeds made in resolutions of $100,150,200$ and $250 \mathrm{ppi}$, and with those seeds in different arrangements.

The following parameters and procedures were studied: resolution of digitalization, size of the sample in function of the required precision, proceeding of the software (model of rectangle circumscribed and the ellipse, availables in SIARCS $3.0^{\oplus}$ software) and arrangements of the seeds while digitalization of the images were been made.

This present research concluded that the image analysis technique is exact and accurate to estimate measures of length and width in corn seeds, and has advantages in relation to the other methods usually used to evaluate corn seeds classification. 


\section{INTRODUÇÃO}

As mudanças político-econômicas que ocorreram nos últimos anos no Brasil têm forçado o sistema agropecuário brasileiro a repensar seu modelo de produção. Os aspectos mais importantes dessa reflexão são: recessão e eliminação de subsídios crescentes no Brasil e no mundo, criação de mercados comuns com modificação de políticas alfandegárias, novos mercados consumidores e preocupação com a poluição do meio ambiente.

Como conseqüência desses acontecimentos, a agricultura mundial têm se modernizado, melhorando sua eficiência e aplicando tecnologia de ponta, notadamente na cultura do milho. Pode-se afirmar que a agricultura do século XXI será marcada pela aplicação da eletrônica e da informática, destacando-se o processamento de imagens digitais, que permite separar os diferentes objetos de uma imagem e de gerar suas descrições.

Recentemente, a EMBRAPA lançou o sistema computacional SIARCS $3.0^{\circledast}$ dedicado à análise de imagens digitais de raizes, que permite realizar medidas quantitativas, como comprimento, e dinâmicas, como topologia e arquitetura, em sistemas radiculares (Jorge et al, 1996). 
O Brasil apresenta um dos maiores volumes mundiais de produção de milho; entretanto, seu rendimento por unidade de área está situado entre os mais baixos. Muitos fatores contribuem para essa realidade durante o processo produtivo; entre eles, destacam-se as condições edafoclimáticas, o potencial genético, a presença de pragas e de plantas daninhas e, principalmente, a incorreta distribuição de plantas, tanto em população por área como distribuição espacial (Mercado de Milho, 1993).

Durante a safra $92 / 93$ estima-se que deixou-se de produzir $15 \%$ de uma produção total de 28 milhões de toneladas em razão da inadequada população de plantas por unidade de área; sendo que a população média de nossos campos é $20 \%$ abaixo da recomendada pela pesquisa (Mercado de Milho, 1993).

Deste contexto, fazem parte as sementes de alta qualidade, que envolvem aspectos relacionados com a pureza genética, a fisiologia, a sanidade, a pureza física e a classificação, salientando-se que constituem o insumo mais seguro e econômico do processo de produção.

No Brasil, durante o ano de 1995, foi cultivado aproximadamente 85 mil hectares de campos de sementes de milho, visando um mercado que movimenta ao redor de 235 milhões de reais por ano (Souza, 1995). A competição entre essas empresas e as exigências dos agricultores, que operam sob condições ambientais as mais diversas, vêm se tornando cada vez mais evidentes, principalmente no que diz respeito à classificação das sementes. 
Para avaliação da classificação dos lotes destinados à comercialização, o único teste oficial prescrito é o Teste de Retenção de Peneiras (Brasil, 1992), que apresenta limitações. Neste sentido, as empresas têm desenvolvido técnicas próprias, a exemplo do teste de plantabilidade; porém, ainda não se têm resultados consistentes que permitam adotá-lo como um teste padrão; além disso, em geral, é um teste complexo e pouco prático.

É interessante desenvolver novas técnicas que permitam avaliar as interações possíveis entre dimensões da semente, semeadura, população e distribuição espacial de plantas e rendimento da cultura.

Assim, o presente trabalho teve por objetivo definir os parâmetros e procedimentos necessários, relativos à viabilização do emprego da técnica de análise de imagens na determinação do comprimento e da largura de sementes de milho. Para tal, foram estudados os seguintes parâmetros e procedimentos: resolução de digitalização da imagem, tamanho da amostra em função da precisão requerida, procedimento computacional (métodos do retângulo circunscrito e da elipse que melhor representa o objeto) e disposição das sementes durante a digitalização das imagens (posição dorsal e ventral, e disposição); bem como foram comparados com e entre si, um método de medição reconhecidamente exato e preciso (projetor de perfil) e métodos tradicionalmente empregados na produção de sementes (paquímetro, teste de retenção de peneiras e longuímetro). 


\section{REVISÃO DE LITERATURA}

\subsection{Semeadura e rendimento da cultura}

Consultando Duncan (1975), Tanaka \& Yamaguchi (1977), França et al (1990) e Fancelli \& Dourado-Neto (1996), é possível concluir que a população e distribuição espacial de plantas por unidade de área são os principais componentes de produção na cultura do milho. Fatores de produção como a presença de pragas e invasoras, o inadequado suprimento de água e fertilidade podem ser contornados após o estabelecimento da cultura, enquanto que a população e a distribuição espacial de plantas não o são.

Como exemplo do efeito da população de plantas sobre o rendimento de grãos, cita-se Merotto et al (1996), que observaram aumento no rendimento de grãos da ordem de $30 \%$ quando empregaram a população recomendada de plantas em comparação à população praticada na maioria dos campos da região sul do Brasil, considerada uma das regiões com maior rendimento e nivel tecnológico da cultura no país. 
A incorreta distribuição de plantas proporciona redução no rendimento de grãos em até $13 \%$ sob condições favoráveis de semeadura (Rossmann \& Cook, 1966). Lenzi \& Machado (1996a e 1996b), verificaram significativa variação no rendimento de grãos quando alteraram a distribuição espacial das plantas mantendo a população.

Dentre os diversos fatores que afetam a população e distribuição espacial de plantas é reconhecida a importância da correta distribuição das sementes por ocasião da semeadura (Chinnan et al, 1975; Mantovani et al, 1991). Os mecanismos dosadores de sementes das semeadoras modernas são originários daqueles empregados em semeadoras de tração animal, introduzidas no Brasil pelos imigrantes europeus, sem maiores alterações. Assim, muitas semeadoras brasileiras foram copiadas sem considerar os principais parâmetros de relacionamento entre os componentes inerentes a cada máquina, bem como a realidade do agricultor brasileiro (Gazzola, 1989).

Na cultura de milho, normalmente são empregadas as chamadas semeadoras de precisão, nas quais as sementes são distribuídas uma a uma mantendo um espaçamento uniforme entre elas. O mecanismo dosador de sementes em semeadoras de precisão pode ser de discos perfurados, correias perfuradas, dedos preensores e sistemas pneumáticos. O sistema de disco perfurado é mais difundido no Brasil (Balastreire, 1990). 
O sistema de discos perfurados é composto por um disco dosador com furos redondos, oblongos ou de formato especial, localizados concentricamente ou nas bordas dos discos. Durante o movimento de rotação do disco, ao mergulhar na massa de sementes, há o alojamento de apenas uma semente em cada orifício, conduzindo-a até um duto responsável pela sua deposição no solo (Balastreire, 1990).

Em semeadoras de discos perfurados, a precisão na distribuição das sementes no solo é decorrente do alojamento da semente na célula do mecanismo dosador e da queda da semente no interior do duto. A captura múltipla ou nula de sementes pelas células do mecanismo dosador é apontada como a principal causa da desuniformidade na distribuição das sementes em semeadoras de precisão (Chinnan et al, 1975).

Em face às dificuldades encontradas na regulagem de semeadoras de discos para semeadura do milho, Mantovani et al (1991), classificaram as sementes quanto à sua espessura: menores que 14/64", denominadas sementes chatas, e maiores que 14/64", denominadas sementes redondas. As sementes chatas foram classificadas quanto à largura em: peneira 24 (largura compreendida entre 26/64" e 24/64"), peneira 22 (largura compreendida entre $24 / 64^{\prime \prime}$ e 22/64"), peneira 20 (largura compreendida entre 22/64" e 20/64") e peneira 18 (largura compreendida entre 20/64" e 18/64"). 
Mantovani et al (1991), testando a distribuição das sementes descritas no parágrafo anterior em quatro marcas de discos, com o dosador de sementes acoplado à uma filmadora registrando células vazias e células contendo mais de uma semente, demonstraram que a classificação proposta atende aos requisitos para melhoria do desempenho das semeadoras, pois, todos os discos testados atingiram um desempenho de $95 \%$ dos orifícios, contendo apenas uma semente, para todas classes de semente.

Em seqüência, a EMBRAPA - SPSB (1994) classificou sementes do híbrido de milho BR-201 conforme proposto por Mantovani et al (1991). Após isso, ordenou as sementes quanto ao comprimento em curtas e longas, respectivamente com o comprimento menor e maior que $28 / 64$ ", verificando que estas classes eram adequadas para uma boa distribuição das sementes do referido híbrido no solo, com emprego de semeadora de discos.

Portanto, é fundamental a uniformização das sementes quanto às suas dimensões de espessura, largura e comprimento para melhor adequar a distribuição das sementes no solo com emprego de semeadoras de precisão. 


\subsection{Metrologia}

Segundo Compain (1974), metrologia é o ramo da ciência física que estuda as medidas; medir é o ato de comparar grandezas de mesma espécie, e medida é um número proveniente do ato de medir. A metrologia trata de grandezas como: distância, tempo, massa, velocidade, etc.

Um paradoxo na física, reconhecida como a ciência da medida, é que uma grandeza física deve ser calculada a partir de outras grandezas que possam ser medidas, entretanto, as grandezas físicas são expressas em termos de três grandezas indefiníveis: comprimento, tempo e massa (Sears \& Zemansky, 1980).

No mundo existem dois sistemas de medidas lineares em uso: 0 sistema métrico, cuja unidade científica é o metro $(\mathrm{m})$ e seus múltiplos a exemplo do milímetro $(\mathrm{mm})$, e o sistema inglês, cuja unidade científica é a polegada (").

O conjunto de regras e padrões para medir grandezas é estabelecido por um comitê internacional denominado Conferência Geral de Pesos e Medidas. A principal característica de um padrão é sua durabilidade; assim, em 1889, quando uma barra de um metro, com perfil em forma de $X$, da liga de platina iridiada foi escolhida como padrão de comprimento para o sistema métrico, julgava-se que esta liga fosse durável em sua estrutura 
química. Embora a platina iridiada seja uma liga particularmente estável, a preservação de uma barra deste material como padrão mundial acarreta uma série de transtornos, a exemplo da confecção de réplicas para vários países, comparando-se periodicamente estas réplicas com o padrão internacional (Sears \& Zemansky, 1980).

Em razão do exposto acima, a Conferência Geral substituiu o padrão de comprimento para uma constante atômica, o comprimento de onda da luz vermelho-laranja emitida por átomos individuais do Criptônio-86 em um tubo cheio de gás de Criptônio, no qual é mantida uma descarga elétrica. Convencionou-se que um metro é igual a $1.650 .763,73$ vezes o comprimento de onda da luz vermelho-laranja do Criptônio-86 (Sears \& Zemansky, 1980).

O sistema inglês adota como padrão de medida linear uma barra de bronze com 38 polegadas de comprimento e seção de uma polegada quadrada. Na superfície superior da barra encontram-se duas cavidades com meia polegada de diâmetro, cujos centros distam entre si em 36 polegadas. No fundo de cada cavidade há um cravo de ouro com diâmetro igual a um décimo de polegada e uma marca. A distância entre as marcas dos cravos de ouro à temperatura de $62^{\circ} \mathrm{F}$ é igual a uma jarda ou 36 polegadas (Hume, 1962).

A cada dez anos os padrões do sistema métrico e sistema inglês são comparados, constatando-se que o padrão do sistema inglês até 1962 havia reduzido em 0,0002 polegadas; portanto, este sistema é menos preciso 
do que o sistema métrico. Outra limitação para o sistema em polegada é a existência de dois fatores de conversão para o sistema métrico, a polegada inglesa igual a $25,399 \mathrm{~mm}$ e a polegada americana igual a $25,400 \mathrm{~mm}$ (Hume, 1962).

Apesar do erro associado à polegada e da existência de dois valores de conversão da polegada para o sistema métrico (polegada inglesa e polegada americana), a polegada americana é a grandeza adotada mundialmente pela indústria mecânica, muito embora a tendência seja a substituição pelo sistema métrico. Por esta razão, as dimensões de peças mecânicas, entre elas crivos de peneiras, são fornecidas em polegadas, usualmente em 64 avos da polegada (Freire, 1984).

\subsubsection{Incerteza de medida}

Além do já comentado, a medida de um objeto está sujeita a erros. Várias medições de um mesmo objeto, por mais meticulosas que sejam, não resultam em medidas iguais. Casillas (1979) comenta ser impossível realizar uma medição isenta de erros: a medida efetiva de um objeto difere mais ou menos de sua medida real e a esta diferença denomina-se incerteza de medida. 
De acordo com Casillas (1979), a incerteza de medida pode ser devida ao ambiente, ao instrumento de medição e ao próprio objeto. Fatores ambientais que alterem as dimensões dos objetos contribuem para a incerteza de medida. Na indústria mecânica, o fator ambiental de maior relevância é a temperatura; para tanto se adota $20^{\circ} \mathrm{C}$ como referência. No caso de sementes, além da temperatura, a umidade relativa do ar pode alterar as dimensões das sementes (Bewley \& Black, 1994).

Alguns fatores ligados ao instrumento de medição como a escala, acoplamento ao objeto, posicionamento do instrumento de medição em relação ao objeto e desgaste do instrumento de medição contribuem o aumento da incerteza da medida. Quanto a escala do instrumento, a incerteza da medida mínima é igual a menor divisão empregada na escala. Já com relação ao acoplamento do instrumento de medição ao objeto, este pode provocar a deformação plástica do objeto (Compain, 1974).

Os principais fatores inerentes ao objeto que contribuem para a incerteza de medida são: a resistência à deformação plástica, a irregularidade da forma e a aspereza de sua superfície (Compain, 1974).

Em geral, sementes de milho apresentam dimensões de comprimento, largura e espessura. As dimensōes de largura e espessura apresentam formas bastante irregulares; portanto, realizar medições da largura ou da espessura em diferentes pontos contribuem para o aumento da incerteza 
de medida. Quanto ao comprimento, as sementes de milho apresentam pedicelo pouco resistente à deformação plástica, portanto estão sujeitas à incerteza de medida em função da força exercida pelo instrumento de medição durante seu acoplamento à semente.

Em razão do exposto acima, desenvolveu-se uma metodologia própria para estimar a incerteza de medida. A indústria mecânica trabalha com limites de tolerância da incerteza de medida positivos ou negativos, em função da aplicação da peça (Kennedy, 1973; Compain, 1974; McCuen, 1985).

Para estimar a incerteza de medida de um instrumento, tomamse várias medidas de um mesmo objeto, ou de vários objetos, comparando-as à medida ou medidas obtidas por um instrumento com reconhecida precisão. Em geral, os instrumentos de medição adotados como referência são projetores de perfil. As medidas obtidas pelo instrumento a ser aferido são subtraídas das medidas correspondentes obtidas pelo instrumento de referência, aplicando-se às diferenças um teste estatístico, a exemplo do teste $t$ de Student (Berndt, 1961; McCuen, 1985).

O teste $t$ de Student permite a comparação entre duas populações a partir de suas médias e desvios padrōes, estimando a significância da diferença entre as duas populações, ou seja, quão significativa é a diferença entre as populações do zero (Gomes, 1990). Com o avanço da informática, foram desenvolvidos sistemas estatísticos que permitem obter 
estatísticas e aplicar testes rapidamente (Heiberger, 1989), a exemplo do sistema estatístico SAS que dispõe da rotina "proc univariate" que obtém estatísticas como média e desvio padrão, e aplicar o teste t de Student, a um conjunto de dados de duas populações (SAS, 1990).

Uma limitação estatística com relação ao método descrito por Berndt (1961) é não considerar o número de medidas, ou seja, o tamanho da amostra a ser tomada. Uma amostra maior do que a necessária implica em desperdício de tempo e recursos, enquanto uma amostra pequena não fornece informações suficientes, a respeito da população, para a tomada de uma decisão dentro de um determinado nível de confiança (Cochran, 1965).

Uma amostra de uma população é representativa quando a inclusão de um novo indivíduo na amostra não altera o valor da variância, ou seja, quando ocorre a estabilização da variância (Cochran, 1965; McCuen, 1985; Spiegel, 1978). Muito embora existam sistemas estatísticos que permitem a avaliação gráfica da estabilidade da variância, este é um procedimento extremamente moroso, não considerando a precisão desejada e a composição da amostra (Heiberger, 1989; SAS, 1990; Fonseca \& Martins, 1995). A precisão desejada pode ser entendida como o total de erro que estamos dispostos a tolerar nas estimativas amostrais (Cochran, 1965).

É complicado decidir qual a grandeza de erro a ser tolerada, principalmente quando os resultados podem ser aplicados de vários modos. 
Existem modelos matemáticos que estimam o erro máximo aceitável ou o nível de significância, entretanto, normalmente a estatística trabalha com limites ou intervalos de confiança de 5 e $1 \%$ (Cochran, 1965).

Um modo prático para estimar o tamanho da amostra representativa de uma população com distribuição normal dos indivíduos, consiste em tomar uma amostra de indivíduos, estimar o desvio padrão, e aplicar o modelo matemático

$$
n=\left(\frac{t_{(\alpha / 2, \varphi)} \times S}{p}\right)^{2}
$$

no qual n é o tamanho da amostra necessária para representar a população

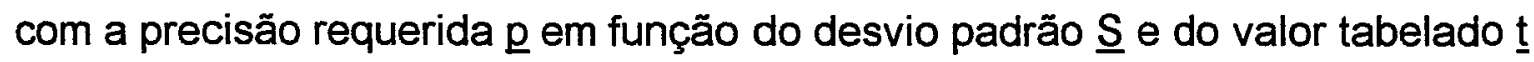
$\left(t_{(\alpha / 2, \varphi)}\right)$ ao nível $\underline{\alpha}$ de significância para uma população com $n-1$ graus de liberdade (ํ) (Spiegel, 1978; Fonseca \& Martins, 1995).

O valor de ț tabelado varia em função do tamanho da amostra, da distribuição normal dos indivíduos e do nível significância $\underline{\alpha}$ requerido. Para populações com distribuição normal e amostras com mais de 120 elementos considera-se $\underline{\varphi}$ igual ao $\underline{\infty}$. Para $\underline{\varphi}$ igual a 99 e 299 , considerando $1 \%$ de significância, os valores tabelados de $t_{(0,01 / 2 ; 99)}$ e $t_{(0,01 / 2 ; 299)}$ são iguais a 2,62 e 2,5758, respectivamente (Fonseca \& Martins, 1995).

A verificação da distribuição normal dos indivíduos pode ser efetuada aplicando-se a técnica do histograma (Spiegel, 1978; Fonseca \& 
Martins, 1995). Para tanto, divide-se a população em K classes, segundo a equação

$$
k=\sqrt{n}
$$

no qual ñ representa o número de indivíduos. Determina-se a amplitude das classes $\left(A_{c}\right)$ aplicando-se a equação

$$
A_{c}=\frac{L-l}{\sqrt{n}}
$$

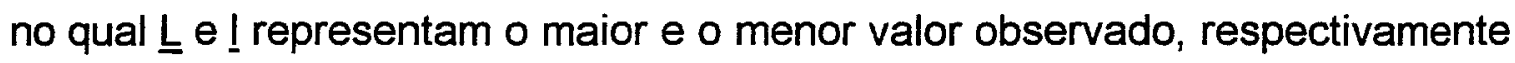
(Spiegel, 1978; Fonseca \& Martins, 1995).

No presente caso, de sementes de milho e dimensões das células dosadoras dos sistemas de distribuição de sementes das semeadoras, na literatura consultada não foram encontrados estudos mais detalhados com relação aos limites de tolerância. Assume-se que as dimensões de comprimento, largura e altura das células dosadoras devem ser, no máximo $10 \%$ maior que a máxima dimensāo das sementes empregadas. Também, dentro de um mesmo lote, as sementes não devem apresentar amplitude de dimensão maior que 2/64" para a largura e espessura e 6/64" para o comprimento (Barmington, 1948; Kepner et al, 1978).

Considerando a explicação sobre medidas de dimensão, devese assumir que não existe definição para dimensão, existe sim, o conceito, 
pragmaticamente aceito, de que um metro é igual a $1.650 .763,73$ comprimentos de onda da luz vermelha alaranjada do Criptonio-86. Enquanto não houver definição da dimensão, o que muitos assumem como impossível, somente pode-se agir com suficiente pragmatismo para aceitar os valores de dimensão como comparativos. Ao agir com suficiente pragmatismo, incorre-se em erros de precisão ou repetitividade, que por sua vez provocam erros de exatidão; em razão de que as escalas de todos instrumentos para determinação de dimensão são direta ou indiretamente comparadas ao modelo do Criptonio 86. Quando empregados diferentes instrumentos para determinar a mesma dimensão de um corpo estável, valores diferentes são medidos devido ao erro de precisão, inerente à fabricação dos instrumentos.

Portanto, o ideal seria desenvolver um modelo para medição que pudesse ser replicado em sua íntegra, independente de variáveis externas, não provocando deformação plástica no objeto a ser medido, com escala variável em função da precisão requerida e com fator de correção para a incerteza da medida. 


\subsubsection{Instrumentos de medida}

Um instrumento de medida é o meio empregado para conhecer as dimensões de um objeto, com um limite da incerteza de medida previamente estabelecido ( Casillas, 1979).

A medida pode ser direta ou indireta. É considerada uma medida direta quando o instrumento de medição se acopla ao objeto, e indireta quando o instrumento de medição não se acopla ao objeto. Em geral, a medida indireta é mais precisa do que a medida direta. A medida direta é mais sujeita à incerteza de medida, principalmente, devido à forma e deformação plástica do objeto, enquanto que na medida indireta, a incerteza de medida está associada apenas ao erro de leitura e do equipamento (Freire, 1984).

Um exemplo de instrumento de medida direta é o paquímetro (Figura 1), fabricado em aço carbono; seus principais componentes são: a escala fixa em medidas métrica ou inglesa, cursor que desliza ao longo de escalas fixas e com o Vernier das escalas métrica e inglesa, uma perna fixa à escala fixa e outra perna fixa ao cursor, um parafuso de fixação da corrediça e uma haste que permite realizar medidas de profundidade (Freire, 1984).

As duas réguas do paquímetro podem deslizar uma sobre a outra, terminando cada uma em uma perna perpendicular às mesmas. Uma das réguas é graduada com uma mandibula fixa e a outra é corrediça, contendo a 
escala de Vernier. O Vernier se destina a subdividir a escala principal e é constituído por um dispositivo formado por duas escalas de unidades diferentes. Geralmente, os paquímetros em milimetros são construídos com aproximações entre 0,1 e 0,02 mm (Freire, 1984).

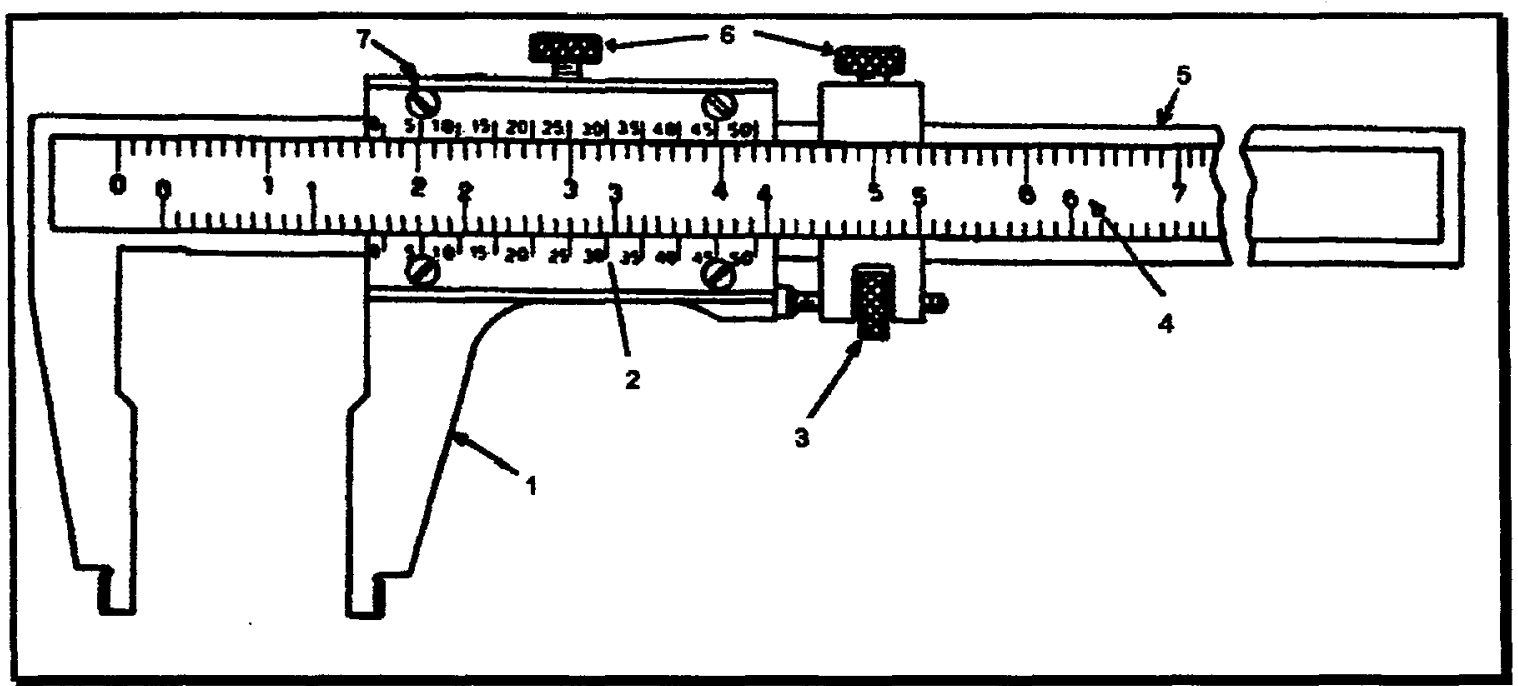

Figura 1: Esquema de um paquímetro e seus componentes, segundo Freire (1984): 1. Garra; 2. Vernier com divisões para leitura direta; 3. Ajuste fino; 4. Escala; 5. Barra temperada e estabilizada; 6 . Parafusos de fixação; 7. Parafuso para ajuste do Vernier, quando desgastadas as garras.

Para o manuseio do paquímetro, afrouxam-se os parafusos de fixação da corrediça e do grampo, acopla-se as mandibulas ao objeto com emprego do parafuso de ajuste, fixa-se a corrediça com o parafuso procedendo a leitura do número inteiro na escala fixa e do decimal na escala de Vernier. 
Um exemplo de instrumento de medição indireta é o projetor de perfil (Figura 2), que projeta a sombra aumentada do perfil de um objeto sobre um visor de cristal polido. A imagem que se vê é a silhueta do objeto.

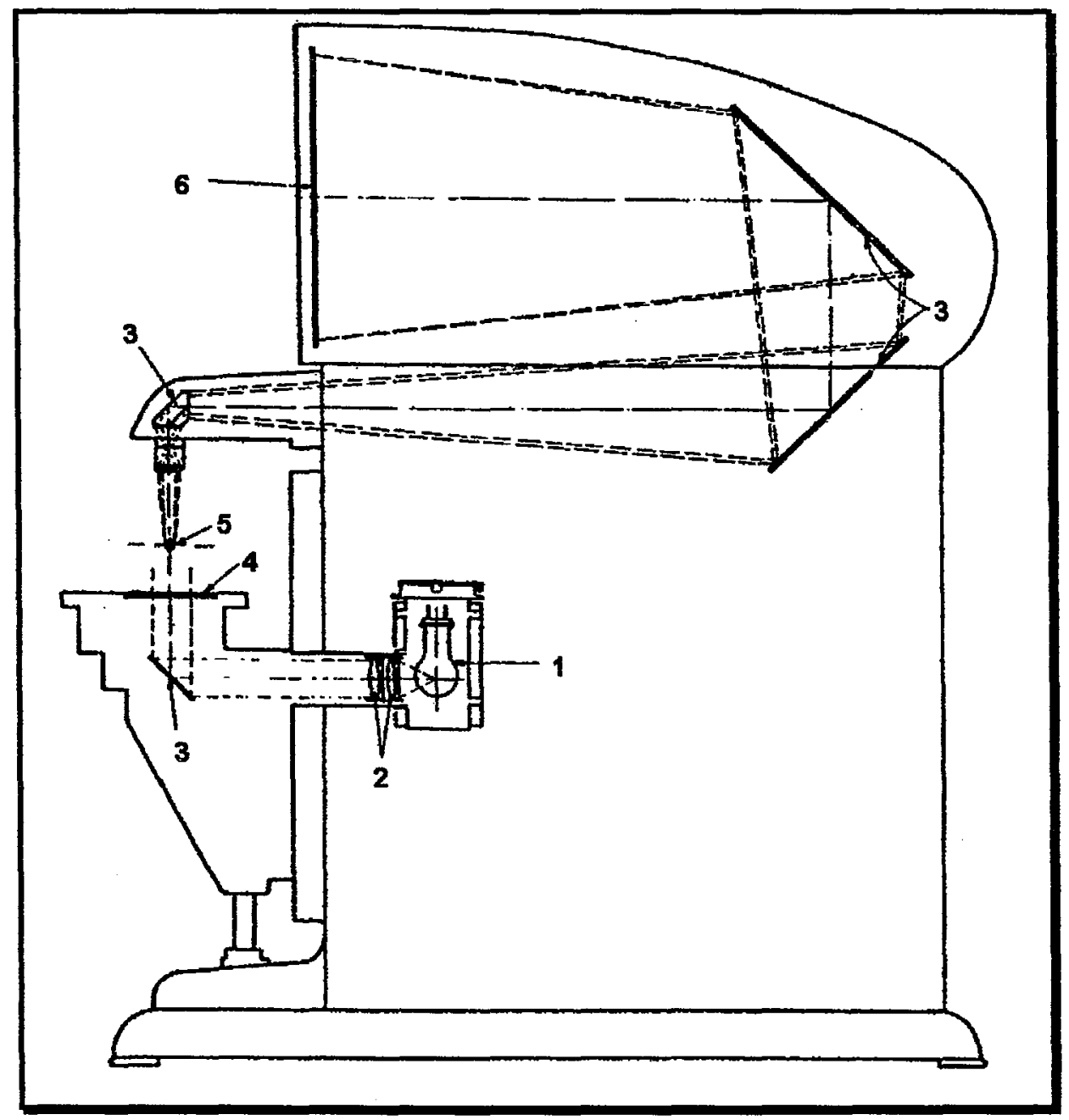

Figura 2: Esquema do circuito de reflexão e projeção ótica de um projetor de perfil, segundo Kennedy (1973): 1. Fonte luminosa; 2. Conjunto de lentes colimadoras; 3 . Conjunto de espelhos; 4 . Mesa transparente; 5. Lente de aumento; 6 . Visor de cristal. 
O projetor de perfil é empregado na indústria mecânica de precisão por apresentar incerteza de medida associada ao equipamento da ordem de $0,00508 \mathrm{~mm}$ sobre todo o visor de cristal. Isto significa que um objeto com a silhueta aumentada em dez vezes apresenta incerteza de medida real na ordem de $0,000508 \mathrm{~mm}$. Ainda, o projetor de perfil não apresenta incerteza de medida associada à deformação plástica do objeto (Kennedy, 1973).

O projetor de perfil possui uma mesa com o centro transparente, acionada por roscas micrométricas ligadas a escalas com aproximação de 0,01 mm. A mesa é deslocada pelas roscas micrométricas horizontalmente, em dois sentidos perpendiculares; verticalmente, ainda gira e inclina de tal modo que o perfil do objeto tome a posição desejada no visor de cristal. O visor de cristal é dividido no sentido vertical e horizontal por uma cruz de mira. Alguns modelos são equipados com jogos de lentes que permitem projetar a silhueta aumentada entre 10 e 50 vezes (Kennedy, 1973).

Para operar o projetor de perfil, ajusta-se o objeto de modo que uma das extremidades do perfil do objeto coincida com um dos eixos da mira gravada no visor de cristal, desloca-se a mesa com emprego da rosca micrométrica até que a extremidade oposta do perfil do objeto coincida com o eixo da mira eleito, procedendo-se a leitura na escala (Kennedy, 1973). 


\subsection{Beneficiamento de sementes}

O beneficiamento de sementes é parte essencial da tecnologia envolvida na produção de sementes. Em sua definição mais ampla, o beneficiamento consiste em todas as etapas de preparação da semente para comercialização, realçando as suas boas características (Vaughan et al, 1976).

Durante a produção de sementes de milho, fatores de ordem genética, climática, técnicas culturais, nutrição das plantas e outros, concorrem para que ocorram sementes com diferentes formas e dimensões. Uma mesma espiga pode produzir sementes com diferentes dimensões de largura, espessura e comprimento e, normalmente, as sementes das extremidades da espiga apresentam maior espessura que sementes da porção mediana (Goodman, 1978). As dimensões de largura e comprimento são mais afetadas por fatores genéticos, população de plantas por unidade de área, distribuição espacial das plantas e nutrição. Neste último caso com destaque para suprimento de nitrogênio. Já a espessura é mais afetada por uma adequada polinização e fertilização dos óvulos (Suphot \& Kitima, 1977; Goodman, 1978).

Dentre as etapas de beneficiamento, a classificação consiste na separação da massa de sementes em frações com intervalos de dimensões previamente estabelecidos, através do emprego de máquinas e equipamentos apropriados (Welch, 1974). 
O principal objetivo da classificação de sementes de milho é a separação das sementes em classes quanto às dimensões de comprimento, largura e espessura, de tal modo que permitam a adequada leitura por parte das células dos mecanismos dosadores existentes nas semeadoras.

\subsubsection{Classificação quanto à largura e à espessura}

Para a classificação das sementes de milho quanto à largura e à espessura, usualmente são empregados equipamentos denominados genericamente de classificadores. O principal componente dos classificadores é a peneira, que pode ser plana ou tubular, fabricada em chapa metálica perfurada ou arame entrelaçado. Peneiras com orifícios ou crivos circulares classificam as sementes quanto à largura, e peneiras com crivos oblongos quanto à espessura (Welch, 1974).

O classificador apresenta movimento vibratório, no caso de peneiras planas, ou rotativo, no caso de peneiras tubulares, cujo princípio é posicionar a semente de tal modo que apresente a dimensão a ser classificada aos orifícios de dimensão específica. Caso a semente apresente dimensão menor que o crivo ela passará através da perfuração, enquanto se ela for maior não passará e será descarregada em uma bica própria. Em geral, os classificadores apresentam uma seqüência de peneiras superpostas, sendo 
que a peneira superior sempre apresenta dimensão de crivo maior que a peneira inferior (Vaughan et al, 1976; Toledo \& Marcos Filho, 1977).

A escolha da dimensão do crivo da peneira, o fluxo de alimentação e a vibração são as principais regulagens no caso de classificadores de peneiras planas. Para os classificadores de peneiras tubulares, as principais regulagens são a escolha da dimensão do crivo da peneira, fluxo de alimentação e velocidade de rotação (Vaughan et al, 1976; Toledo \& Marcos Filho, 1977).

Em ambos os casos, o principal atributo do equipamento é a calibração das dimensões dos crivos. Além dos problemas inerentes à deformação natural sofrida pelas peneiras, a exemplo do efeito da temperatura e o desgaste provocado pelo atrito da passagem das sementes, não é raro encontrar peneiras novas com as dimensões dos crivos descalibrados, em razão de problemas no método de fabricação artesanal empregado no Brasil (EMBRAPA - CNPMS, 1993; EMBRAPA - SPSB, 1994).

Uma providência prática, que com certeza minimizaria os problemas inerentes à classificação, é a avaliação periódica da calibração dos crivos, por parte das empresas produtoras de sementes, com emprego de calibradores "passa não passa", empregados na indústria mecânica. O calibrador "passa não passa", constitui-se de uma haste de metal resistente à deformação, com perfil em forma do orifício a ser aferido, reduzida incerteza de 
medida e com as dimensões das extremidades um pouco maior e menor do que o orifício a ser aferido (Kennedy, 1973). Para a calibração do orifício, introduzse a menor extremidade do calibrador, seguida da maior extremidade; o orifício estará calibrado quando a menor e a maior extremidade do calibrador, respectivamente, transpassar e não transpassar o orifício (Kennedy, 1973).

Embora não se disponha de estudos com relação ao limite de incerteza de medida e as dimensões do calibrador, segundo relato pessoal do Sr. Adélcio Piagentini, diretor da Indústria de Máquinas Agrícolas Pinhalense, sua indústria adota calibradores com o diâmetro das extremidades $0,05 \mathrm{~mm}$ maior e menor que o crivo da peneira e, com incerteza de medida de $0,05 \mathrm{~mm}$ para 100 medidas, ou seja, para 100 medidas realizadas de um mesmo objeto a amplitude máxima é de $0,05 \mathrm{~mm}$. Portanto, as dimensões dos crivos das peneiras podem apresentar uma diferença de medida máxima da ordem de 0,1 $\mathrm{mm}$.

\subsubsection{Classificação quanto ao comprimento}

Para a classificação de sementes de milho quanto à dimensão de comprimento, usualmente é empregado equipamento denominado cilindro alveolado ou "trieur". Este é constituído de um cilindro metálico giratório, cuja superficie interna apresenta alvéolos de tamanho específico e mesma 
dimensão. No interior do cilindro e em toda sua extensão, encontramos uma calha de altura regulável e, sob a calha, um transportador de sementes. Ao passar pelo interior do cilindro, a massa de sementes é revolvida pelo seu movimento giratório permitindo que as sementes se alojem nos alvéolos. As sementes curtas são levantadas, depositadas sobre a calha e levadas pelo transportador a uma bica de descarga própria. As sementes longas permanecem no interior do cilindro, sendo transportadas pelo movimento de rotação e inclinação longitudinal do cilindro para uma bica de descarga própria. Portanto, o princípio de funcionamento deste equipamento é a comparação do comprimento entre sementes. Este equipamento é de difícil regulagem e exige constantes verificações durante o beneficiamento no fluxo de alimentação, rotação e inclinação longitudinal do cilindro e posicionamento da calha (Vaughan et al, 1976; Toledo \& Marcos Filho, 1977).

Segundo relato pessoal do diretor da Indústria de Máquinas Agrícolas Pinhalense, Adélcio Piagentini, recomenda-se utilizar cilindros com alvéolos de diâmetro 6/64" maior que a largura da semente a ser classificada; por exemplo, para sementes classificadas por largura em peneira 18/64", deve ser empregado cilindro com diâmetro do alvéolo igual a 24/62". Portanto, para - adequado funcionamento do "trieur", as sementes devem ter sido previamente classificadas quanto à largura. 
No caso do "trieur", a precisão da classificação é prejudicada em função do princípio de separação do equipamento: as sementes não são comparadas com um crivo de dimensão relativamente estável e uniforme como no caso da peneira, mas sim comparadas entre si, ou seja, a semente mais curta vai ser elevada para a calha não importando sua dimensão de comprimento. Estima-se que em razão de seu princípio de classificação, o "trieur" não consegue separar sementes com diferenças na dimensão de comprimento menores do que 15\% (EMBRAPA - CNPMS, 1993; EMBRAPA SPSB, 1994).

Devido ao método de fabricação empregado no Brasil, no qual a chapa é dobrada após serem estampados os alvéolos na chapa metálica plana, é raro encontrar cilindros com as dimensões dos alvéolos calibrados. Também neste caso, devido ao desgaste provocado pelo atrito das sementes, o alvéolo pode sofrer alteração no diâmetro (EMBRAPA - CNPMS, 1993; EMBRAPA SPSB, 1994).

\subsubsection{Avaliação da classificação}

O principal objetivo na classificação de sementes de milho é a separação das sementes em classes quanto às dimensões de comprimento, largura e espessura, de tal modo que permitam a adequada leitura por parte 
das células dos mecanismos dosadores existentes nas semeadoras. Entretanto, conforme abordado no capítulo anterior, os equipamentos de classificação estão sujeitos ao desgate e erros que comprometem sua eficiência, necessitando de constante avaliação do processo.

Para avaliação da classificação dos lotes destinados à comercialização o único teste oficial prescrito é o teste de retenção de peneiras (Brasil, 1992). Este teste consiste na tomada de duas sub-amostras com $100 \mathrm{~g}$ de sementes puras passando-as através de peneiras manuais agitadas por um minuto. As sementes retidas pela peneira indicada, que tenham obrigatoriamente passado pelo orifício da peneira imediatamente superior, são separadas, pesadas e calculado seu percentual (Brasil, 1992). A legislação de alguns estados brasileiros determina o valor de $94 \%$ de retenção, como índice mínimo para comercialização.

O teste de retenção de peneiras apresenta sérias limitações quanto ao desempenho das sementes durante a semeadura, principalmente por não levar em consideração a dimensão de comprimento das sementes. Este teste também apresenta limitação com relação à calibração dos crivos das peneiras manuais, limitação esta que pode ser minimizada com a verificação periódica da calibração dos crivos empregando-se calibradores "passa não passa". 
Mesmo adotando a calibração periódica dos crivos, esta pode variar em função das condições ambientes; limitação passivel de ser contornada com a padronização do material de fabricação das peneiras e do ambiente de realização do teste.

Normalmente, a agitação das peneiras é manual, podendo variar; esta limitação poderia ser contornada com a adoção de agitadores mecânicos padronizados.

Como pode ser constatado, o teste deveria sofrer inúmeras padronizações para avaliar a classificação quanto à espessura e largura das sementes, restando a avaliação da classificação quanto ao comprimento.

Para dimensão de comprimento em sementes de milho, a legislação brasileira não prescreve limites de tolerância e metodologia para sua determinação, devido à inexistência de metodologia precisa. Usualmente é realizada com emprego de paquímetro, determinando-se o comprimento médio em quatro repetições com 100 sementes, ficando a critério da empresa o estabelecimento de limites de tolerância. Embora não existam resultados que permitam concluir sobre o teste, a princípio, parece estar sujeito a erros inerentes ao paquímetro e à baixa resistência à deformação oferecida pelo pedicelo da semente; além disso, o teste é pouco prático.

$\mathrm{Na}$ falta de um teste oficial preconizado para avaliação da classificação das sementes quanto ao comprimento e das restrições 
apresentadas pelo emprego do paquímetro, a EMBRAPA, dentro de seu programa de controle de qualidade, desenvolveu o longuímetro para avaliação da classificação quanto ao comprimento das sementes (Figura 3).

O longuímetro se constitui de um sulco com profundidade aproximada de $50 \mathrm{~mm}$ e forma de $\mathrm{V}$ em uma barra de alumínio, com escala nas laterais entre 16 e 50/64". As sementes são encaixadas no sulco com a sua dimensão do comprimento perpendicular ao sentido da altura do sulco. A leitura é feita diretamente na escala onde o pedicelo da semente toca a lateral do sulco. Embora moroso, o instrumento é um pouco mais prático do que o paquímetro (EMBRAPA - SPSB, 1994).

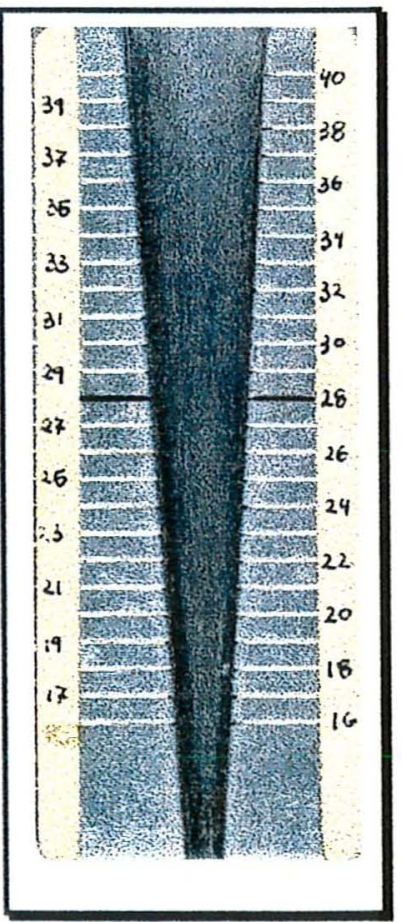

Figura 3: Imagem digital de um longuímetro desenvolvido pela EMBRAPA SPSB (1994). 
Devido à importância da classificação e da carência de testes adequados para avaliá-la, as empresas têm desenvolvido técnicas próprias, a exemplo do teste de plantabilidade. O teste de plantabilidade procura simular o desempenho de uma semeadora; para tanto, um sistema dosador de sementes é acionado por um motor elétrico de velocidade controlada e montado sobre uma correia transportadora impregnada com cola. Quando o sistema dosador de sementes é acionado, as sementes são depositadas sobre a correia transportadora, permitindo assim a avaliação na uniformidade da distância entre as sementes; porém, ainda não se têm resultados consistentes que permitam estabelecer métodos padronizados; além disso, em geral, é um teste complexo e pouco prático.

Considerando o exposto até o presente, conclui-se ser de suma importância para obtenção de adequada população e distribuição espacial de plantas, com influência sobre o rendimento da cultura de milho, a classificação das sementes em suas três dimensões: comprimento, largura e espessura.

Entretanto, o processo de produção de sementes está sujeito a inúmeras variáveis que contribuem para o insucesso da operação, destacandose, a carência de métodos precisos e repetitivos para avaliação da classificação. 
O desenvolvimento de um instrumento de aferição das dimensões das sementes capaz de ser reproduzido a partir de um modelo repetitivo, com aplicação independente de variáveis externas, não provocando deformação plástica à semente, com escala variável em função da precisão requerida e de fácil operação em muito contribuiria para minimizar os erros de classificação durante o processo de produção de sementes. Este instrumento deve ser comparado a outros instrumentos sabidamente precisos para determinar a incerteza de medida.

\subsection{Processamento de imagens digitais}

O advento do primeiro microcomputador em um único circuito integrado, no ano de 1971, iniciou uma revolução tecnológica que hoje aloca os dispositivos eletrônicos microprocessados em praticamente todas as atividades humanas, sendo sua presença nos dias atuais facilmente notada em diversas atividades, a exemplo da indústria, no comércio, na medicina e etc. (McDonald \& Chen, 1990; Wayner, 1996).

A agricultura é uma das atividades desenvolvidas pelo homem que podem se beneficiar desta tecnologia. A presença de microcomputadores na agropecuária está assumindo maior importância. Muitos equipamentos e métodos tradicionais têm sido substituidos por sistemas de medição eletrônicos 
e técnicas sofisticadas para obtenção e análise de dados, como o processamento de imagens digitais. Um exemplo marcante, e talvez pioneiro da revolução digital na agricultura, é a automação da medição de parâmetros agrometeorológicos, que passou de um processo manual e rudimentar para um sistema de medição totalmente automatizado (Assad \& Sano, 1993).

A visão é considerada como o sentido mais eficiente que o ser humano dispõe para receber informações a respeito do ambiente que o cerca. Os raios luminosos refletidos pelas superfícies dos objetos são focalizados pelo cristalino do olho para estimularem células nervosas localizadas sobre a superfície da retina e sensíveis à intensidade e ao comprimento de onda da luz, denominadas por cones e bastonetes. Os cones e bastonetes transformam as respectivas informações em sinais nervosos, os quais são remetidos ao cérebro pelo nervo óptico para serem processados. Existem várias teorias de compreensão do processamento de imagens pelo cérebro; uma abordagem interessante é considerar que o cérebro armazena dados para efetuar uma comparação entre a informação recebida e alguns padrões de situações semelhantes armazenados (Facon, 1996).

Os sistemas de processamento de imagens representam a busca do ser humano em automatizar o sentido da visão. Para a aquisição das imagens, foram desenvolvidos equipamentos baseados em sensores, a exemplo dos cones e bastonetes, que permitem a transformação da 
intensidade do sinal luminoso em sinal elétrico, os CCDs. Para o processamento das imagens, foram desenvolvidos sistemas de informática baseados no princípio de armazenamento de dados e comparação de padrões (Facon, 1996). O processamento de imagens digitais, segundo Kranzeir (1985), pode ser dividido em três categorias: análise de imagens, visão robótica e inspeção.

O objetivo da análise de imagens, principal enfoque do presente trabalho, é a extração de atributos empregados na modelagem geométrica de uma imagem digital. O contrário, ou seja, a síntese de imagens, possibilita gerar uma imagem a partir de modelos geométricos. Estas duas áreas constituem a base dos processos que envolvem o trabalho com imagens. A rigor, em análise de imagens, o processamento da imagem constitui-se em uma fase pré-processamento, seguida da análise propriamente dita que basicamente envolve técnicas de extração, segmentação e classificação de atributos (Cruvinel et al, 1996).

A análise de imagens, além da agrometeorologia, têm sido empregada para a análise de formas e dimensões de objetos contidos em uma cena ou imagem (MacDonal \& Chen, 1990). A quantificação de doenças foliares e danos causados por insetos herbivoros em folhagens, a determinação das dimensões de órgãos de uma planta e a avaliação de sistemas radiculares, entre outras, são exemplos de outras aplicaçōes da 
análise de imagens na agricultura (Kranzeir, 1985; Vooren \& Heijden, 1993; Crestana et al, 1994).

Com relação à análise de sistemas radiculares, recentemente a EMBRAPA lançou o sistema computacional SIARCS $3.0^{\circledast}$ dedicado à análise de imagens digitais de raizes. $\mathrm{O}$ sistema permite realizar medidas quantitativas, como comprimento, e dinâmicas, como topologia e arquitetura, de sistemas radiculares (Jorge et al, 1996).

Apesar do grande potencial que a área da tecnologia e produção de sementes representa para a análise de imagens, poucos trabalhos e equipamentos têm sido desenvolvidos nesta área, quando comparados com outras áreas, a exemplo da agrometeorologia e solos. Dentre os equipamentos desenvolvidos, cita-se um equipamento composto por um divisor de amostras e uma câmara filmadora acoplada a um microcomputador, para a identificação da presença de sementes silvestres em amostras de sementes de aveia (Avena sativa, L.), cevada (Hordeum vulgare, L.), centeio (Secale cereale, L.) e trigo (Triticum aestivum, L.) (Westerlind, 1988).

Ainda dentro da área de tecnologia e produção de sementes, é possivel o emprego da análise de imagens para a avaliação de danos mecânicos em sementes de soja (Gunasekaran et al, 1988a) e sementes de milho (Zayas et al, 1990), avaliação de danos provocados por patógenos em 
sementes de soja e milho (Gunasekaran et al, 1988b) e a avaliação do vigor de sementes de milho pelo teste de tetrazólio (Howarth \& Stanwood, 1993).

Demonstrando a possibilidade da identificação de espécies e cultivares com emprego da análise de imagens, Vooren et al (1992) procederam a identificação de cultivares de cogumelo [Agaricus bisporus (Lange) Imbach] através da análise de imagens do esporóphoro.

Diante do exposto, a análise de imagens mostra-se como uma eficiente ferramenta, com inúmeras aplicações práticas inexploradas, a ser empregada na área de tecnologia e produção de sementes. Para melhor compreensão do assunto, torna-se necessário abordar alguns aspectos a respeito de imagem, imagem digital, digitalização de imagens, técnicas de préprocessamento e análise de imagens.

\subsubsection{Imagem e imagem digital}

A luz é a energia radiante que se move em ondas. Uma imagem pode ser entendida como um conjunto de estímulos luminosos refletidos por um objeto que vão de encontro ao sistema visual. Portanto, uma imagem pode ser representada por uma função $C(x, y, t, \lambda)$, em que $C$ representa a distribuição espacial de energia, ou cor, nas coordenadas espaciais $\underline{x}$ e $\underline{y}$, ao tempo $\underline{t}$ e comprimento de onda $\underline{\lambda}$ (Gonzalez \& Wints, 1977; Pratt, 1978). 
Os cones e bastonetes do olho humano são estimulados por comprimento de onda compreendidos aproximadamente entre 400 a 500, 500 a 600 e 600 a $700 \mathrm{~nm}$, correspondendo respectivamente às cores azul, verde e vermelha, ou cores básicas (Day, 1997). Considerando que um ponto de coordenadas espaciais $\underline{x}$ e $\underline{y}$ pode apresentar vários $\underline{\mathrm{C}}$ a intervalos de $\underline{\mathrm{t}}$ menores do que a capacidade de percepção e processamento do sistema visual, então, uma imagem colorida é composta por uma mescla de três estímulos referentes as radiações azul, verde e vermelha; também chamado de modelo aditivo, ou RGB, de cores (Day, 1997; Pratt, 1978).

O sistema visual humano é capaz de perceber bilhões de mesclas, ou cores, ao serem considerados a matiz, a saturação e o brilho. Já os sistemas artificiais atuais baseados no modelo RGB são bastante limitados, quando comparados ao visual humano. Considerando o modelo RGB, a mescla de intensidades iguais das cores básicas resulta em diferentes tonalidades da cor cinza, a mescla de máximas intensidades das cores básicas resulta na cor branca e, a ausência de radiação resulta na cor preta (Pratt, 1978; Day, 1997).

Uma imagem monocromática é representada pela função $C(x, y)$, pois assume-se $\underline{\lambda}$ como constante e conseqüentemente não há a necessidade de considerar $\underline{t}$. Portanto, uma imagem monocromática refere-se apenas a niveis de cinza. Neste caso, $\underline{x}$ e $y$ representam as coordenadas 
espaciais do ponto e $\underline{\mathrm{C}}$ a intensidade, ou o brilho, ou ainda, o nivel de cinza para aquele ponto (Gonzalez \& Wints, 1977; Pratt, 1978; Cruvinel et al, 1996).

A imagem digital é uma imagem $C(x, y)$ que pode ser analisada em termos de coordenada espacial e cor. Pode-se considerar uma imagem digital como uma matriz em que os índices das linhas e colunas identificam um ponto na imagem, e o correspondente valor de $\underline{C}$ identifica o nível de cinza para aquele ponto. O caso mais simples de discretização consiste em tomar um retângulo e discretizá-lo em linhas e colunas, onde o elemento da matriz é chamado de "pixel", ou elemento de imagem (Gonzalez \& Wints, 1977; Pratt, 1978; Cruvinel et al, 1996).

O número de linhas da matriz de "pixeis" e o número de colunas são chamados de resolução vertical e horizontal, respectivamente. O produto das resoluções vertical e horizontal é chamado de resolução espacial, ou simplesmente resolução. A resolução espacial da imagem é diretamente proporcional ao número de detalhes possíveis de serem identificados na imagem. A resolução espacial em termos absolutos não representa a resolução real da imagem distinguida pelo sistema visual humano, em razão da não determinação da dimensão real do "pixel". Uma medida mais confiável de resolução é fornecida pela densidade de resolução da imagem, determinada em número de "pixeis" por unidade de medida linear. Em geral, emprega-se o 
número de "pixeis" por polegada americana, ppi ("pixeis per inch") e dpi ("dots per inch") (Pratt, 1978; Cruvinel et al, 1996).

Conforme já comentado, a imagem digital é representada pela função $C(x, y)$. $\underline{\mathrm{C}}$ representa niveis de cinza e é função do produto da iluminação (i) e da reflectância (r). A iluminação diz respeito ao total de luz que incide sobre o objeto e pode variar entre o zero e o infinito, enquanto que reflectância é o total de luz refletida pelo objeto podendo variar entre zero e um. Sendo $\underline{\mathrm{C}}$ o produto entre $\underline{\mathrm{r}} \mathrm{e} \underline{\mathrm{i}}$, este pode variar entre zero e $\mathrm{o}$ infinito, representando as cores preta e branca, respectivamente (Gonzalez \& Wints, 1977; Pratt, 1978).

Denomina-se resolução de cor ao número de bits (b) utilizados para armazenar o vetor de cor de cada "pixel" da imagem (Cruvinel et al, 1996) e os níveis de cinza (L) são estimados pela equação abaixo, citada em (Pratt, 1978).

$$
L=2^{b}
$$

Em geral, as imagens digitais são apresentadas nos formatos de oito e vinte e quatro bits resultando, respectivamente, em 256 e 16.777 .216 niveis de cinza ou cores (Ihrig \& Ihrig, 1987). Convencionou-se representar as cores em uma imagem digital com oito bits, em niveis de cinza variando entre zero e 255, sendo zero a cor preta e 255 a cor branca (Facon, 1996). 
Os sistemas atualmente disponíveis permitem trabalhar com: um bit, reproduz todas as tonalidades e cores em preto ou branco; oito bits, reproduz as tonalidades e cores originais usando 256 níveis de cinza; 24 bits RGB, reproduz a imagem em três canais com oito bits cada, ou seja, 16.777.216 cores (Ihrig \& Ihrig, 1997).

O número máximo de cores fica limitado pela capacidade de armazenamento dos equipamentos; a busca é a relação entre a capacidade máxima de armazenamento e processamento dos equipamentos e o total de cores requeridos pelo trabalho.

\subsubsection{Digitalização de imagens}

O processo de digitalização de imagens pode ser feito com emprego de scanners ou de placas digitalizadoras conectadas a uma filmadora (Cruvinel et al, 1996).

Scanners, principal objeto de estudo do presente trabalho, podem ser comparados ao olho humano. Eles operam basicamente com uma fonte luminosa sob uma superfície transparente, em geral um vidro, lentes focalizando os raios luminosos, como o cristalino do olho humano, em sensores que recebem a radiação refletida por um objeto depositado sobre o vidro, conforme exemplo apresentado na Figura 4 ( Day, 1997). 
Existem vários tipos de sensores que recebem radiação e geram sinais elétricos. Os scanners comumente empregados são dotados de "chargcoupled devices" (CCD) e "analog to digital converts" (conversor A/D) (Ihrig \& Ihrig, 1997).

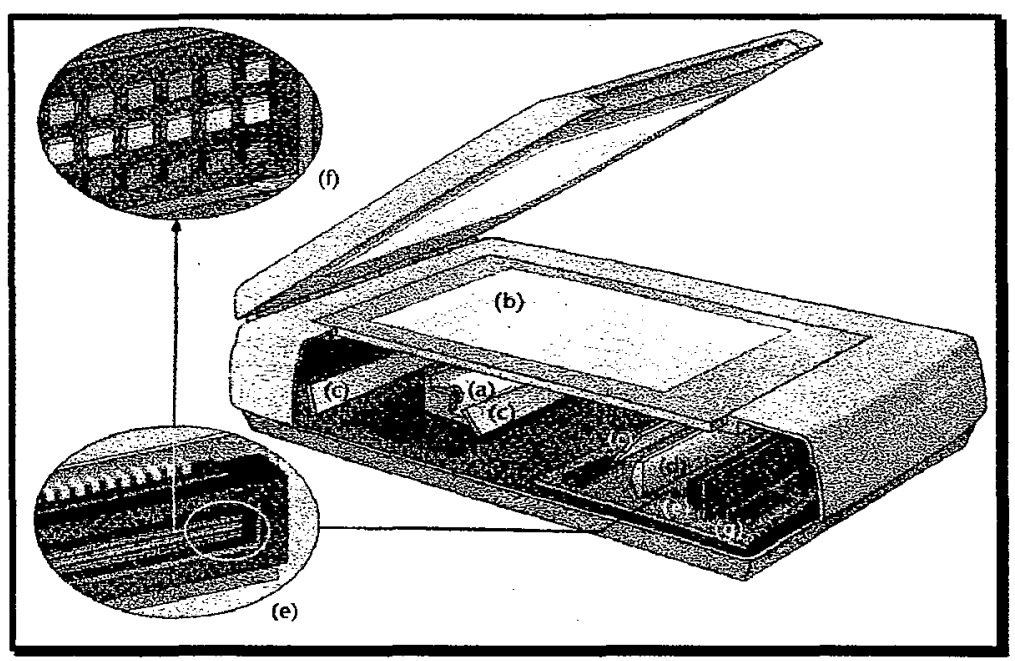

Figura 4: Esquema, segundo Ihrig \& Ihrig (1997), de um scanner representando a fonte luminosa (a), o vidro (b) e os espelhos (c) que focalizam os raios luminosos sobre os CCDs (e) dispostos em uma ou três linhas (f). O CCD registra os raios luminosos como cargas elétricas, convertidas para sinal digital pelos conversores A/D $(\mathrm{g})$.

O CCD é um sensor eletrônico capaz de produzir um sinal elétrico proporcional à intensidade de luz recebida. Em geral, os scanners apresentam CCDs arranjados em uma ou três linhas; este arranjo permite ao equipamento proceder a leitura da imagem em linhas. A cada linha amostrada da imagem real, o CCD envia sinais elétricos, onde cada sinal corresponde a 
um "pixel" da linha, para o conversor A/D que o converte em um dígito binário (bit) (Ihrig \& Ihrig, 1997).

Um dígito binário é aquele que admite apenas duas situações, falso ou verdadeiro, representados na informática por zero e um número inteiro, respectivamente (Pratt, 1978). Bits de imagens digitais são representados pelos números zero e um, que correspondem às cores branca e preta, respectivamente. Para representar outras cores, ou níveis de cinza, são usadas combinações de zeros e uns (Day, 1997).

Scanners trabalham com "pixeis" quadrados, portanto, a densidade de linhas lidas por extensão, polegadas ou milímetros, durante a digitalização caracteriza a resolução de digitalização da imagem. Em geral, scanners, a exemplo da marca Hewlett Packard modelo HP 4C, permitem digitalizar imagens entre 75 e 300 ppi (Day, 1997). Comumente dpi e ppi são empregados como sinônimos; a rigor, ppi refere-se a densidade de informações por polegada digitalizada e dpi a densidade de informações por polegada analisada (Ihrig \& Ihrig, 1997). Scanners permitem a digitalização de imagens em 2, 4, 16 e 32 bits, a exemplo da marca Hewlett Packard modelo HP 4C (Day, 1997).

A adequada digitalização da imagem real é, sem dúvida, fundamental para a futura análise da imagem. A qualidade dos CCDs empregados na fabricação do scanner é fundamental para a resolução da 
imagem digitalizada. Entretanto, outros fatores contribuem, como luminosidade ambiente, posição do objeto sobre o vidro e qualidade do vidro. Um fenômeno comum é a formação de sombras, que podem ser comparadas ao olho humano observando um objeto em diferentes ângulos, formando imagens com diferentes formas e dimensões (Ihrig \& Ihrig, 1997).

\subsubsection{Técnicas de pré-processamento da imagem digital}

Esta etapa não é obrigatória para a análise da imagem digital, mas muitas vezes é necessária. O pré-processamento permite realçar detalhes da imagem, adequá-la à análise e corrigir defeitos e imperfeições que surgem durante a digitalização da imagem, em função das características do sistema, iluminação ambiente, etc. (Facon, 1996).

Várias são as técnicas de pré-processamento, entretanto, abordaremos apenas algumas de interesse ao presente trabalho como: conversão da imagem, binarização da imagem e separação de objetos.

Uma imagem pode ser digitalizada com resoluções de cores entre dois e vinte e quatro bits, sendo sua definição proporcional ao aumento da resolução. Entretanto, o aumento da resolução afeta a capacidade de armazenamento e a velocidade de processamento do equipamento, ou ainda, os sistemas de análise de imagens operam com resolução limitada, a exemplo 
do SIARCS $3.0^{\circledast}$ que opera em 256 cores (Jorge et al, 1996). Em alguns casos, esta limitação pode ser contornada digitalizando a imagem com maior resolução e a seguir convertendo-a para menor resolução com emprego de sistemas específicos. Um exemplo destes sistemas é o "Corel Draw" 6.0 que emprega o modelo de subdivisão recursiva pelo corte mediano (Day, 1997).

A binarização é uma técnica implementada no sistema SIARCS $3.0^{\circledR}$, que pode segmentar a imagem, selecionando objetos de interesse. A técnica consiste na utilização de um filtro "thresholding", que permite destacar da imagem "pixeis" com base na avaliação do nivel de cinza, ou cor, de cada "pixel". Em uma palheta, que representa todas as cores contidas na imagem, são selecionadas as cores do objeto que desejamos destacar, substituindo-as por uma cor escolhida em uma palheta de cores própria. A seguir, procede-se a binarização propriamente dita, que consiste na transformação dos "pixeis" selecionados para a cor preta, índice um, e o restante dos "pixeis" para a cor branca, indice zero (Jorge et al, 1996).

Como inconveniente da técnica destaca-se que, como a seleção é baseada em cores dos "pixeis", são selecionados todos os "pixeis" que apresentam as cores selecionadas, inclusive aqueles não pertencentes ao objeto desejado. No caso de sementes de milho, é comum serem selecionados e binarizados resíduos destacados da semente durante sua manipulação sobre o scanner. 
A separação de objetos é realizada por um algoritmo que permite a erosão das bordas da imagem do objeto por discos com aumento de diâmetro progressivo. A técnica foi empregada com sucesso por Shatadal et al (1995) para desconectar grãos de cereais em imagens digitais.

\subsubsection{Análise da imagem}

A análise da imagem consiste na obtenção de informações a respeito de objetos presentes em uma imagem digital, com base em algumas características como cor, textura, etc.

Dentre as técnicas empregadas na análise de imagem, é de interesse para o presente trabalho a seleção de objetos e o cálculo de momentos. A seleção de objetos aplica-se em uma imagem binarizada, discriminando-se os objetos presentes e atribuindo-lhes um indice.

Conforme relato pessoal do pesquisador da EMBRAPA-CNPDIA, Lúcio André de Castro Jorge, no caso do sistema SIARCS $3.0^{\circledR}$, como a imagem contém apenas as cores zero (fundo) e um (objetos), o índice é uma cor entre 1 e 254, ou seja, os objetos são identificados por cores e o sistema permite selecionar até 254 objetos. O algoritmo utilizado no SIARCS $3.0^{\circledR}$ consiste em percorrer a imagem a partir de seu canto inferior esquerdo, até encontrar um "pixel" de valor um, ou seja, o primeiro "pixel" do primeiro objeto, 
marcando-o com o valor dois. Então, a imagem é varrida atribuindo o valor dois a todos os "pixeis" com valor um conectados a um "pixel" com valor dois. A seguir, o processo é repetido para os demais objetos, identificando-os com valores sucessivos.

A partir da seleção de objetos, conhecendo-se a resolução da imagem e quantificando os "pixeis" do objeto, é possivel estimar sua área e dimensões, também chamados de momentos. Vooren \& Heijden (1993) aplicando a técnica chamada de erosão, que permite obter a imagem do esqueleto central do objeto, estimaram o comprimento e área de vagens de feijão. O comprimento das vagens foi considerado como o comprimento dos esqueletos, estimados usando o algoritmo "corner-count" proposto por Vossepoel \& Smeuders (1992). A área foi estimada pela equação

$$
A=\frac{\pi}{4} \times E \times e
$$

na qual $\underline{A}$ representa a área da elipse que melhor descreve a vagem, $\underline{E}$ e $\underline{\mathrm{e}} \mathrm{o}$ maior e menor eixo da elipse, respectivamente.

Conforme relato pessoal do pesquisador da EMBRAPA-CNPDIA, Lúcio André de Castro Jorge, no caso do sistema SIARCS $3.0^{\circledR}$ os momentos implementados foram a área do objeto, seu centro de massa, ângulo de seu eixo principal com a horizontal, largura e comprimento do menor retângulo 
circunscrito ao objeto e a elipse que melhor represente o objeto, descritos a seguir.

Dada uma imagem binária $\mathrm{M} \times \mathrm{N}$, com os "pixeis" da região $\underline{\mathrm{R}}$ representados pelo índice um, os momentos principais podem ser estimados por:

$$
m_{p q}=\sum \sum_{i, j \in R} I^{p} J^{q}
$$

Os valores de $\alpha_{\min }, \alpha_{\max }, \beta_{\min }$ e $\beta_{\max }$ para os pontos $(x, y)$ da região $\underline{R}$ serão as coordenadas do menor retângulo circunscrito à região, sobre os eixos $\alpha$ e $\beta$. O maior $(A)$ e menor (a) lado do retângulo são:

$$
\begin{aligned}
& A=\alpha_{\text {min }}-\alpha_{\text {max }} \\
& a=\beta_{\text {min }}-\beta_{\text {max }}
\end{aligned}
$$

A elipse que melhor representa o contorno da região $\underline{\mathrm{R}}$, ou seja, a elipse que melhor representa o objeto, pode ter as dimensões de seu maior eixo (E) e seu menor eixo (e), estimados pelas equações apresentadas a seguir:

$$
E=\left(\frac{4}{\pi}\right)^{1 / 4}\left[\frac{\left(I_{\max }\right)^{3}}{I_{\min }}\right]^{1 / 8}
$$




$$
e=\left(\frac{4}{\pi}\right)^{1 / 4}\left[\frac{\left(I_{m i n}\right)^{3}}{I_{\max }}\right]^{1 / 8}
$$

equações cujos membros $I_{\min }$ e $I_{\max }$ representam, respectivamente, o menor e o maior momentos de inércia, que podem ser estimados pelas equações apresentadas a seguir:

$$
\begin{gathered}
I_{\min }=\sum \sum_{i, j \in R}[(j-y) \cos \theta-(i-x) \operatorname{sen} \theta]^{2} \\
I_{\max }=\sum \sum_{i, j \in R}[(j-y) \operatorname{sen} \theta+(j-x) \cos \theta]^{2}
\end{gathered}
$$




\section{MATERIAL E MÉTODOS}

\subsection{Localização}

O presente trabalho foi realizado durante o ano de 1997 , utilizando-se as instalaçōes do Laboratório de Análise de Imagens (LAI) da EMBRAPA - Instrumentação Agropecuária, localizado em Săo Carlos/SP, do Laboratório de Análise de Sementes (LAS) e do Laboratório de Metrologia (LM), pertencentes, respectivamente, a Escola Superior de Agricultura "Luiz de Queiroz" e Serviço Nacional da Indústria (SENAI), ambos localizados em Piracicaba, São Paulo.

\subsection{Obtenção das sementes}

Foram utilizadas oito amostras representativas de oito lotes de sementes de milho híbrido, cultivar BR-201, classificados durante os meses de janeiro a fevereiro na Unidade de Beneficiamento de Sementes da Gerência Local de Sete Lagoas, MG, da EMBRAPA - SPSB, em peneiras 18 curta (18C), 
18 longa(18L), 20 curta(20C), 20 longa(2OL), 22 curta(22C), 22 longa (22L), 24 curta (24C) e 24 longa (24L), conforme proposto por EMBRAPA - SPSB (1994) e Mantovani et al (1991). As amostras foram identificadas, segundo sua classificação, ou seja, como 18C, 18L, 20C, 20L, 22C, 22L, 24C e 24L.

Os lotes apresentavam-se dentro dos padrōes exigidos para comercialização e foram tratados com mistura de inseticida, fungicida e corante. O teor de água era uniforme, variando entre 12 e 12,3\%, conforme determinação realizada no LAS pelo método da estufa a $105 \pm 3^{\circ} \mathrm{C}$ durante 24 horas (Brasil, 1992).

\subsection{Estimativa do tamanho da amostra}

Com emprego do projetor de perfil, a ser descrito no item 3.5. , foram medidas as dimensões de comprimento e largura de 100 sementes do amostra 24L. Considerando-se as medidas determinadas verificou-se, com o emprego da técnica do histograma descrita em 2.2.1., a distribuição normal dos indivíduos e com o emprego da equação (1), descrita em 2.2.1, estimou-se o tamanho da amostra necessária para representar a população com a precisão requerida de $0,01 \mathrm{~mm}$.

No LAI, empregando um computador padrão IBM-PC equipado com 16 MB de memória RAM e processador Pentium $100 \mathrm{MHz}$, e um scanner 
de mesa, marca Hewlett Packard, modelo Scanjet 4C, foram digitalizadas imagens contendo entre 10 a 100 sementes, com incremento de dez sementes, da amostra 24L. As imagens foram digitalizadas em 24 bits e nas resoluções de $75,100,150,200,250$ e 300 ppi. As imagens foram convertidas para oito bits, pré-processadas e analisadas.

\subsection{Amostras}

No LAS, as amostras foram submetidas ao teste de retenção de peneiras, segundo método descrito em Brasil (1992). De cada amostra, das sementes retidas na peneira manual, com o emprego do longuimetro, foram selecionadas quanto ao comprimento 300 sementes segundo EMBRAPA-SPSB (1994). Adotou-se o tamanho da amostra de 300 sementes com base no teste preliminar.

Com caneta de tinta azul, marca Tiger Family ${ }^{\circledR}$, as 300 sementes de cada amostra foram identificadas em sua face dorsal (D), lado oposto ao embriäo, com números de 1 a 300.

Embora a determinação da incerteza de medida tenha sido efetuada considerando amostras de 300 sementes, para facilitar a manipulação, as amostras foram divididas e identificadas em seis sub-amostras de 50 sementes, correspondendo às sementes 1 a 50, 51 a 100, 101 a 150, 
151 a 200,201 a 250 e 251 a 300 . A sub-amostra contendo 50 sementes foi escolhida em função do tamanho máximo de arquivo possivel de ser processada a imagem durante o teste preliminar.

As sub-amostras foram acondicionadas em sacos de papel, identificados pela peneira da amostra seguida pelo número da sub-amostra. $O$ exemplo da amostra 24L1, representa amostra da peneira $24 \mathrm{~L}$ contendo as sementes numeradas entre 1 e 50 . A seguir, foram armazenadas no Laboratório de Metrologia em ambiente controlado com a temperatura de $20^{\circ} \mathrm{C}$ e umidade relativa do ar (UR) de $60 \%$.

\subsection{Determinação das dimensões de referência.}

Durante os meses de março a maio, no Laboratório de Metrologia com ambiente controlado, foram determinadas individualmente as dimensões de comprimento e largura de cada semente, segundo o método descrito por Kennedy (1973): os dados foram coletados em milimetros, com emprego do projetor de perfil marca Mitutoyo, modelo PJ-300H, equipado com lente de aumento 10x. As sementes foram posicionadas com a face ventral (V) voltada para a mesa do projetor, pois assim foi proporcionado maior apoio e estabilidade às mesmas. 


\subsection{Determinação das dimensões com o paquímetro.}

Durante os meses de março a maio no Laboratório de Metrologia, com ambiente controlado, foram determinadas individualmente as dimensões de comprimento e largura de cada semente, segundo o método descrito por Freire (1984). Os dados foram apontados em milimetros, com emprego de paquímetro marca Mitutoyo, modelo 530-104, com aproximação de $0,05 \mathrm{~mm}$ e incerteza de medida de $\pm 0,05 \mathrm{~mm}$. Procurou-se aplicar forças semelhantes ao paquímetro para minimizar a incerteza da medida.

\subsection{Digitalização das imagens.}

Durante o mês de julho no Laboratório de Metrologia, com ambiente controlado, foram digitalizadas em 24 bits e nas resoluções de 100, 150,200 e 250 ppi as imagens das sub-amostras componentes de cada amostra, individualmente, com emprego de um scanner de mesa marca Hewlett Packard, modelo Scanjet 4C, e um computador padrão IBM-PC, equipado com $32 \mathrm{MB}$ de memória RAM e processador Pentium de $200 \mathrm{MHz}$.

Com auxilio de uma grade confeccionada em cartolina, com dimensões externas iguais às do vidro do scanner e orifícios dispostos em 
cinco linhas e dez colunas dentro de um retângulo com $15 \times 17 \mathrm{~cm}$, as sementes foram depositadas de forma ordenada $(0)$ diretamente sobre o vidro do scanner com sua face dorsal (D) voltada para o vidro. A seguir, foram digitalizadas as imagens conforme o exemplo da Figura 5, apresentando em sua porção superior imagem contendo sementes dispostas ordenadas e dorsais (OD) da sub-amostra 24L1, digitalizada na resolução de 250 ppi.

Com outra cartolina de mesmas dimensões externas da primeira e contendo um orifício retangular com dimensões de $15 \times 17 \mathrm{~cm}$ em sua área central, as sementes foram desordenadas e digitalizadas as imagens respeitando a mesma área do vidro do scanner para o procedimento anterior. 0 exemplo da Figura 5 apresenta em sua porção inferior imagem contendo sementes dispostas desordenadas e dorsais (DD) da sub-amostra 24L1, digitalizada na resolução de 250 ppi.

Com as cartolinas e a ordenação das sementes descritas, foram digitalizadas imagens das sementes com sua face ventral (V) voltada para o vidro, conforme o exemplo da Figura 6, que apresenta em sua porção superior imagem contendo sementes dispostas ordenadas e ventrais (OV) e em sua porção inferior imagem contendo sementes dispostas desordenadas e ventrais (DV), da sub-amostra 24L1, ambas digitalizadas na resolução de 250 ppi. 

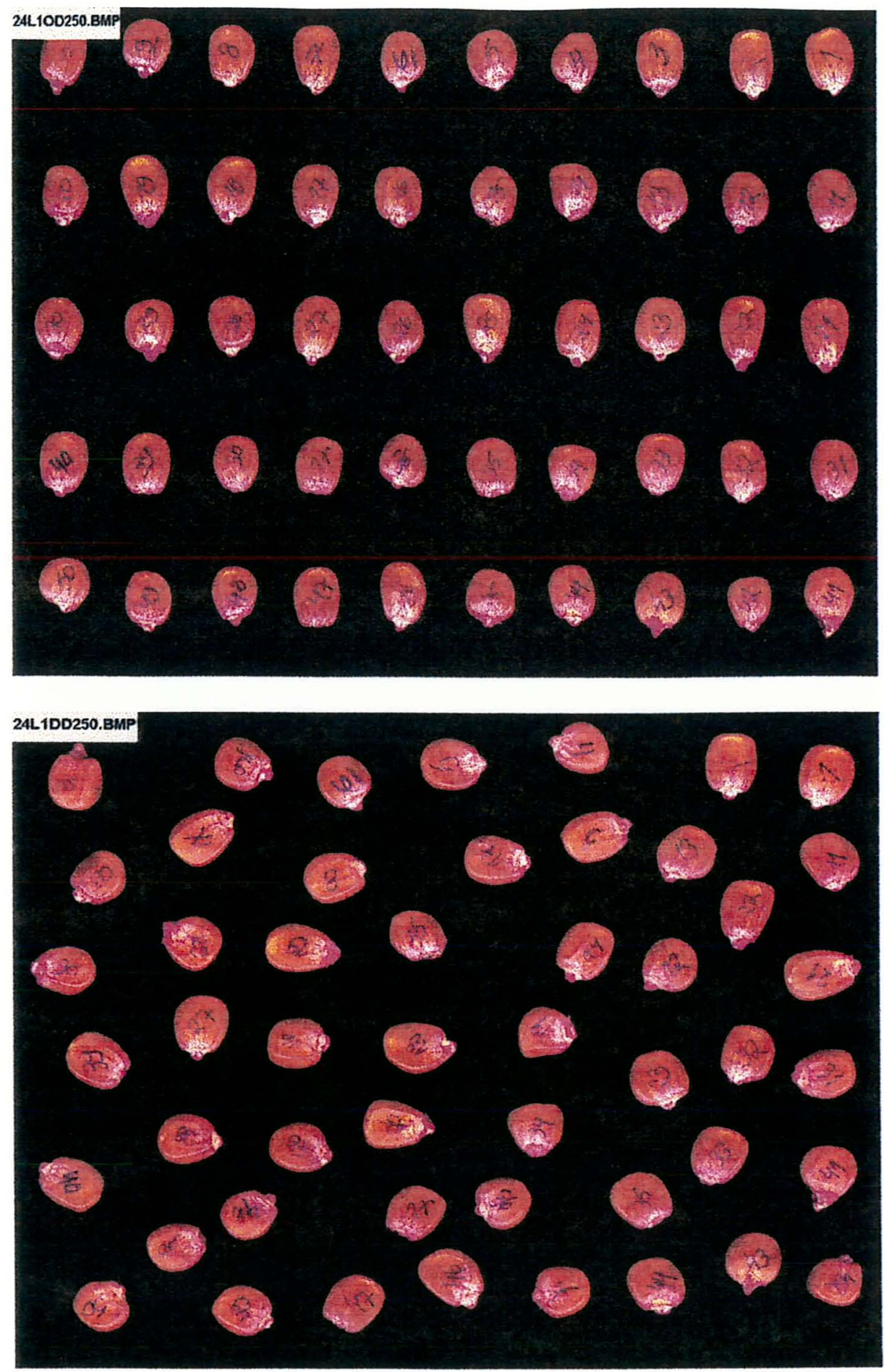

Figura 5: Imagem digitalizada, com resolução de 250 ppi e 24 bits, de sementes de milho, amostra 24L, ordenadas (24L1OD250.BMP) e desordenadas (24L1DD250.BMP), com a face dorsal (D) voltada para o vidro do scanner. 

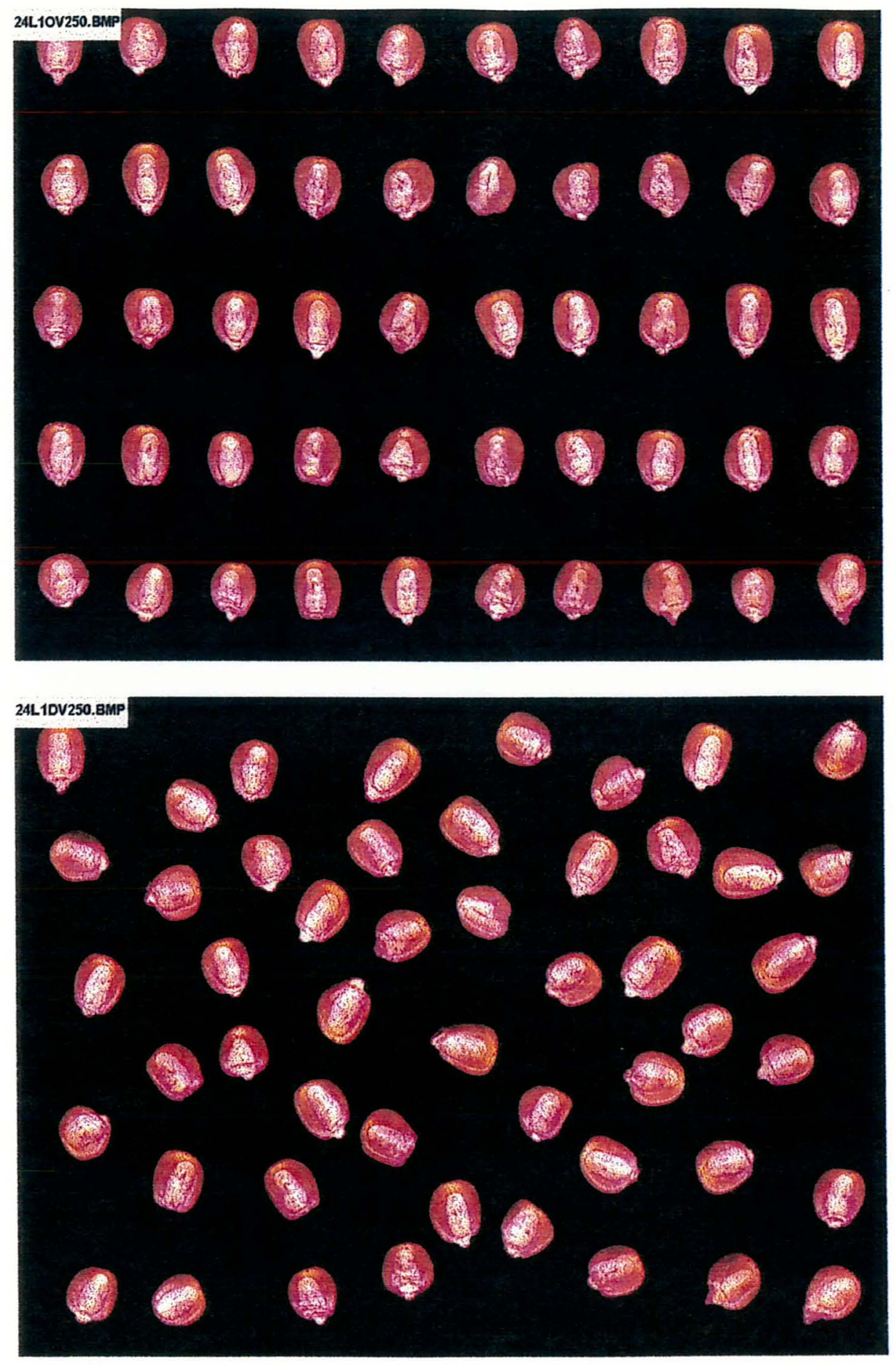

Figura 6: Imagem digitalizada, com resolução de 250 ppi e 24 bits, de sementes de milho, amostra 24L, ordenadas (24L1OV250.BMP) e desordenadas (24L1DV250.BMP), com a face ventral (V) voltada para o vidro do scanner. 
A identificação dos arquivos das imagens digitais, todos no formato *.BMP, consistiu da amostra, seguida por: número da sub-amostra, ordenação das sementes, posição dorsal ou ventral da semente voltada para o vidro e por resolução de digitalização. No exemplo apresentado na Figura 6, o arquivo 24L1DD250.BMP, significa a imagem digital de sementes da amostra $24 \mathrm{~L}$, contendo as sementes identificadas como 1 a 50 , desordenadas sobre 0 vidro, com a face dorsal voltada para o vidro e na resolução de 250ppi.

Para o caso das sementes com a face ventral voltada para $\circ$ vidro, as imagens também foram digitalizadas na resolução de 75 ppi, nas quais foram anotadas sobre as imagens das sementes, com emprego do sistema "Corel Draw" $6.0^{\circledR}$, os números presentes na face dorsal de cada semente, garantindo assim, a perfeita identificação de cada semente. No exemplo da Figura 7, são apresentadas imagens contendo sementes identificadas conforme descrito, da sub-amostra $24 \mathrm{~L} 1$, com as sementes dispostas ordenadas e ventrais (OV) em sua porção superior e desordenadas e ventrais (DV) em sua porção inferior.

Durante a digitalização, respeitou-se para todas as imagens a mesma área do vidro, procurando eliminar qualquer influência do vidro sobre as imagens. $O$ ambiente foi mantido sem iluminação o que proporcionou um fundo preto às imagens, procurando assim minimizar os efeitos de sombras. 

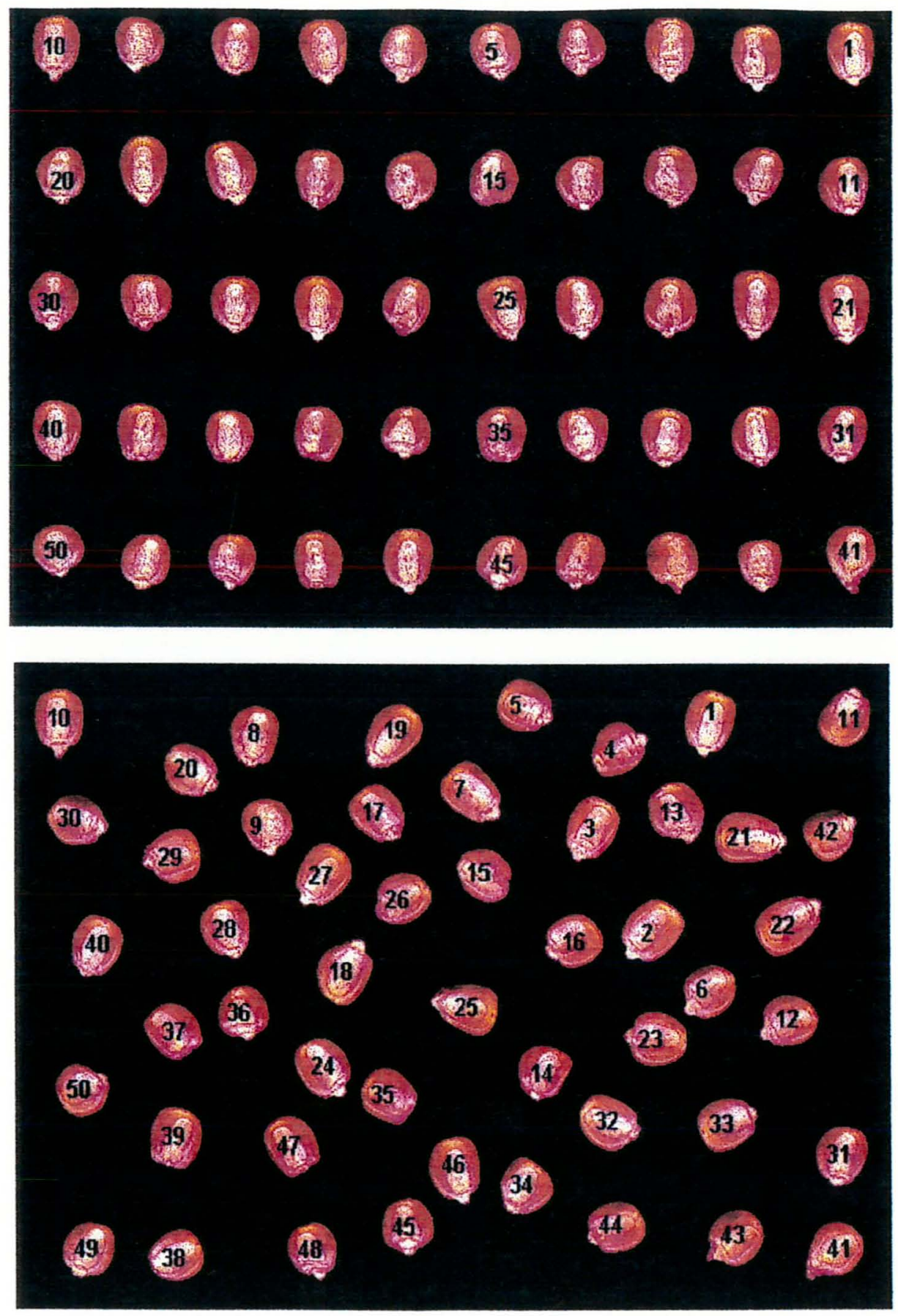

Figura 7: Imagem digitalizada, com resolução de 75 ppi e 24 bits, de sementes de milho, amostra 24L, ordenadas (superior) e desordenadas (inferior), com a face ventral voltada para o vidro do scanner e identificadas com números inseridos com emprego do sistema Corel Draw $6.0^{\circledR}$. 


\subsection{Pré-processamento das imagens}

Utilizando o sistema "Corel Draw" $6.0^{\circledR}$, as imagens foram convertidas para a resolução de oito bits, ou seja, 256 cores, conforme descrito por Day (1997).

Com emprego do sistema SIARCS $3.0^{\oplus}$ foram destacadas as sementes em cada imagem, conforme descrito por Jorge et al (1996). Para tanto, empregou-se o filtro "thresholding", destacando-as na imagem com aplicação da cor amarela previamente selecionada na paleta de cores, conforme exemplo apresentado na Figura 8 da sub-amostra 24L1, com as sementes dispostas desordenadas e ventrais na resolução de 250 ppi. Um problema foi a presença de resíduos destacados na imagem por apresentarem "pixeis" de cores iguais as selecionadas nas sementes.

A seguir, procedeu-se a binarização propriamente dita, conforme o exemplo apresentado na Figura 9, da sub-amostra 24L1, com as sementes dispostas desordenadas e ventrais na resolução de 250 ppi.

Para melhor ilustrar a presença de resíduos, a Figura 9 apresenta destacados (V) alguns resíduos binarizados que serão selecionados e terão seus momentos estimados, requerendo a eliminação futura dos dados destes objetos nos relatórios emitidos. 


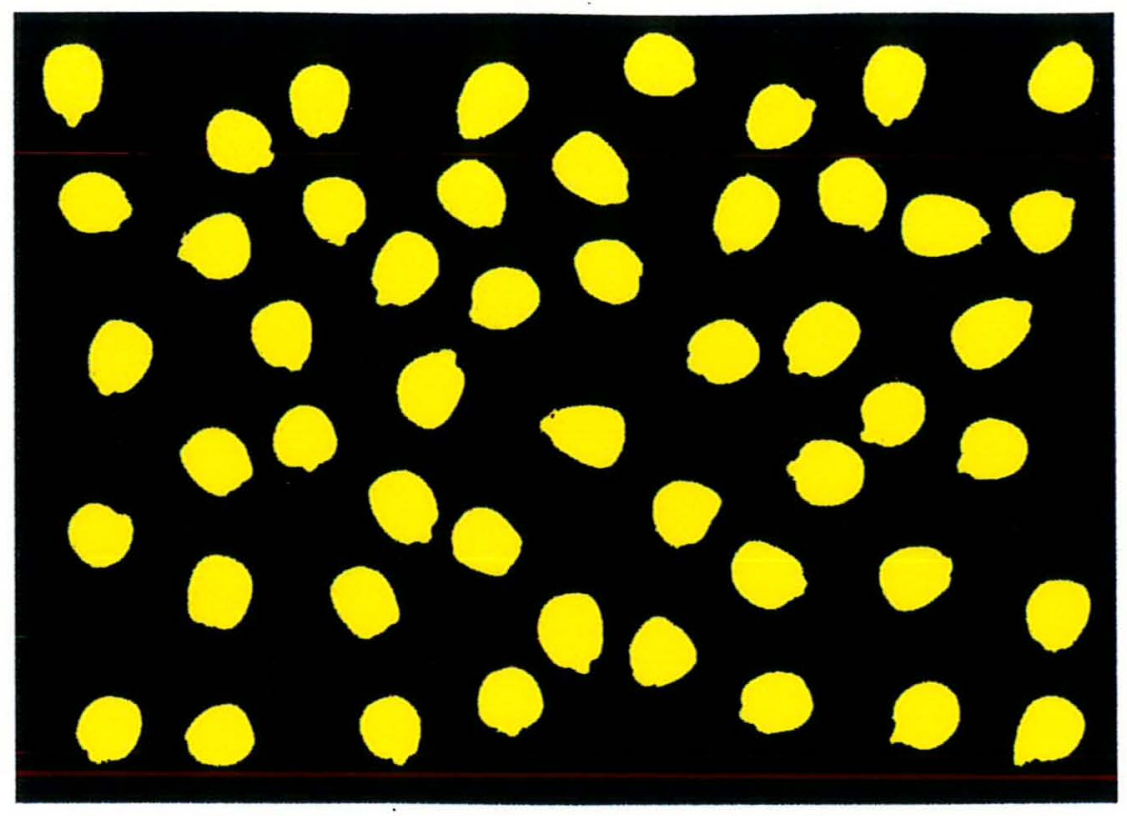

Figura 8: Imagem digital (250 ppi e 8 bits) com aplicação do filtro "thresholding" em cor amarela para destacar na imagem as sementes de milho, amostra $24 \mathrm{~L}$, desordenadas e com a face ventral (V) voltada para o vidro do scanner (24L1DV250.BMP).

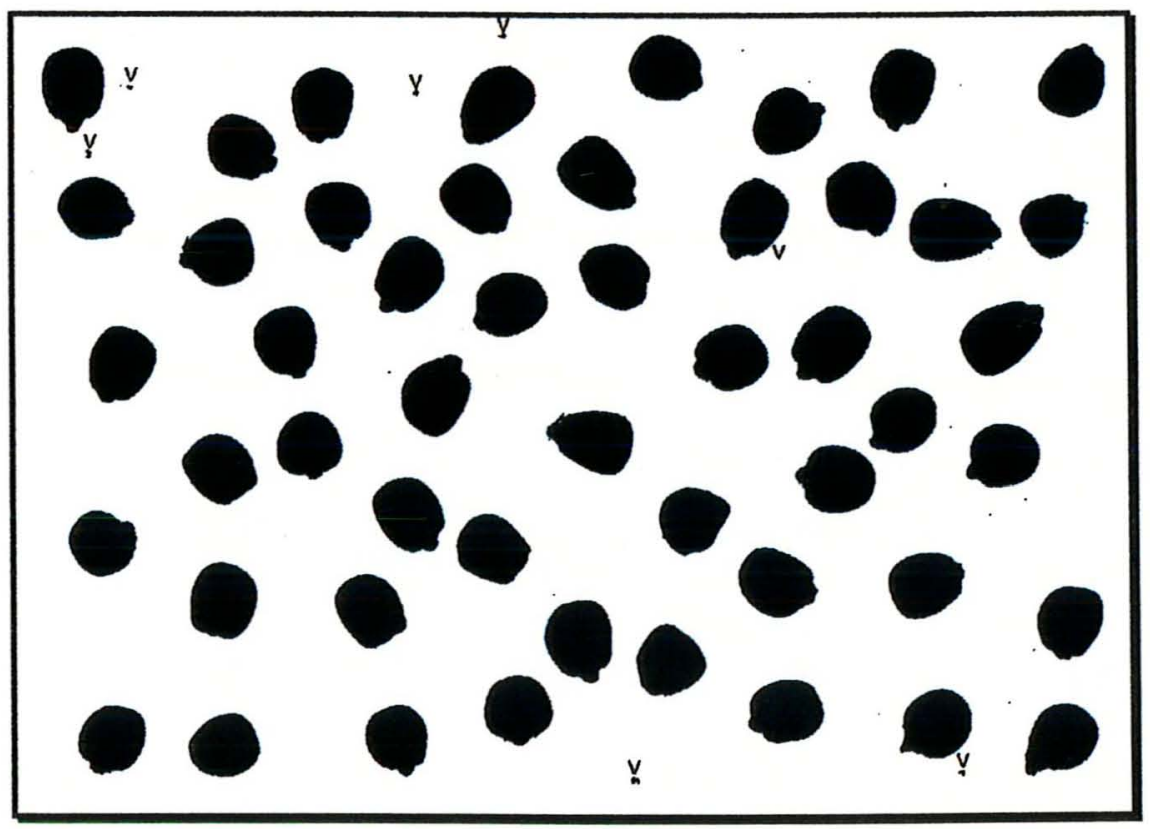

Figura 9: Imagem digital (250 ppi e 8 bits) binarizada, de sementes de milho, amostra $24 \mathrm{~L}$, desordenadas e com a face ventral (V) voltada para o vidro do scanner (24L1DV250.BMP). 


\subsection{Análise das imagens}

Após binarizadas as imagens e aplicando a ferramenta seleção de objetos presente no sistema SIARCS $3.0^{\circledR}$, os objetos foram selecionados conforme descrito em Jorge et al (1996) para, a seguir, aplicar a ferramenta de cálculo dos momentos área, centro, ângulo, dimensões dos objetos com através dos modelos do menor retângulo circunscrito e da elipse que melhor representa o objeto.

No exemplo da seleção de objetos apresentado na Figura 10, referente ao arquivo 24L1DV250.BMP, foram selecionados 105 objetos, portanto, 55 resíduos terão seus momentos estimados.

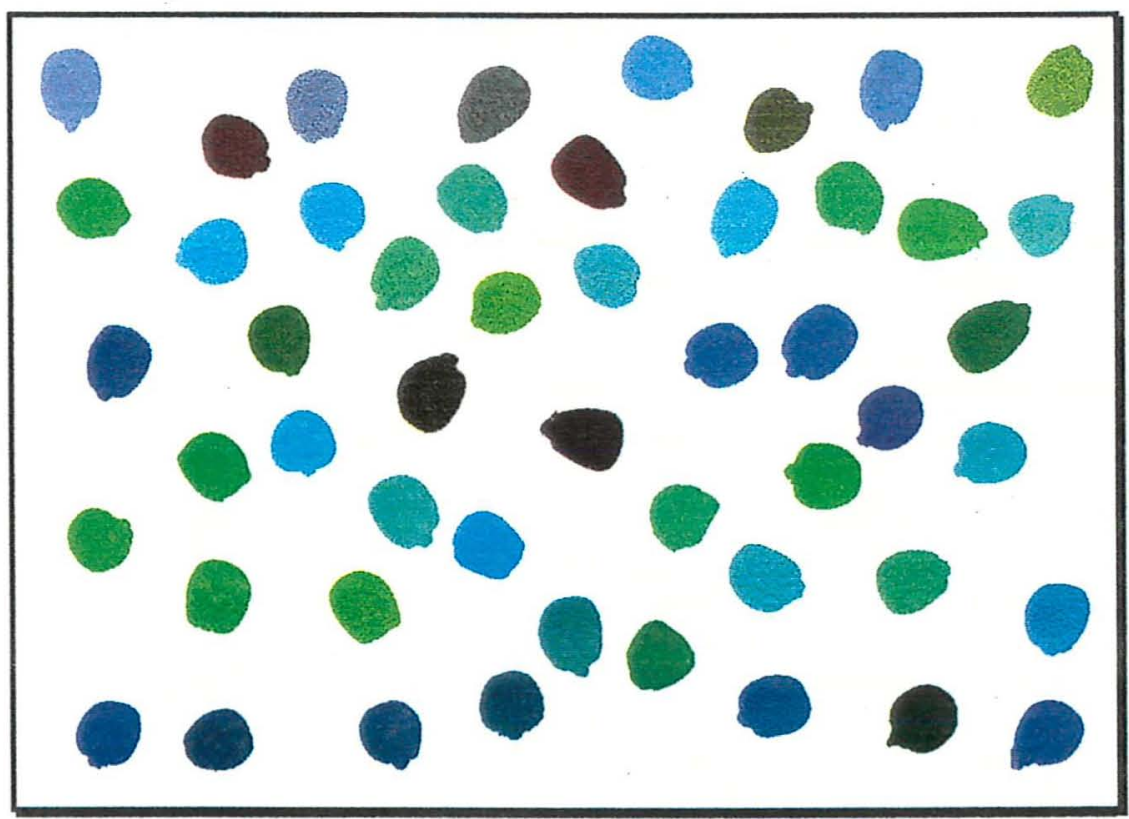

Figura 10: Imagem digital (250 ppi e 8 bits) apresentando selecionadas as sementes de milho da amostra 24L, desordenadas e com a face ventral (V) voltada para o vidro do scanner (24L1DV250.BMP). 
Os relatórios contendo os resultados estimados dos momentos para cada imagem, gerados pelo sistema SIARCS $3.0^{\circledR}$ no formato *.TXT, como o exemplo apresentado na Figura 11 que refere-se a parte do relatório do arquivo 24L1DV250.TXT, foram convertidos para o formato de colunas do sistema Excel ( $\left.{ }^{*} . \mathrm{XLS}\right)$, mais adequado para o tratamento de dados numéricos, com auxílio de uma rotina desenvolvida em linguagem C, Borland, versão 3.1 , pelo Técnico da EMBRAPA-CNPDIA, Ednaldo José Ferreira.

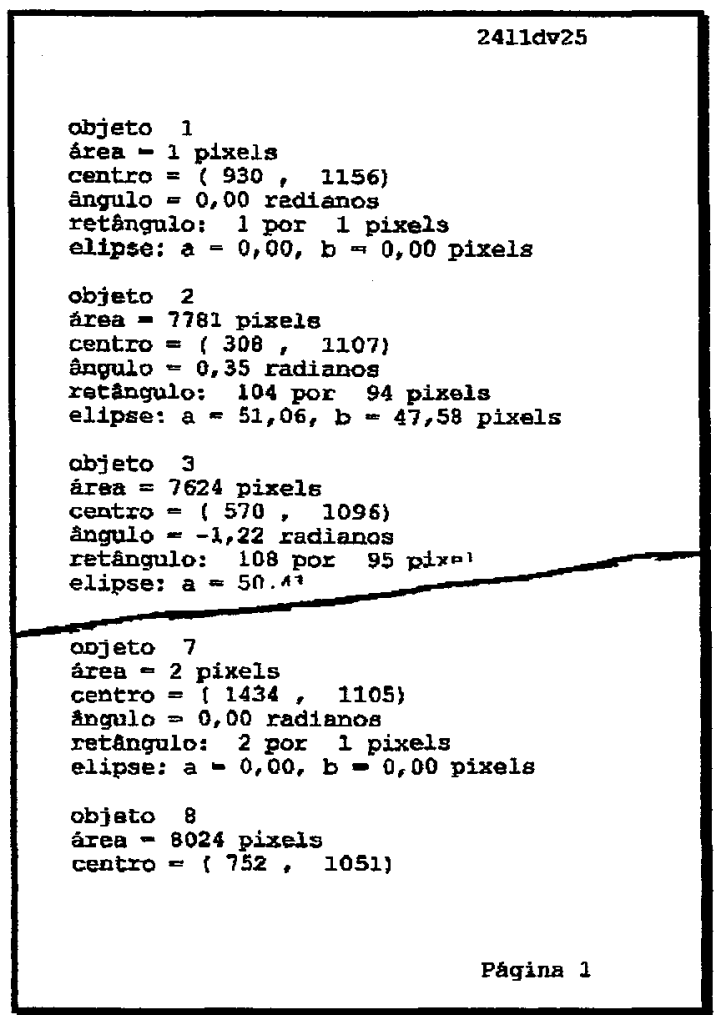

Figura 11: Exemplo parcial do relatório gerado pelo sistema SIARCS $3.0^{\circledR} \mathrm{em}$ formato *.TXT, com os resultados estimados dos momentos: área, centro, ângulo, dimensões dos objetos com emprego do modelo do menor retângulo circunscrito e da elipse que melhor representa o objeto, em sementes de milho, peneira 24L desordenadas e com a face ventral (V) voltada para o vidro do scanner (24L1DV250). 
Aplicando um algoritmo, desenvolvido em linguagem $\mathrm{C}$, Borland, versão 3.1, com o propósito de ordenar em razão crescente de área os objetos, bem como seus respectivos momentos, eliminando a seguir os objetos e seus momentos correspondentes com área menor que $20 \%$ da área média dos objetos presentes. É apresentado como exemplo a Figura 12, que refere-se a parte do relatório do arquivo 24L1DV250.XLS.

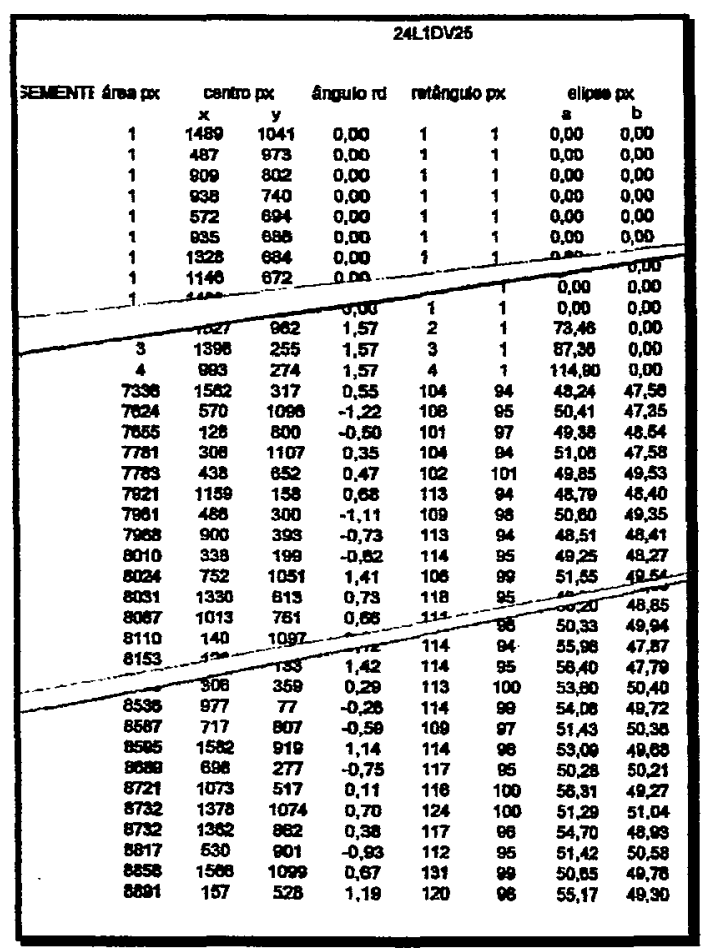

Figura 12: Exemplo parcial do relatório em formato *.XLS, convertido a partir do relatório 24L1DV250.TXT.

Observa-se no exemplo da Figura 12, a coluna referente à área em ordem crescente, permitindo assim a exclusão dos objetos com área inferior a $20 \%$ da área média. 


\subsection{Identificação das sementes nas imagens}

Através do centro do objeto foi possivel identificar a semente correspondente, apontando seu número na coluna denominada semente do relatório *.XLS. Para tanto, com emprego do sistema "Corel Photo Paint" $6.0^{\circledR}$, posicionado o ponteiro do cursor sobre cada semente, verificadas as coordenadas da posição do ponteiro do cursor em relação aos eixos $\underline{x}$ e $\underline{y}$ da imagem, foi pesquisado nos relatórios o objeto com o centro correspondente às coordenadas do ponteiro do cursor e anotado o número da semente no citado relatório.

\subsection{Estimativas das medidas em milímetros}

Conforme descrito no item 2.4.4. em relato pessoal do pesquisador da EMBRAPA-CNPDIA, Lúcio André de Castro Jorge, foram estimadas as dimensões de comprimento e largura das sementes considerando-se as dimensões dos lados do retângulo ou dos eixos da elipse citada.

Para o caso do modelo do menor retângulo circunscrito, as dimensões de comprimento (C) e largura (L) das sementes, em milímetros, foram estimadas a partir do produto do número de "pixeis" contidos no maior (A) e menor (a) lado do retângulo, respectivamente, pelo fator de conversão da 
polegada americana para milímetros $(25,4)$, dividido pela resolução de digitalização da imagem (R), dada em ppi, conforme a seguir:

$$
\begin{aligned}
& C=\frac{A \times 25,4}{R} \\
& L=\frac{a \times 25,4}{R}
\end{aligned}
$$

Para o caso do modelo da elipse que melhor representa o objeto, as dimensões de comprimento (C) e largura (L) das sementes, em milimetros, foram estimadas a partir do dobro do produto do número de "pixeis" contidos no maior (E) e menor (e) eixos da elipse, respectivamente, pelo fator de conversão da polegada americana para milimetros $(25,4)$, dividido pela resolução de digitalização da imagem $(R)$, dada em ppi, conforme a seguir:

$$
\begin{aligned}
& C=2\left(\frac{E \times 25,4}{R}\right) \\
& L=2\left(\frac{e \times 25,4}{R}\right)
\end{aligned}
$$




\subsection{Estimativa da incerteza de medida}

Foi considerado o diâmetro do crivo da peneira indicado na amostra, como a largura da semente determinada pela peneira, conforme a seguir:

- $\quad$ peneira $18=7,14 \mathrm{~mm}$

- $\quad$ peneira $20=7,94 \mathrm{~mm}$

- $\quad$ peneira $22=8,73 \mathrm{~mm}$

- $\quad$ peneira $24=9,52 \mathrm{~mm}$

Quanto à medida de comprimento determinada com emprego do longuímetro, foram consideradas como longas e curtas, sementes com o comprimento, respectivamente maior e menor, do que $28 / 62$ ", ou seja, 11,11 $\mathrm{mm}$.

A incerteza de medida para as medidas de comprimento e largura foram determinadas individualmente em cada amostra. Aplicando a rotina "proc univariate" do sistema estatístico SAS (SAS, 1990) às diferenças de medidas das 300 sementes de cada amostra, foi determinada a diferença de medida média, o intervalo de confiança e o número de diferenças maior do que zero. Determinou-se ainda, a significância das diferenças de medida para cada amostra, ou seja, quando as medidas obtidas com os diferentes métodos de 
medição diferiram significativamente das medidas determinadas com o projetor de perfil, considerando $t_{(0,01 / 2,299)}$.

Para as diferenças de medidas, assumiu-se como referência as medidas determinadas com o projetor de perfil, por tratar-se de um instrumento de medição reconhecidamente exato e preciso. Das medidas determinadas com o paquímetro, com a peneira no caso da largura e com o longuímetro no caso do comprimento, foram subtraídas as medidas correspondentes determinadas com o projetor de perfil (PP), obtendo a diferença de medida para o paquimetro e para a peneira, respectivamente. Igualmente, foi subtraida a medida determinada pelo projetor de perfil (PP) da medida correspondente estimada pelo sistema SIARCS $3.0^{\circledR}$, nas imagens com emprego dos modelos do menor retângulo circunscrito e da elipse que melhor representa o objeto.

A diferença de medida $D_{i}$ foi representada pela equação $D_{i}=i-P P$, na qual o índice $\mathrm{i}$ pode ser substituído por: medida determinada com o paquímetro (PA); medida determinada com a peneira, para o caso da largura e pelo longuímetro para o caso de comprimento (PE) ou as medidas PRM estimadas nas imagens digitais pelo sistema SIARCS $3.0^{\circledR} \mathrm{em}$ que:

- $\quad$ P diz respeito à posição das sementes, podendo ser: ordenadas com a face dorsal voltada para o vidro do "scanner" (OD), ordenadas com a face ventral voltada para o vidro do "scanner" (OV), desordenadas com a face 
dorsal voltada para o vidro do "scanner" (DD) e desordenadas com a face ventral voltada para o vidro do "scanner" (DV);

- $\quad \mathrm{R}$ diz respeito a resolução em que a imagem foi digitalizada, podendo ser: $100,150,200$ e 250 ppi, e;

- M diz respeito ao modelo empregado para estimar a medida, podendo ser: o menor retângulo circunscrito $(R)$ ou a elipse que melhor represente o objeto (E).

Aplicando-se a técnica estatística dos contrastes ortogonais é possivel comparar médias representativas de várias populações com aplicação do teste t de Student. Assim, foi aplicado contrastes ortogonais para verificar em cada método de medição empregado, se a média geral para o método foi composta por médias de amostras diferentes entre si. Métodos que apresentaram a média geral composta por médias de amostras significativamente iguais a um porcento, foram considerados métodos precisos.

\subsection{Estimativa do tamanho da amostra}

Aplicando-se a equação (1)

$$
n=\left(\frac{t_{(1-0,01)} \times S}{p}\right)^{2}
$$


na qual o valor tabelado de $\underline{t}_{(0,01 / 2,299)}$ é igual a 2,5758 (Fonseca \& Martins, 1995), estimou-se para cada uma das oito amostras qual o tamanho da amostra necessária para representar a população com as precisões $\mathrm{p}$ iguais a $0,01,0,05$ e $0,1 \mathrm{~mm}$ a um porcento de significância. A precisão de $0,1 \mathrm{~mm}$ foi adotada em função do relato pessoal do diretor da Indústria de Máquinas Agrícolas Pinhalense, Adélcio Piagentini, citado no item 2.3.1. As precisōes de 0,05 e 0,01 foram adotadas em função das escalas de medida do paquímetro e do projetor de perfil, respectivamente. 


\section{RESULTADOS E DISCUSSÃO}

Para uma melhor interpretação dos resultados o ideal seria a apresentação de todas as medidas e suas diferenças; entretanto, isso implicaria na apresentação de um número exagerado de dados que dificultaria a visualização dos resultados. Optou-se por apresentar as médias referentes a cada uma das oito amostras, com duas casas decimais, em função da incerteza de medida proposta.

Durante a discussão dos resultados foi empregado o termo exato para as diferenças de medida $\left(D_{i}\right)$ que não diferem significativamente a $1 \%$ de probabilidade em relação ao zero, pelo teste t Student. O termo preciso é empregado como referência que as $D_{i}$ médias das amostras não diferem significativamente entre si a $1 \%$ de probabilidade, também pelo teste t Student.

\subsection{Estimativa do tamanho da amostra}

Observando-se os resultados das medidas de comprimento e largura distribuidos em histograma (Figuras 5 e 6), verifica-se que ambas as 
medidas apresentam distribuição normal. A maior concentração de indivíduos encontra-se na classes intermediárias (4 a 6), 49 e 55 indivíduos respectivamente para as medidas de comprimento e largura, e as classes extremas ( 1 a 3 e 7 a 10 ) apresentam totais de indivíduos semelhantes a $1 \%$ de probabilidade, 30 e 25 indivíduos para as classes 1 a 3 e, 21 e 20 indivíduos para as classes 7 a 10, respectivamente para as medidas de comprimento e largura.

Considerando o discutido no parágrafo anterior e que a equação exige como premissa que a população apresente distribuição normal, concluise que é possivel a aplicação da equação (1) para a determinação do tamanho da amostra, considerando o valor tabelado de $t_{(0,01 / 2 ; 99)}$ bilateral.

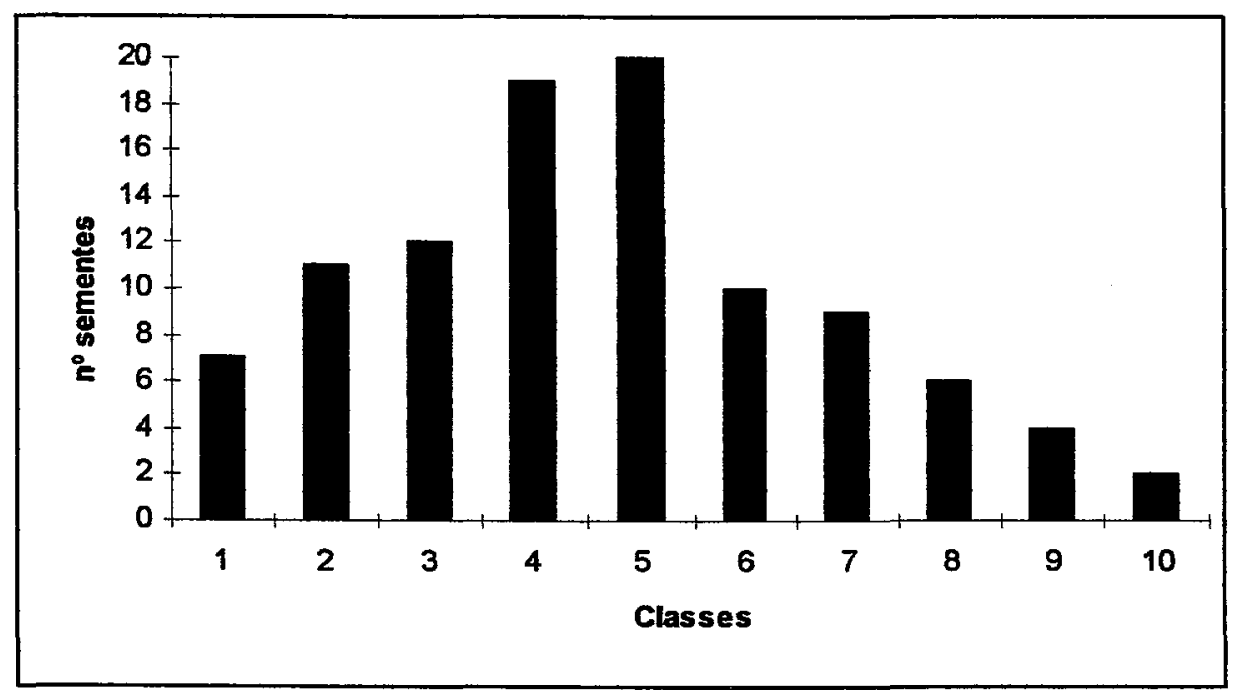

Figura 13: Histograma das freqüências relativas das medidas de comprimento, determinadas em 100 sementes de milho da amostra 24L. 


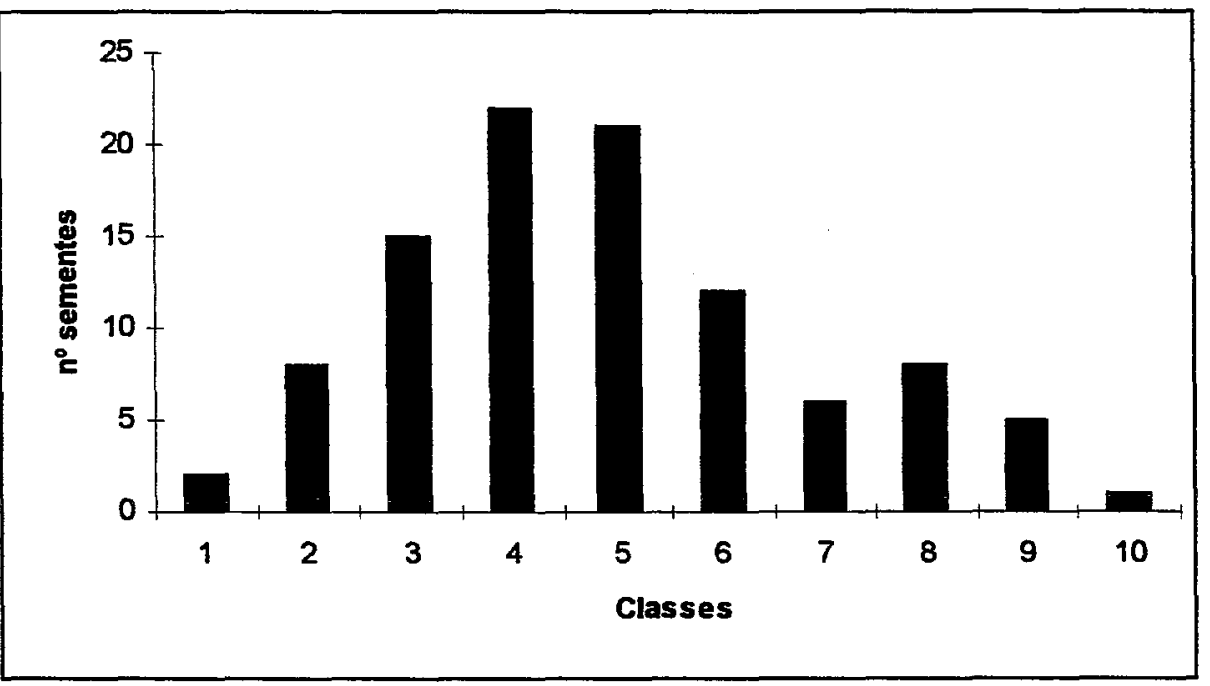

Figura 14: Histograma das freqüências relativas das medidas de largura, determinadas em 100 sementes de milho da amostra 24L.

Aplicando-se as medidas determinadas de comprimento e largura na equação (1), descrita em 2.2.1, estimou-se que uma amostra contendo 335,78 sementes representaria a população para uma precisão requerida de $0,01 \mathrm{~mm}$, sendo o comprimento a medida limitante.

Os resultados das imagens convertidas, pré-processadas e analisadas demonstraram que a resolução de 75 ppi não apresentava diferença significativa da resolução de 100 ppi quanto aos tamanhos dos arquivos e medidas de comprimento e largura estimadas. Quanto à resolução de 300 ppi, mostrou-se inviável trabalhar com imagens contendo 50 sementes em razão da capacidade insuficiente dos equipamentos disponiveis, apresentando principalmente problemas de insuficiência de memória no computador. 


\subsection{Eliminação dos momentos referentes aos residuos}

O total de 768 arquivos gerados pelo sistema SIARCS $3.0^{\circledR}$ contendo os resultados dos momentos descritos em 2.4.4. em oito amostras divididas em seis sub-amostras, de imagens de sementes de milho digitalizadas nos arranjos e resoluções propostos em 3.7. apresentaram 92,13 objetos em média. Após empregar o algoritmo para eliminar os objetos, e seus respectivos momentos, com área inferior à $20 \%$ da área média, todos os arquivos apresentaram 50 objetos, ou seja, foram eliminados todos os resultados referentes aos resíduos. Portanto, é viável a incorporação do algoritmo descrito ao sistema SIARCS $3.0^{\circledR}$ para eliminar os momentos referentes aos resíduos, quando o sistema for empregado para estimar as dimensões de sementes de milho.

\subsection{Análise das imagens}

Os resultados médios, em "pixeis" ( $p x)$, dos momentos dos lados do menor retângulo circunscrito $(A, a)$ e eixos da elipse que melhor representa o objeto $(E, e)$, estimados em imagens contendo 50 sementes de milho arranjadas nas posições ordenada/dorsal (OD), ordenada/ventral (OV), 
desordenada/dorsal (DD) e desordenada/ventral (DV), digitalizadas nas resoluções 100, 150, 200 e 250 ppi em oito amostras (18C, 18L, 20C, 20L, 22C, 22L, 24C E 24L), são apresentados nas Tabelas 1 a 8.

Observa-se coerência dos dados determinados com emprego do modelo do retângulo circunscrito, pois apresentam valores crescentes em razão direta a resolução e, ao considerar os dados para uma mesma resolução, não apresentam valores discrepantes entre si. Já os dados determinados com o emprego do modelo da elipse que melhor representa o objeto apresentam maior discrepância quando comparados aos do modelo do menor retângulo circunscrito sob os mesmos critérios.

Como o objetivo do trabalho foi verificar a precisão e a exatidão das medidas estimadas após convertidas de pixeis para milímetros, não foi aplicada análise estatística aos resultados. Portanto, os resultados devem ser considerados apenas como indicativos de que o modelo da elipse que melhor representa o objeto é menos exato e preciso quando comparado ao modelo do menor retângulo circunscrito, não sendo possivel qualquer conclusão a respeito. 
Tabela 1: Médias* dos momentos dos lados do menor retângulo circunscrito $(A$, a) e eixos da elipse que melhor representa o objeto $(E, e)$, em "pixeis" (px), estimados em sementes de milho da amostra 18C arranjadas nas posições ordenada/dorsal (OD), ordenada/ventral (OV), desordenada/dorsal (DD) e desordenada/ventral (DV), digitalizadas com as resoluções 100, 150, 200 e 250 ppi.

\begin{tabular}{cccccc}
\hline \hline Arquivo & \multicolumn{2}{c}{ Retângulo (px) } & & \multicolumn{2}{c}{ Elipse (px) } \\
\cline { 2 - 3 } \cline { 5 - 6 } & $\mathrm{A}$ & $\mathrm{a}$ & $\mathrm{E}$ & $\mathrm{e}$ \\
\hline OD100 & 43,52 & 29,77 & & 21,08 & 14,72 \\
OV100 & 43,41 & 29,73 & & 21,17 & 14,70 \\
DD100 & 43,66 & 29,83 & & 19,10 & 15,26 \\
DV100 & 43,64 & 29,82 & & 19,16 & 15,27 \\
OD150 & 65,11 & 44,80 & & 31,54 & 22,15 \\
OV150 & 64,95 & 44,67 & & 31,68 & 22,07 \\
DD150 & 65,39 & 44,52 & & 28,54 & 22,74 \\
DV150 & 65,31 & 44,57 & & 28,62 & 22,81 \\
OD200 & 86,14 & 59,59 & & 41,54 & 29,46 \\
OV200 & 85,23 & 59,32 & & 41,50 & 29,31 \\
DD200 & 86,57 & 58,87 & & 37,79 & 30,08 \\
DV200 & 86,33 & 58,83 & & 37,79 & 30,10 \\
OD250 & 108,22 & 74,32 & & 52,35 & 36,71 \\
OV250 & 107,89 & 74,42 & 52,58 & 36,74 \\
DD250 & 108,91 & 74,11 & 47,53 & 37,89 \\
DV250 & 108,62 & 74,01 & 47,57 & 37,86 \\
\hline
\end{tabular}


Tabela 2: Médias* dos momentos dos lados do menor retângulo circunscrito ( $A$, a) e eixos da elipse que melhor representa o objeto $(E, e)$, em "pixeis" ( $p x)$, estimados em sementes de milho da amostra 18L arranjadas nas posições ordenada/dorsal (OD), ordenada/ventral (OV), desordenada/dorsal (DD) e desordenada/ventral (DV), digitalizadas com as resoluções de 100, 150, 200 e 250 ppi.

\begin{tabular}{|c|c|c|c|c|}
\hline \multirow[t]{2}{*}{ Arquivo } & \multicolumn{2}{|c|}{ Retângulo (px) } & \multicolumn{2}{|c|}{ Elipse (px) } \\
\hline & $\bar{A}$ & $\bar{a}$ & $E$ & $\mathrm{e}$ \\
\hline OD100 & 53,33 & 30,06 & 26,14 & 15,14 \\
\hline OV100 & 53,15 & 30,10 & 26,24 & 15,16 \\
\hline DD100 & 53,40 & 30,15 & 23,37 & 15,80 \\
\hline DV100 & 53,35 & 30,13 & 23,56 & 15,76 \\
\hline OD150 & 79,83 & 45,18 & 39,12 & 22,76 \\
\hline ov150 & 79,49 & 45,08 & 39,22 & 22,73 \\
\hline DD150 & 80,07 & 45,05 & 35,01 & 23,63 \\
\hline DV150 & 79,96 & 45,03 & 35,26 & 23,57 \\
\hline OD200 & 104,93 & 59,86 & 51,36 & 30,19 \\
\hline 0V200 & 104,62 & 59,94 & 51,56 & 30,21 \\
\hline DD200 & 105,93 & 59,47 & 46,30 & 31,20 \\
\hline DV200 & 105,93 & 59,51 & 46,70 & 31,17 \\
\hline OD250 & 132,72 & 75,02 & 64,98 & 37,77 \\
\hline OV250 & 132,35 & 75,09 & 65,27 & 37,81 \\
\hline DD250 & 133,47 & 74,98 & 58,31 & 39,34 \\
\hline DV250 & 133,27 & 74,81 & 58,74 & 39,14 \\
\hline
\end{tabular}


Tabela 3: Médias* dos momentos dos lados do menor retângulo circunscrito ( $A$, a) e eixos da elipse que melhor representa o objeto $(E, e)$, em "pixeis" (px), estimados em sementes de milho da amostra 20C arranjadas nas posições ordenada/dorsal (OD), ordenada/ventral (OV), desordenada/dorsal (DD) e desordenada/ventral (DV), digitalizadas com as resoluções 100, 150, 200 e 250 ppi.

\begin{tabular}{lccccc}
\hline Arquivo & \multicolumn{2}{c}{ Retângulo $(\mathrm{px})$} & \multicolumn{2}{c}{ Elipse $(\mathrm{px})$} \\
\cline { 2 - 4 } \cline { 5 - 5 } & $\mathrm{A}$ & $\mathrm{a}$ & $\mathrm{E}$ & $\mathrm{e}$ \\
\hline OD100 & 48,77 & 35,07 & & 23,77 & 17,44 \\
OV100 & 44,74 & 32,25 & & 21,84 & 16,05 \\
DD100 & 45,06 & 32,48 & & 20,11 & 16,58 \\
DV100 & 44,94 & 32,33 & & 19,87 & 16,58 \\
OD150 & 67,23 & 48,61 & & 32,76 & 24,12 \\
OV150 & 66,86 & 48,54 & & 32,61 & 24,10 \\
DD150 & 67,40 & 48,50 & & 30,05 & 24,75 \\
DV150 & 67,42 & 48,28 & & 29,78 & 24,75 \\
OD200 & 88,43 & 64,74 & & 42,99 & 32,06 \\
OV200 & 87,84 & 64,46 & & 42,81 & 32,02 \\
DD200 & 89,21 & 64,29 & 39,71 & 32,77 \\
DV200 & 88,89 & 63,91 & 39,25 & 32,76 \\
OD250 & 111,80 & 80,90 & 54,46 & 40,11 \\
OV250 & 111,21 & 80,71 & 54,21 & 40,08 \\
DD250 & 112,33 & 80,82 & 50,01 & 41,21 \\
DV250 & 111,89 & 80,46 & 49,37 & 41,20 \\
\hline \hline
\end{tabular}


Tabela 4: Médias* dos momentos dos lados do menor retângulo circunscrito ( $A$, a) e eixos da elipse que melhor representa o objeto $(E, e)$, em "pixeis" (px), estimados em sementes de milho da amostra $20 \mathrm{~L}$ arranjadas nas posições ordenada/dorsal (OD), ordenada/ventral (OV), desordenada/dorsal (DD) e desordenada/ventral (DV), digitalizadas com as resoluções 100, 150, 200 e 250 ppi.

\begin{tabular}{|c|c|c|c|c|}
\hline \multirow[t]{2}{*}{ Arquivo } & \multicolumn{2}{|c|}{ Retângulo (px) } & \multicolumn{2}{|c|}{ Elipse (px) } \\
\hline & $\bar{A}$ & $\bar{a}$ & $E$ & e \\
\hline OD100 & 53,77 & 35,07 & 26,80 & 16,44 \\
\hline OV100 & 54,77 & 32,25 & 26,77 & 16,12 \\
\hline DD100 & 53,80 & 32,48 & 21,15 & 16,68 \\
\hline DV100 & 53,74 & 32,33 & 22,01 & 16,61 \\
\hline OD150 & 80,23 & 48,61 & 40,05 & 24,75 \\
\hline OV150 & 80,20 & 48,54 & 40,12 & 24,10 \\
\hline DD150 & 80,25 & 48,50 & 30,05 & 24,85 \\
\hline DV150 & 80,30 & 48,28 & 29,78 & 24,80 \\
\hline OD200 & 107,02 & 64,74 & 53,55 & 32,42 \\
\hline OV200 & 107,05 & 64,74 & 53,41 & 32,25 \\
\hline DD200 & 107,03 & 64,74 & 51,01 & 32,99 \\
\hline DV200 & 107,04 & 64,74 & 51,87 & 32,78 \\
\hline OD250 & 134,00 & 80,90 & 67,10 & 40,51 \\
\hline OV250 & 133,54 & 80,71 & 66,98 & 40,52 \\
\hline DD250 & 133,81 & 80,82 & 50,10 & 41,59 \\
\hline DV250 & 133,79 & 80,46 & 52,23 & 41,32 \\
\hline
\end{tabular}

*referentes a 300 sementes 
Tabela 5: Médias* dos momentos dos lados do menor retângulo circunscrito ( $A$, a) e eixos da elipse que melhor representa o objeto $(E, e)$, em "pixeis" (px), estimados em sementes de milho da amostra 22C arranjadas nas posições ordenada/dorsal (OD), ordenada/ventral (OV), desordenada/dorsal (DD) e desordenada/ventral (DV), digitalizadas com as resoluções 100, 150, 200 e 250 ppi.

\begin{tabular}{cccccc}
\hline \hline Arquivo & \multicolumn{2}{c}{ Retângulo $(\mathrm{px})$} & & \multicolumn{2}{c}{ Elipse (px) } \\
\cline { 2 - 3 } \cline { 5 - 6 } & $\mathrm{A}$ & $\mathrm{a}$ & $\mathrm{E}$ & $\mathrm{e}$ \\
\hline OD100 & 49,06 & 35,73 & & 23,84 & 17,88 \\
OV100 & 48,85 & 35,74 & & 23,81 & 17,87 \\
DD100 & 49,11 & 35,78 & & 22,26 & 18,33 \\
DV100 & 48,97 & 35,74 & & 22,10 & 18,37 \\
OD150 & 73,18 & 53,60 & & 35,52 & 26,82 \\
OV150 & 72,80 & 53,38 & & 35,46 & 26,75 \\
DD150 & 73,41 & 53,34 & & 33,26 & 27,37 \\
DV150 & 73,29 & 53,42 & & 33,01 & 27,44 \\
OD200 & 96,31 & 71,12 & & 46,70 & 35,60 \\
OV200 & 96,07 & 71,12 & & 46,73 & 35,60 \\
DD200 & 97,14 & 70,64 & & 43,94 & 36,21 \\
DV200 & 97,12 & 70,82 & & 43,71 & 36,37 \\
OD250 & 121,80 & 89,08 & & 59,12 & 44,56 \\
OV250 & 121,44 & 89,04 & 59,12 & 44,58 \\
DD250 & 122,25 & 88,83 & 55,32 & 45,52 \\
DV250 & 122,23 & 89,02 & 54,99 & 45,70 \\
\hline \hline
\end{tabular}


Tabela 6: Médias* dos momentos dos lados do menor retângulo circunscrito ( $A$, a) e eixos da elipse que melhor representa o objeto $(E, e)$, em "pixeis" (px), estimadas em sementes de milho da amostra $22 \mathrm{~L}$ arranjadas nas posições ordenada/dorsal (OD), ordenada/ventral (OV), desordenada/dorsal (DD) e desordenada/ventral (DV), digitalizadas com as resoluções 100, 150, 200 e 250 ppi.

\begin{tabular}{lccccc}
\hline Arquivo & \multicolumn{2}{c}{ Retângulo $(\mathrm{px})$} & & \multicolumn{2}{c}{ Elipse (px) } \\
\cline { 2 - 4 } \cline { 5 - 6 } & $\mathrm{A}$ & $\mathrm{a}$ & $\mathrm{E}$ & $\mathrm{e}$ \\
\hline OD100 & 51,70 & 35,73 & & 25,06 & 18,00 \\
OV100 & 51,49 & 35,65 & & 25,10 & 17,98 \\
DD100 & 51,69 & 35,63 & & 22,89 & 18,51 \\
DV100 & 51,61 & 35,49 & & 23,10 & 18,42 \\
OD150 & 77,22 & 53,52 & & 37,40 & 26,98 \\
OV150 & 76,98 & 53,45 & & 37,52 & 26,97 \\
DD150 & 77,43 & 53,30 & & 34,29 & 27,72 \\
DV150 & 77,37 & 53,05 & & 34,56 & 27,51 \\
OD200 & 101,63 & 71,21 & & 49,14 & 35,89 \\
OV200 & 101,24 & 71,14 & & 49,27 & 35,87 \\
DD200 & 102,48 & 70,32 & & 45,30 & 36,55 \\
DV200 & 98,44 & 67,49 & 43,97 & 35,03 \\
OD250 & 128,30 & 89,26 & 62,14 & 44,96 \\
OV250 & 123,64 & 86,19 & 60,22 & 43,42 \\
DD250 & 129,05 & 88,80 & 57,07 & 46,13 \\
DV250 & 129,11 & 88,64 & 57,65 & 45,96 \\
\hline \hline
\end{tabular}


Tabela 7: Médias* dos momentos dos lados do menor retângulo circunscrito (A, a) e eixos da elipse que melhor representa o objeto $(E, e)$, em "pixeis" (px), estimados em sementes de milho da amostra 24C arranjadas nas posições ordenada/dorsal (OD), ordenada/ventral (OV), desordenada/dorsal (DD) e desordenada/ventral (DV), digitalizadas com as resoluções 100, 150, 200 e 250 ppi.

\begin{tabular}{lccccc}
\hline Arquivo & \multicolumn{2}{c}{ Retângulo $(\mathrm{px})$} & \multicolumn{2}{c}{ Elipse (px) } \\
\cline { 2 - 3 } \cline { 5 - 6 } & $\mathrm{A}$ & $\mathrm{a}$ & $\mathrm{E}$ & $\mathrm{e}$ \\
\hline OD100 & 40,00 & 45,79 & & 19,19 & 25,40 \\
OV100 & 39,98 & 45,89 & & 19,51 & 25,45 \\
DD100 & 40,49 & 45,45 & & 21,01 & 25,23 \\
DV100 & 40,89 & 45,55 & & 21,01 & 25,28 \\
OD150 & 59,56 & 67,59 & & 29,22 & 36,30 \\
OV150 & 59,10 & 67,69 & & 29,99 & 36,35 \\
DD150 & 59,66 & 67,55 & & 32,12 & 36,28 \\
DV150 & 59,65 & 67,61 & & 32,99 & 36,31 \\
OD200 & 79,01 & 90,10 & & 38,65 & 47,55 \\
OV200 & 79,12 & 90,07 & & 39,02 & 47,54 \\
DD200 & 79,31 & 90,08 & 39,99 & 47,54 \\
DV200 & 79,40 & 90,05 & & 41,52 & 47,53 \\
OD250 & 99,50 & 112,78 & 48,22 & 58,89 \\
OV250 & 99,02 & 112,40 & 49,58 & 58,70 \\
DD250 & 99,91 & 112,65 & 49,99 & 58,83 \\
DV250 & 99,99 & 112,74 & 51,01 & 58,87 \\
\hline \hline
\end{tabular}


Tabela 8: Médias* dos momentos dos lados do menor retângulo circunscrito ( $\mathrm{A}$, a) e eixos da elipse que melhor representa o objeto $(E, e)$, em "pixeis" (px), estimados em sementes de milho da amostra 24L arranjadas nas posições ordenada/dorsal (OD), ordenada/ventral (OV), desordenada/dorsal (DD) e desordenada/ventral (DV), digitalizadas com as resoluções 100, 150, 200 e 250 ppi.

\begin{tabular}{|c|c|c|c|c|}
\hline \multirow[t]{2}{*}{ Arquivo } & \multicolumn{2}{|c|}{ Retângulo (px) } & \multicolumn{2}{|c|}{ Elipse (px) } \\
\hline & $\bar{A}$ & $a$ & $\bar{E}$ & e \\
\hline OD100 & 39,00 & 48,01 & 19,12 & 26,51 \\
\hline OV100 & 39,00 & 48,50 & 19,41 & 26,75 \\
\hline DD100 & 39,12 & 47,51 & 19,78 & 26,26 \\
\hline DV100 & 39,11 & 47,62 & 20,01 & 26,31 \\
\hline OD150 & 58,12 & 71,19 & 29,12 & 38,10 \\
\hline OV150 & 58,00 & 71,21 & 29,79 & 38,11 \\
\hline DD150 & 57,91 & 71,15 & 31,01 & 38,08 \\
\hline DV150 & 57,99 & 71,12 & 29,45 & 38,06 \\
\hline OD200 & 77,20 & 94,80 & 38,52 & 49,90 \\
\hline OV200 & 77,22 & 94,61 & 38,62 & 49,81 \\
\hline DD200 & 77,21 & 94,82 & 39,39 & 49,91 \\
\hline DV200 & 77,30 & 94,79 & 39,81 & 49,90 \\
\hline OD250 & 96,80 & 118,75 & 48,02 & 61,88 \\
\hline OV250 & 97,01 & 118,81 & 48,98 & 61,91 \\
\hline DD250 & 96,99 & 118,77 & 49,09 & 61,89 \\
\hline DV250 & 97,12 & 118,53 & 49,21 & 61,77 \\
\hline
\end{tabular}




\subsection{Medidas determinadas}

$\mathrm{Na}$ Tabela 9 e 10 são apresentadas, respectivamente, as médias de comprimento e largura, em milímetros $(\mathrm{mm})$, referentes às 300 sementes de milho contidas nas oito amostras (18C, 18L, 20C, 20L, 22C, 22L, $24 \mathrm{C}$ e 24L), determinadas com emprego do projetor de perfil (PP) e 0 paquímetro (PA), bem como, as medidas fixadas para o longuímetro (LG) e a peneira (PE).

Tabela 9: Médias* das medidas de comprimento determinadas em oito amostras de sementes de milho, com emprego do projetor de perfil (PP), do paquímetro (PA) e a medida fixada para o longuímetro (LG). Dados em milimetros ( $\mathrm{mm}$ ).

\begin{tabular}{cccc}
\hline \hline Amostra & \multicolumn{3}{c}{ Comprimento $(\mathrm{mm})$} \\
\cline { 2 - 4 } & PP & PA & LG \\
\hline \hline $18 \mathrm{C}$ & 10,88 & 10,88 & $<11,11$ \\
$18 \mathrm{~L}$ & 13,40 & 13,28 & $>11,11$ \\
$20 \mathrm{C}$ & 11,26 & 11,24 & $<11,11$ \\
$2 \mathrm{LL}$ & 13,59 & 13,58 & $>11,11$ \\
$22 \mathrm{C}$ & 12,29 & 12,19 & $<11,11$ \\
$22 \mathrm{~L}$ & 12,98 & 12,83 & $>11,11$ \\
$24 \mathrm{C}$ & 11,43 & 11,37 & $<11,11$ \\
$24 \mathrm{~L}$ & 12,03 & 11,99 & $>11,11$ \\
\hline \hline
\end{tabular}


Tabela 10: Médias* das medidas de largura determinados em oito amostras de sementes de milho, com emprego do projetor de perfil (PP) do paquímetro (PA), e a medida fixada para a peneira (PE). Dados em milimetros $(\mathrm{mm})$.

\begin{tabular}{lccc}
\hline \hline Amostra & \multicolumn{3}{c}{ Largura $(\mathrm{mm})$} \\
\cline { 2 - 4 } & PP & PA & PE \\
\hline $18 \mathrm{C}$ & 7,45 & 7,40 & 7,14 \\
$18 \mathrm{~L}$ & 7,59 & 7,46 & 7,14 \\
$20 \mathrm{C}$ & 8,16 & 8,11 & 7,94 \\
$20 \mathrm{~L}$ & 8,22 & 8,21 & 7,94 \\
$22 \mathrm{C}$ & 9,00 & 8,90 & 8,73 \\
$22 \mathrm{~L}$ & 8,99 & 8,90 & 8,73 \\
$24 \mathrm{C}$ & 10,06 & 9,98 & 9,52 \\
$24 \mathrm{~L}$ & 9,80 & 9,80 & 9,52 \\
\hline \hline
\end{tabular}

*referentes a 300 sementes

Observa-se quanto as médias das medidas de comprimento (Tabela 9) que para as amostras $20 \mathrm{C}, 22 \mathrm{C}$ e $24 \mathrm{C}$, as médias das medidas determinadas com o projetor de perfil encontram-se acima de $11,11 \mathrm{~mm}$, indicando que o longuímetro não foi eficiente para a classificação destas amostras. Já as médias das medidas de largura determinadas com o projetor de perfil (Tabela 10), em todas as amostras apresentam valores médios superiores ao diâmetro do crivo da peneira empregada (Tabela 10), indicando que as peneiras foram eficazes para a classificação das sementes quanto a largura. Estes resultados serão melhor discutidos oportunamente, após calculo e analise estatística das diferenças de medida. 


\subsection{Medidas estimadas}

Nas Tabelas 11 e 12 são apresentadas, respectivamente, as médias de comprimento e largura convertidas de "pixeis" para milímetros (mm) com emprego das equações descritas em 3.11. As médias são referentes às medidas de 300 sementes de milho contidas nas oito amostras (18C, 18L, 20C, $20 \mathrm{~L}, 22 \mathrm{C}, 22 \mathrm{~L}, 24 \mathrm{C}$ e $24 \mathrm{~L}$ ), estimadas pelo sistema SIARCS $3.0^{\circledR}$ com emprego do modelo do menor retângulo circunscrito, em seis imagens contendo 50 sementes para cada amostra, digitalizadas nas resoluções de 100, 150, 200 e $250 \mathrm{ppi}$, com as sementes arranjadas nas posições ordenada/dorsal (OD), ordenada/ventral (OV), desordenada/dorsal (DD) e desordenada/ventral (DV).

Nas Tabelas 13 e 14 são apresentadas, respectivamente, as médias de comprimento e largura convertidas de "pixeis" para milímetros ( $\mathrm{mm}$ ) com emprego das equações descritas em 3.11. As médias são referentes às medidas de 300 sementes de milho contidas nas oito amostras (18C, 18L, 20C, 20L, 22C, 22L, 24C e 24L), estimadas pelo sistema SIARCS $3.0^{\circledR}$ com emprego do modelo da elipse que melhor representa o objeto, em seis imagens contendo 50 sementes para cada amostra, digitalizadas em resoluções de 100, 150, 200 e 250 ppi e com as sementes arranjadas nas posições ordenada/dorsal (OD), ordenada/ventral (OV), desordenada/dorsal (DD) e desordenada/ventral (DV). 


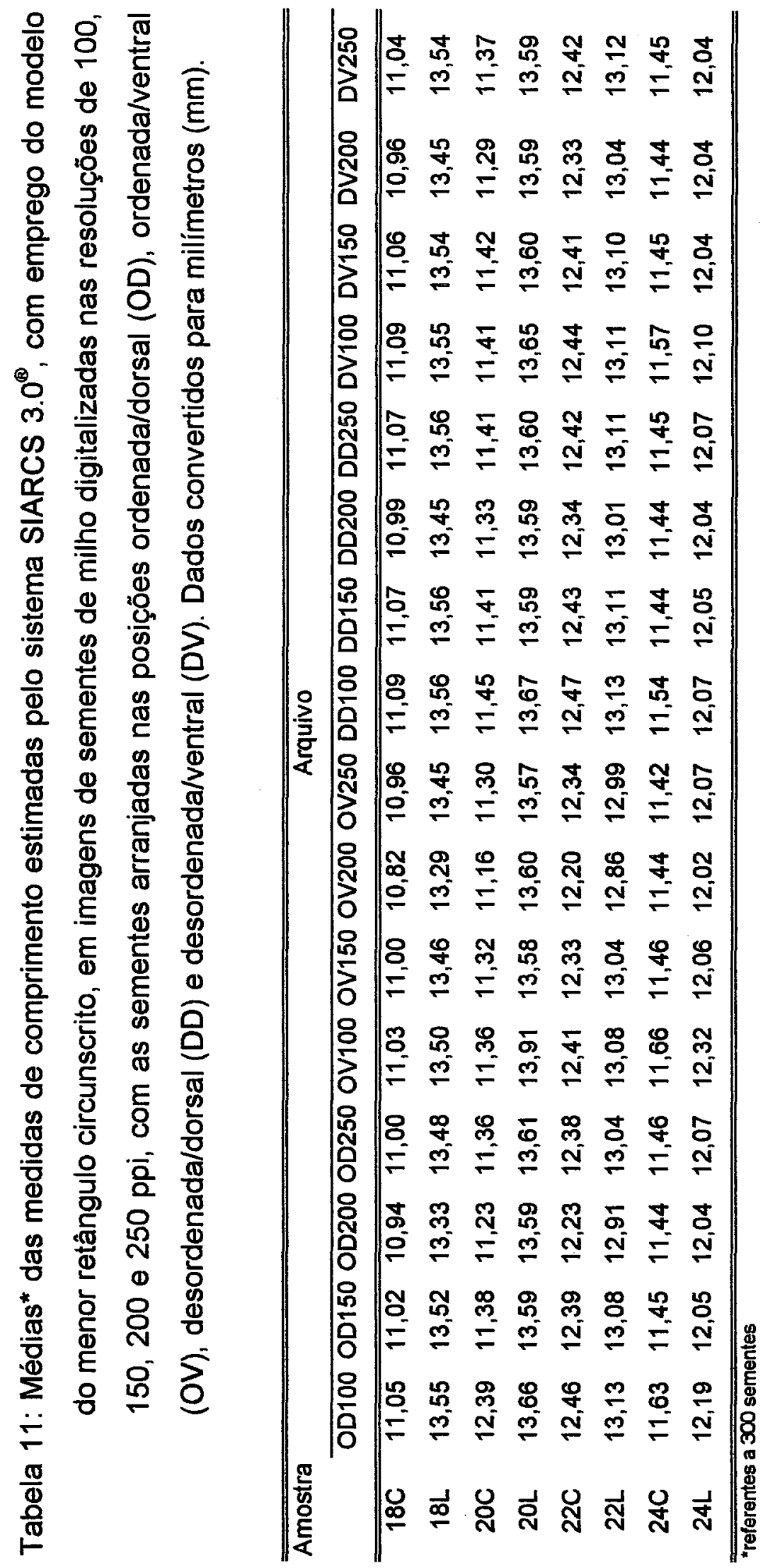




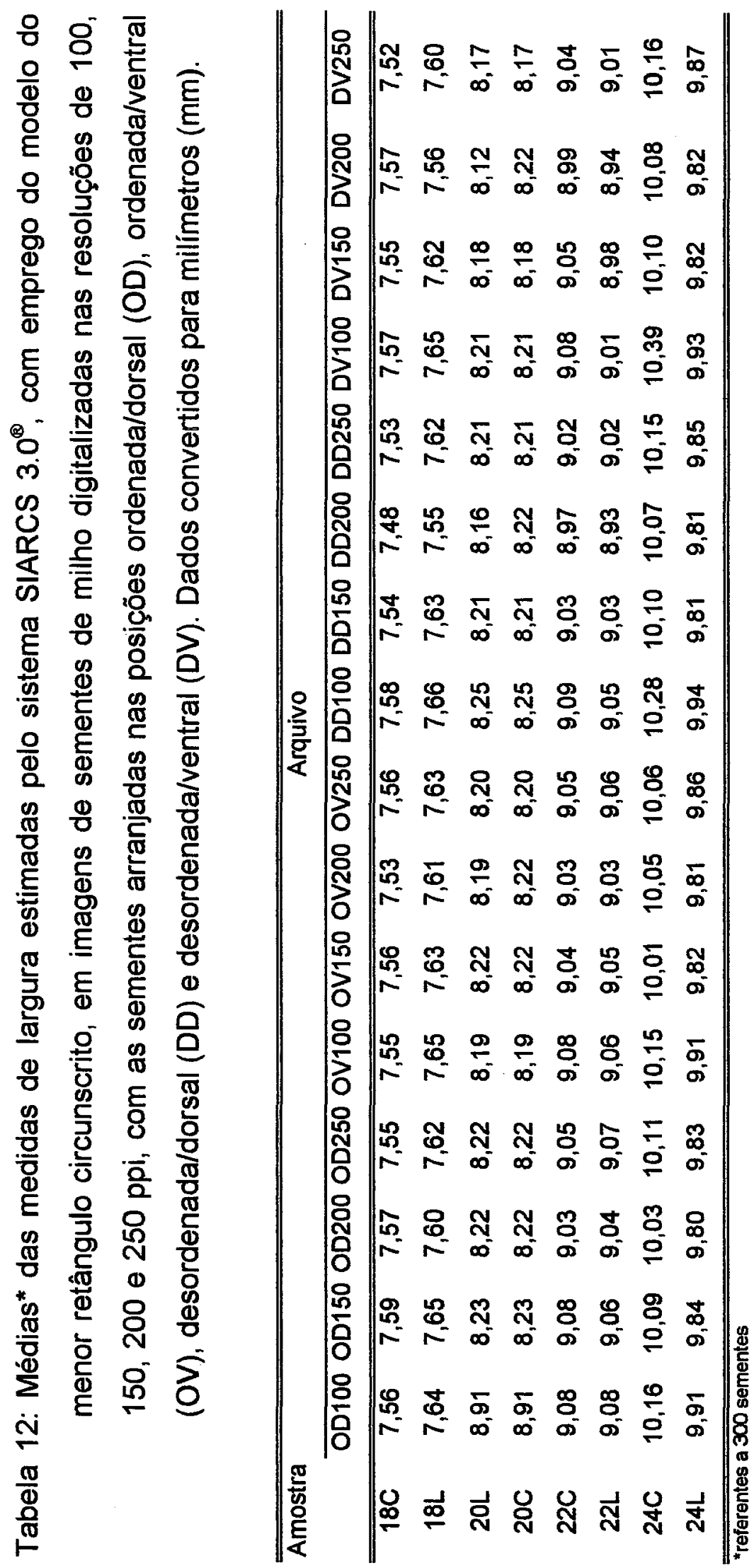




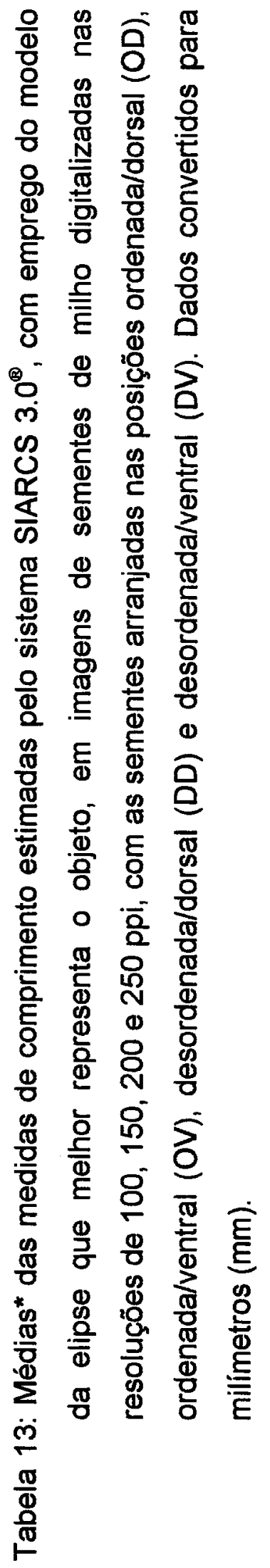

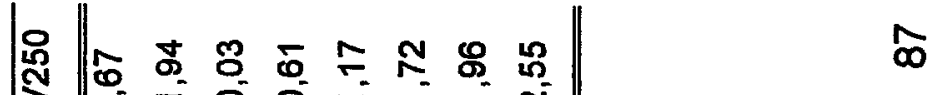

敢

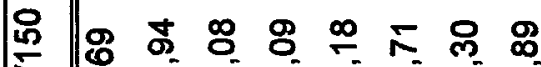
穴

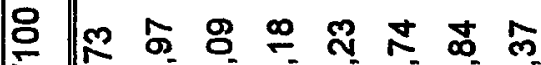

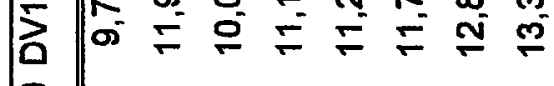
总

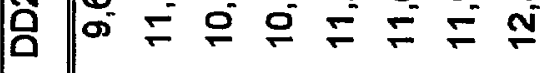
通 8 용 O)

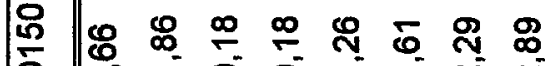
范

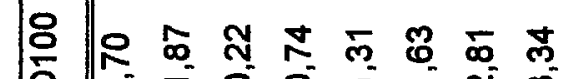
产 家 赵 व) 웅 웅응 d) 苗 象 \& o 0 年

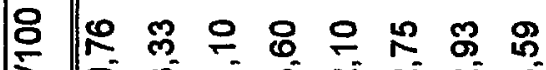
J 通 论 गิ 员 峁 ग) 草 Dิ

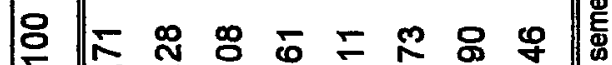
ग)

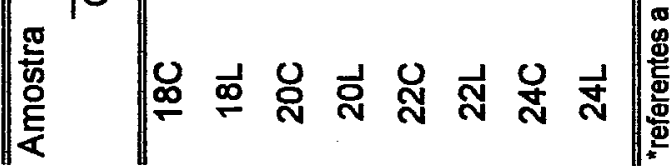



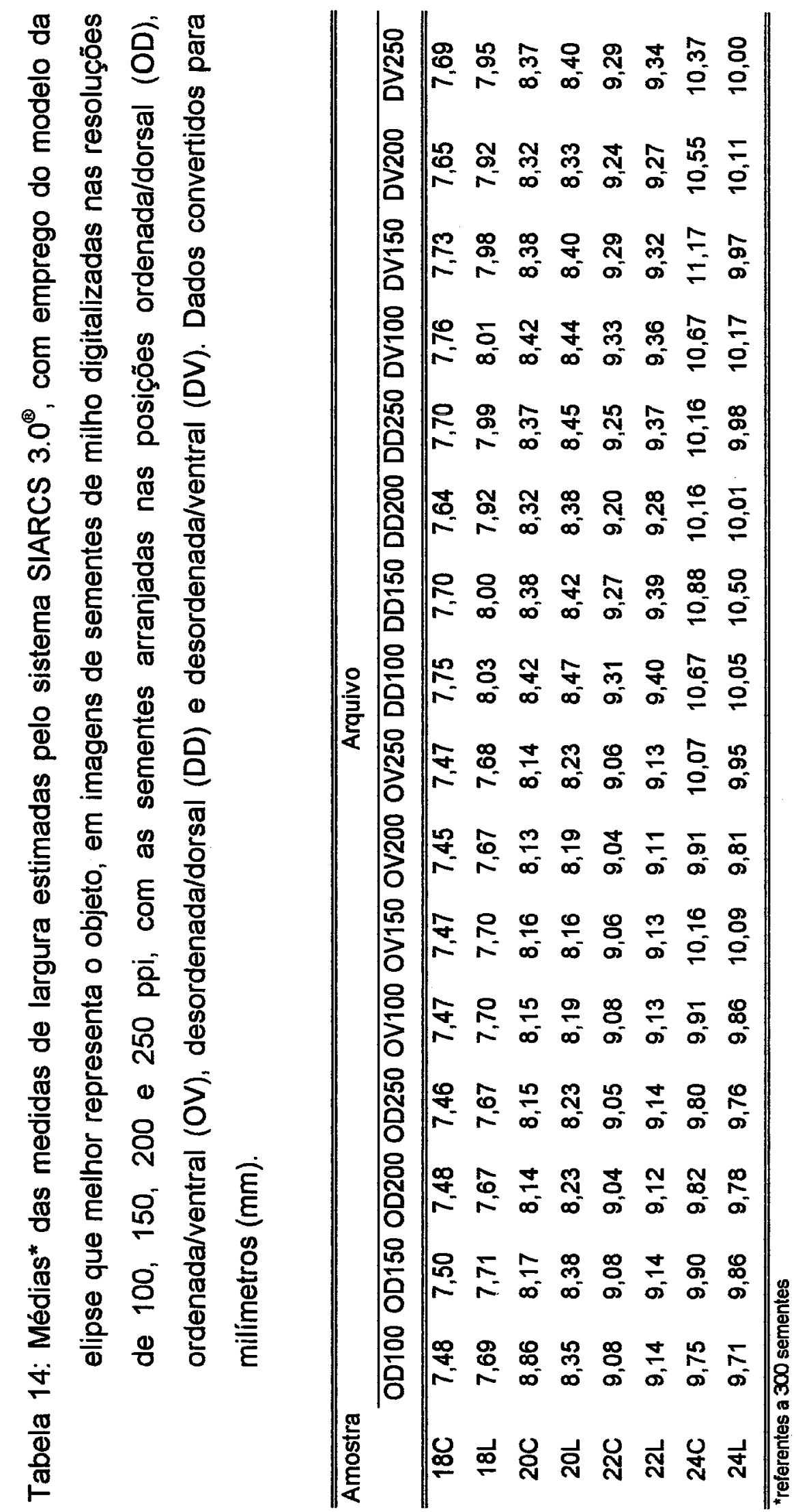


\subsection{Incerteza de medida}

\subsubsection{Medidas determinadas}

Com relação às médias das diferenças das medidas de comprimento (MComp), determinadas nas oito amostras, apresentadas na Tabela 15, verifica-se que o paquímetro apresentou medidas menores do que as correspondentes determinadas com o projetor de perfil em razão da deformação plástica provocada no pedicelo da semente durante a medição, entretanto, a incerteza de medida não foi significativamente diferente a $1 \%$ de probabilidade pelo teste $\mathrm{t}$ Student. Os resultados apresentados demonstram que as medidas de comprimento das sementes determinadas com 0 paquímetro não diferiram das correspondentes determinadas com o projetor de perfil, ou seja, o paquimetro determinou medidas exatas.

O paquímetro não foi preciso, pois as médias das amostras que compõem a média geral, apresentada na Tabela 15 , diferiram entre si a $1 \%$ de probabilidade pelo teste $t$ Student. Sua exatidão pode variar em função da amostra e de sua manipulação. Ainda, não pode ser empregada a média geral e o intervalo de confiança das amostras como um fator de correção geral. Quando empregado o paquímetro para determinar a medida de comprimento 
em sementes de milho, deve-se determinar a incerteza de medida referente às sementes em questão.

Tabela 15: Médias* das diferenças das medidas de comprimento (MComp) e de largura (MLarg), intervalos de confiança* $\left(\mathrm{IC}_{(1-0,01)}\right)$ e diferenças maiores do que zero* $\left(D_{i}>0\right)$, das diferenças de comprimento e largura determinadas com o paquímetro em relação às medidas correspondentes determinadas com o projetor de perfil em oito amostras de sementes de milho. Dados em milimetros ( $\mathrm{mm})$.

\begin{tabular}{|c|c|c|c|c|c|c|}
\hline \multirow[t]{2}{*}{ Amostra } & \multicolumn{3}{|c|}{ Comprimento } & \multicolumn{3}{|c|}{ Largura } \\
\hline & $\begin{array}{c}\text { MComp } \\
(\mathrm{mm})\end{array}$ & $\begin{array}{c}\mathrm{IC}_{(1-0,01)} \\
(\mathrm{mm})\end{array}$ & $D_{i}>0$ & $\begin{array}{c}\text { MLarg } \\
(\mathrm{mm})\end{array}$ & $\begin{array}{c}\mathrm{IC}_{(1-0,01)} \\
(\mathrm{mm})\end{array}$ & $D_{i}>0$ \\
\hline$\overline{18 C}$ & $0,00^{n S}$ & $\overline{0,02}$ & $\overline{154}$ & $-0,05^{\mathrm{ns}}$ & 0,02 & $\overline{91}$ \\
\hline $18 \mathrm{~L}$ & $-0,12^{n s}$ & 0,01 & 3 & $-0,13^{* *}$ & 0,02 & 11 \\
\hline $20 \mathrm{C}$ & $-0,02^{\text {ns }}$ & 0,01 & 59 & $-0,05^{* *}$ & 0,02 & 57 \\
\hline $20 \mathrm{~L}$ & $-0,01^{\mathrm{ns}}$ & 0,01 & 5 & $-0,01^{\mathrm{ns}}$ & 0,01 & 7 \\
\hline $22 \mathrm{C}$ & $-0,10^{\text {ns }}$ & 0,02 & 42 & $-0,10^{-m}$ & 0,02 & 44 \\
\hline $22 \mathrm{~L}$ & $-0,14^{\text {ns }}$ & 0,02 & 9 & $-0,09^{-m}$ & 0,01 & 26 \\
\hline $24 C$ & $-0,05^{\mathrm{ns}}$ & 0,02 & 45 & $-0,08^{* m}$ & 0,02 & 45 \\
\hline $24 \mathrm{~L}$ & $-0,04^{n s}$ & 0,01 & 3 & $0,00^{\mathrm{ns}}$ & 0,01 & 5 \\
\hline Média & $-0,060^{\mathrm{B}}$ & 0,015 & 40 & $-0,063^{B}$ & 0,016 & 36 \\
\hline
\end{tabular}

Para a dimensão de largura, as diferenças de medida de largura (MLarg) apresentadas na Tabela 15, demonstram que o paquímetro não se 
mostrou exato; portanto, não se recomenda seu emprego para a determinação da medida de largura em sementes de milho. Neste caso, o principal fator que contribui para inexatidão é a forma piramidal das sementes, diferentes pontos sobre o eixo do comprimento da semente correspondem as diferentes larguras. Portanto, determinar a largura da semente exige a determinação de várias medidas aleatórias na região identificada visualmente como a de maior largura, elegendo a maior largura determinada com o paquímetro como a largura da semente. Importante considerar que esse procedimento é subjetivo estando sujeito a erros.

Embora tenham sido estimadas as estatísticas referentes às diferenças de medidas de comprimento entre a medida fixada para o longuímetro e as medidas determinadas com o projetor de perfil (Tabela 16), não é pertinente avaliar a precisão e exatidão do instrumento, em razão da escala de medida empregada maior ou menor do que $11,11 \mathrm{~mm}$. Neste caso, deve ser considerado o número de sementes que apresentam diferença de medida $\left(D_{i}\right)$ inferior ou superior a zero, respectivamente, para amostras de sementes longas e curtas.

Com relação a medida de comprimento, determinada com o emprego do longuímetro nas amostras contendo sementes longas, a porcentagem de sementes curtas, ou seja, com diferença de medida maior do que zero $\left(D_{i}>0\right)$ foi insignificante $(0,67 \%)$ quando comparada com o limite oficial 
mínimo fixado para o teste de retenção de peneiras (6\%). A comparação foi extrapolada uma vez não existir padrão oficial para a dimensão de comprimento.

Tabela 16: Médias* das diferenças das medidas de comprimento (MComp) e de largura (MLarg), intervalos de confiança* $\left(\mathrm{IC}_{(1-0,01)}\right)$ e diferenças maiores do que zero* $\left(D_{i}>0\right)$, das diferenças de comprimento e largura determinadas, respectivamente, com o longuímetro e a peneira em relação às medidas correspondentes determinadas com o projetor de perfil em oito amostras de sementes de milho. Dados em milímetros $(\mathrm{mm})$.

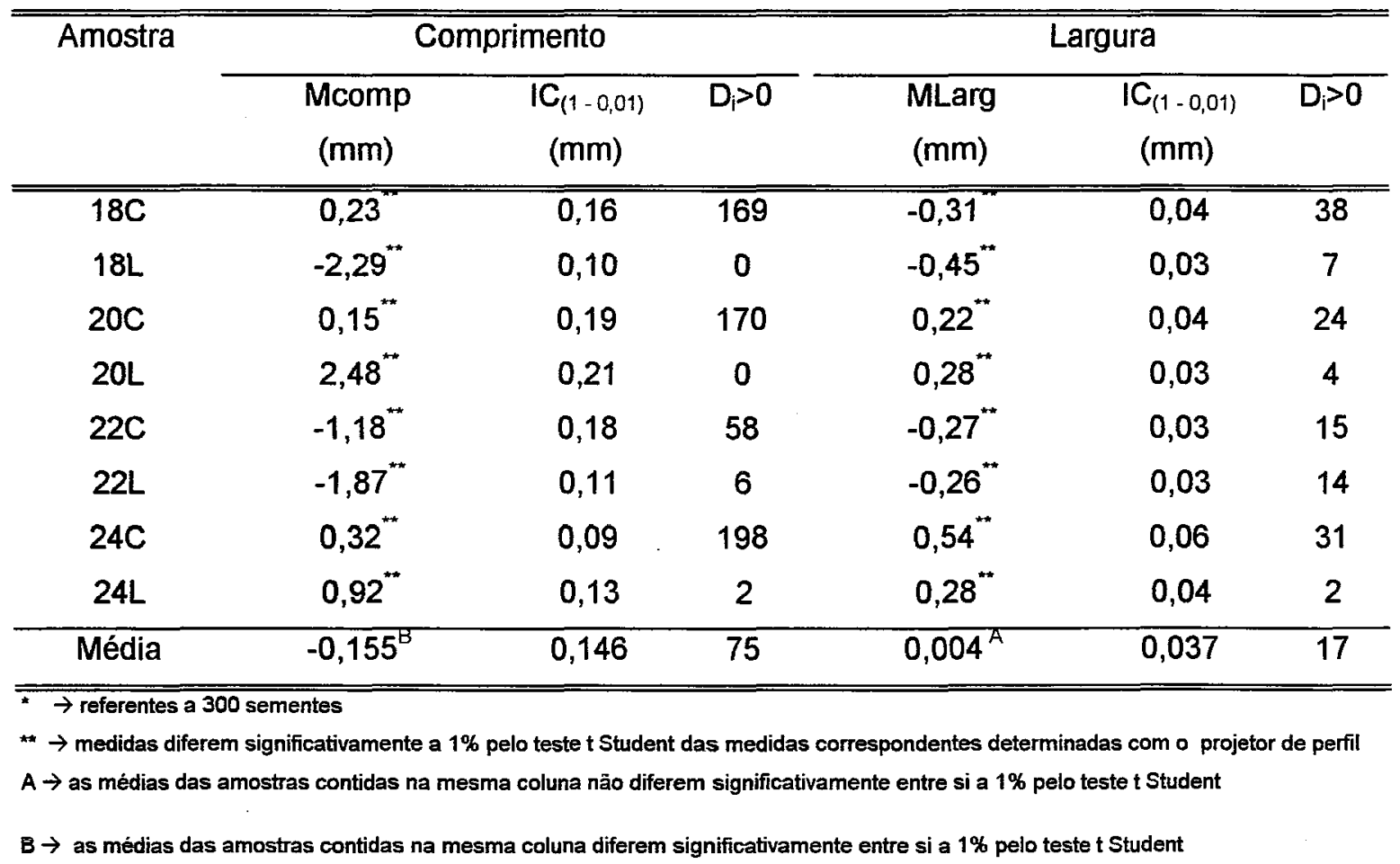


Para as amostras contendo sementes curtas o longuímetro mediu $49,59 \%$ de sementes longas como curtas, ou seja, com a diferença de medida menor do que zero. Adotando-se a comparação ao padrão oficial de retenção de peneiras, o longuímetro foi ineficiente, sendo sua principal limitação a dificuldade na manipulação e encaixe das sementes ao instrumento, o que determina o emprego de força exagerada, provocando deformação plástica ao pedicelo da semente. Portanto, não é recomendável o emprego do longuímetro para aferir a classificação de sementes quanto ao comprimento, principalmente em lotes contendo sementes curtas.

Os resultados das diferenças de medida referentes às peneiras apresentados na Tabela 16, devem ser interpretados sob o mesmo enfoque dado ao longuímetro. Em geral, as peneiras retiveram uma porcentagem de sementes com as dimensões de largura menores do que o diâmetro do seu crivo, muito próximas ao limite mínimo determinado pelo padrão oficial (94\%), no caso da peneira 18 a porcentagem estimada de $87,33 \%$ é inferior ao limite mínimo determinado pelo padrão oficial. Provavelmente o erro está associado à agitação das peneiras e à calibração de seus crivos, apresentando crivos com diâmetro menor do que o prescrito. Há a probabilidade da ocorrência de crivos com o diâmetro maior do que o prescrito, entretanto, a metodologia empregada não permitiu determiná-los, devendo ser esta possibilidade considerada ao ser empregado o teste de retenção de peneiras. 


\subsubsection{Medidas estimadas}

Os resultados das médias das diferenças das medidas de comprimento (MComp) e de largura (MLarg), intervalos de confiança $\left(\mathrm{IC}_{(1-0,01)}\right)$ e diferenças maiores do que zero $\left(D_{i}>0\right)$, das diferenças de comprimento e largura estimadas com emprego do sistema SIARCS $3.0^{\circledR}$ pelo modelo do menor retângulo circunscrito e da elipse que melhor representa o objeto em imagens de sementes de milho digitalizadas nas resoluções de 100, 150, 200 e $250 \mathrm{ppi}$, com as sementes arranjadas nas posições ordenada/dorsal (OD), ordenada/ventral (OV), desordenada/dorsal (DD) e desordenada/ventral (DV) em relação às medidas correspondentes determinadas com o projetor de perfil, conforme descrito em 3.12, são apresentados nas Tabelas 17 a 48. 
Tabela 17: Médias* das diferenças das medidas de comprimento (MComp) e de largura (MLarg), intervalos de confiança* $\left(\mathrm{IC}_{(1-0,01)}\right)$ e diferenças maiores do que zero* $\left(D_{i}>0\right)$, das diferenças de comprimento $e$ largura estimadas pelo modelo do menor retângulo circunscrito em imagens de sementes de milho arranjadas na posição ordenada/dorsal e digitalizadas com a resolução de 100 ppi, em relação às medidas correspondentes determinadas com o projetor de perfil em oito amostras. Dados em milimetros $(\mathrm{mm})$.

\begin{tabular}{|c|c|c|c|c|c|c|}
\hline \multirow[t]{2}{*}{ Amostra } & \multicolumn{3}{|c|}{ Comprimento } & \multicolumn{3}{|c|}{ Largura } \\
\hline & Mcomp & $\mid \mathrm{IC}_{(1-0,01)}$ & $D_{i}>0$ & MLarg & $\mathbf{I C}_{(1-0,01)}$ & $D_{i}>0$ \\
\hline & $(\mathrm{mm})$ & $(\mathrm{mm})$ & & $(\mathrm{mm})$ & $(\mathrm{mm})$ & \\
\hline $18 \mathrm{C}$ & $0,18^{\text {ns }}$ & 0,02 & 265 & $0,11^{*}$ & 0,03 & 225 \\
\hline $18 \mathrm{~L}$ & $0,15^{* *}$ & 0,02 & 265 & $0,04^{\mathrm{ns}}$ & 0,03 & 178 \\
\hline $20 \mathrm{C}$ & $1,13^{* *}$ & 0,21 & 274 & $0,75^{\star * *}$ & 0,29 & 201 \\
\hline $20 \mathrm{~L}$ & $0,07^{\text {ns }}$ & 0,02 & 278 & $0,69^{* *}$ & 0,29 & 228 \\
\hline $22 \mathrm{C}$ & $0,17^{\mathrm{ns}}$ & 0,02 & 265 & $0,07^{* *}$ & 0,03 & 198 \\
\hline $22 \mathrm{~L}$ & $0,15^{\text {ns }}$ & 0,02 & 257 & $0,09^{* *}$ & 0,02 & 216 \\
\hline $24 \mathrm{C}$ & $0,20^{\text {ns }}$ & 0,02 & 276 & $0,10^{* *}$ & 0,04 & 223 \\
\hline $24 \mathrm{~L}$ & $0,16^{\mathrm{ns}}$ & 0,02 & 281 & $0,11^{*}$ & 0,03 & 201 \\
\hline Média & $0,276^{B}$ & 0,043 & 270 & $0,245^{B}$ & 0,095 & 209 \\
\hline
\end{tabular}

$\rightarrow$ referentes a 300 sementes

ns $\rightarrow$ medidas näo diferem significativamente a $1 \%$ pelo teste $t$ Student das medidas correspondentes determinadas com o projetor de perfil

** $\rightarrow$ medidas diferem significativamente a $1 \%$ pelo teste $t$ Student das medidas correspondentes determinadas com o projetor de perfil

$B \rightarrow$ as médias das amostras contidas na mesma coluna diferem significativamente entre si a $1 \%$ pelo teste $t$ Student 
Tabela 18: Médias* das diferenças das medidas de comprimento (MComp) e de largura (MLarg), intervalos de confiança* $\left(\mathrm{IC}_{(1-0,01)}\right)$ e diferenças maiores do que zero* $\left(D_{i}>0\right)$, das diferenças de comprimento e largura estimadas pelo modelo do menor retângulo circunscrito em imagens de sementes de milho arranjadas na posição ordenada/dorsal e digitalizadas com a resolução de 150 ppi, em relação às medidas correspondentes determinadas com o projetor de perfil em oito amostras. Dados em milimetros $(\mathrm{mm})$.

\begin{tabular}{|c|c|c|c|c|c|c|}
\hline \multirow[t]{2}{*}{ Amostra } & \multicolumn{3}{|c|}{ Comprimento } & \multicolumn{3}{|c|}{ Largura } \\
\hline & $\begin{array}{c}\text { MComp } \\
(\mathrm{mm})\end{array}$ & $\begin{array}{c}\mathrm{IC}_{(1-0,01)} \\
(\mathrm{mm})\end{array}$ & $\overline{D_{i}>0}$ & $\begin{array}{c}\text { MLarg } \\
(\mathrm{mm})\end{array}$ & $\begin{array}{c}\mathrm{IC}_{(1-0,01)} \\
(\mathrm{mm})\end{array}$ & $\overline{D_{i}}>0$ \\
\hline $18 \mathrm{C}$ & $0,15^{n \mathrm{~s}}$ & 0,02 & 257 & $\overline{0,14}$ & 0,02 & 251 \\
\hline $18 \mathrm{~L}$ & $0,12^{n s}$ & 0,02 & 265 & $0,06^{*}$ & 0,02 & 206 \\
\hline $20 \mathrm{C}$ & $0,12^{\mathrm{ns}}$ & 0,02 & 274 & $0,07^{+\infty}$ & 0,02 & 201 \\
\hline $20 \mathrm{~L}$ & $0,01^{\text {ns }}$ & 0,01 & 278 & $0,01^{\mathrm{ns}}$ & 0,02 & 228 \\
\hline $22 \mathrm{C}$ & $0,10^{\text {ns }}$ & 0,02 & 243 & $0,07^{*}$ & 0,02 & 215 \\
\hline 22L & $0,10^{\text {ns }}$ & 0,02 & 243 & $0,08^{* \prime}$ & 0,02 & 223 \\
\hline $24 \mathrm{C}$ & $0,02^{n s}$ & 0,01 & 256 & $0,03^{*}$ & 0,02 & 243 \\
\hline $24 \mathrm{~L}$ & $0,02^{\mathrm{ns}}$ & 0,01 & 276 & $0,04^{* *}$ & 0,02 & 256 \\
\hline Média & $0,080^{8}$ & 0,016 & 262 & $0,062^{B}$ & 0,020 & 228 \\
\hline
\end{tabular}

\footnotetext{
$\rightarrow$ referentes a 300 sementes
}

ns $\rightarrow$ medidas nāo diferem significativamente a $1 \%$ pelo teste $t$ Student das medidas correspondentes determinadas com o projetor de periil

** $\rightarrow$ medidas diferem significativamente a $1 \%$ pelo teste $t$ Student das medidas correspondentes determinadas com o projetor de peril

$B \rightarrow$ as médias das amostras contidas na mesma coluna diferem significativamente entre si a $1 \%$ pelo teste $t$ Student 
Tabela 19: Médias* das diferenças das medidas de comprimento (MComp) e de largura (MLarg), intervalos de confiança* $\left(\mathrm{IC}_{(1-0,01)}\right)$ e diferenças maiores do que zero* $\left(D_{i}>0\right)$, das diferenças de comprimento e largura estimadas pelo modelo do menor retângulo circunscrito em imagens de sementes de milho arranjadas na posição ordenada/dorsal e digitalizadas com a resolução de 200 ppi, em relação às medidas correspondentes determinadas com o projetor de perfil em oito amostras. Dados em milímetros $(\mathrm{mm})$.

\begin{tabular}{|c|c|c|c|c|c|c|}
\hline \multirow[t]{2}{*}{$\overline{\text { Amostra }}$} & \multicolumn{3}{|c|}{ Comprimento } & \multicolumn{3}{|c|}{ Largura } \\
\hline & $\begin{array}{l}\text { MComp } \\
(\mathrm{mm})\end{array}$ & $\begin{array}{c}\mathrm{IC}_{(1-0,01)} \\
(\mathrm{mm})\end{array}$ & $D_{i}>0$ & $\begin{array}{l}\text { MLarg } \\
(\mathrm{mm})\end{array}$ & $\begin{array}{c}\mathrm{IC}_{(1-0,01)} \\
(\mathrm{mm})\end{array}$ & $\overline{D_{i}}>0$ \\
\hline$\overline{\overline{18 C}}$ & $0,06^{n \mathrm{~ns}}$ & $\overline{\overline{0,02}}$ & 203 & $0,08^{\text {ns }}$ & $\overline{0,02}$ & 237 \\
\hline $18 \mathrm{~L}$ & $-0,07^{n s}$ & 0,02 & 72 & $0,01^{\mathrm{ns}}$ & 0,02 & 152 \\
\hline $20 \mathrm{C}$ & $-0,03^{\text {ns }}$ & 0,01 & 109 & $0,06^{\mathrm{ns}}$ & 0,01 & 234 \\
\hline $20 \mathrm{~L}$ & $0,00^{n s}$ & 0,01 & 229 & $0,00^{\text {ns }}$ & 0,02 & 236 \\
\hline $22 \mathrm{C}$ & $-0,06^{\mathrm{ns}}$ & 0,02 & 83 & $0,03^{\text {ns }}$ & 0,02 & 176 \\
\hline $22 \mathrm{~L}$ & $-0,07^{\text {ns }}$ & 0,01 & 62 & $0,06^{\mathrm{ns}}$ & 0,02 & 208 \\
\hline $24 \mathrm{C}$ & $0,01^{\mathrm{ns}}$ & 0,01 & 109 & $-0,03^{\mathrm{ns}}$ & 0,01 & 102 \\
\hline $24 \mathrm{~L}$ & $0,01^{\text {ns }}$ & 0,01 & 101 & $0,00^{\text {ns }}$ & 0,01 & 187 \\
\hline Média & $-0,018^{A}$ & 0,013 & 121 & $0,026^{A}$ & 0,016 & 192 \\
\hline
\end{tabular}

- $\rightarrow$ referentes a 300 sementes

ns $\rightarrow$ medidas nāo diferem significativamente a $1 \%$ pelo teste $t$ Student das medidas correspondentes determinadas com o projetor de perfil

$\mathrm{A} \rightarrow$ as médias das amostras contidas na mesma coluna não diferem significativamente entre si a $1 \%$ pelo teste $\mathrm{t}$ Student 
Tabela 20: Médias* das diferenças das medidas de comprimento (MComp) e de largura (MLarg), intervalos de confiança* $\left(\mathrm{IC}_{(1-0,01)}\right)$ e diferenças maiores do que zero* $\left(D_{i}>0\right)$, das diferenças de comprimento e largura estimadas pelo modelo do menor retângulo circunscrito em imagens de sementes de milho arranjadas na posição ordenada/dorsal e digitalizadas com a resolução de 250 ppi, em relação às medidas correspondentes determinadas com o projetor de perfil em oito amostras . Dados em milímetros (mm)

\begin{tabular}{|c|c|c|c|c|c|c|}
\hline \multirow[t]{2}{*}{ Amostra } & \multicolumn{3}{|c|}{ Comprimento } & \multicolumn{3}{|c|}{ Largura } \\
\hline & $\begin{array}{c}\text { MComp } \\
(\mathrm{mm})\end{array}$ & $\begin{array}{c}\mathrm{IC}_{(1-0,01)} \\
(\mathrm{mm})\end{array}$ & $\mathrm{D}_{\mathrm{i}}>0$ & $\begin{array}{l}\text { MLarg } \\
(\mathrm{mm})\end{array}$ & $\begin{array}{c}\mathrm{IC}_{(1-0,01)} \\
(\mathrm{mm})\end{array}$ & $\overline{D_{i}>0}$ \\
\hline $18 \mathrm{C}$ & $0,12^{\text {ns }}$ & 0,02 & 254 & 0,10 & 0,02 & 232 \\
\hline $18 \mathrm{~L}$ & $0,09^{\mathrm{ns}}$ & 0,01 & 254 & $0,03^{\text {ns }}$ & 0,02 & 183 \\
\hline $20 \mathrm{C}$ & $0,10^{\text {ns }}$ & 0,02 & 278 & $0,06^{\text {ns }}$ & 0,01 & 254 \\
\hline $20 \mathrm{~L}$ & $0,02^{\text {ns }}$ & 0,01 & 238 & $0,00^{\mathrm{ns}}$ & 0,01 & 199 \\
\hline $22 \mathrm{C}$ & $0,08^{\text {ns }}$ & 0,02 & 250 & $0,05^{* *}$ & 0,02 & 198 \\
\hline $22 \mathrm{~L}$ & $0,06^{\text {ns }}$ & 0,02 & 216 & $0,08^{* *}$ & 0,02 & 231 \\
\hline $24 \mathrm{C}$ & $0,03^{\mathrm{ns}}$ & 0,01 & 265 & $0,05^{* *}$ & 0,02 & 197 \\
\hline $24 \mathrm{~L}$ & $0,04^{\mathrm{ns}}$ & 0,01 & 276 & $0,03^{\mathrm{ns}}$ & 0,02 & 187 \\
\hline Média & $0,067^{A}$ & 0,015 & 254 & $0,050^{B}$ & 0,017 & 210 \\
\hline
\end{tabular}

\footnotetext{
$\rightarrow$ referentes a 300 sementes
}

ns $\rightarrow$ medidas não diferem significativamente a $1 \%$ pelo teste $t$ Student das medidas correspondentes determinadas com o projetor de peril

* $\rightarrow$ medidas diferem significativamente a $1 \%$ pelo teste $t$ Student das medidas correspondentes determinadas com o projetor de perfil

$A \rightarrow$ as médias das amostras contidas na mesma coluna não diferem significativamente entre si a $1 \%$ pelo teste $t$ Student

$B \rightarrow$ as médias das amostras contidas na mesma coluna diferem significativamente entre si a $1 \%$ pelo teste $t$ Student 
Tabela 21: Médias* das diferenças das medidas de comprimento (MComp) e de largura (MLarg), intervalos de confiança* $\left(\mathrm{IC}_{(1-0,01)}\right)$ e diferenças maiores do que zero* $\left(D_{i}>0\right)$, das diferenças de comprimento e largura estimadas pelo modelo do menor retângulo circunscrito em imagens de sementes de milho arranjadas na posição ordenada/ventral e digitalizadas com a resolução de 100 ppi, em relação às medidas correspondentes determinadas com o projetor de perfil em oito amostras . Dados em milimetros (mm).

\begin{tabular}{|c|c|c|c|c|c|c|}
\hline \multirow[t]{2}{*}{ Amostra } & \multicolumn{3}{|c|}{ Comprimento } & \multicolumn{3}{|c|}{ Largura } \\
\hline & $\begin{array}{c}\text { MComp } \\
(\mathrm{mm})\end{array}$ & $\begin{array}{c}\mathrm{IC}_{(1-0,01)} \\
(\mathrm{mm})\end{array}$ & $\mathrm{D}_{i}>0$ & $\begin{array}{l}\text { MLarg } \\
(\mathrm{mm})\end{array}$ & $\begin{array}{c}\mathrm{IC}_{(1-0,01)} \\
(\mathrm{mm})\end{array}$ & $D_{i}>0$ \\
\hline $18 \mathrm{C}$ & $0,15^{\mathrm{nS}}$ & 0,02 & 249 & $0,10^{\circ}$ & 0,03 & 224 \\
\hline $18 \mathrm{~L}$ & $0,11^{n s}$ & 0,02 & 244 & $0,05^{\text {***}}$ & 0,02 & 185 \\
\hline $20 \mathrm{C}$ & $0,10^{\text {ns }}$ & 0,02 & 237 & $0,03^{* *}$ & 0,02 & 201 \\
\hline $20 \mathrm{~L}$ & $0,32^{* *}$ & 0,05 & 262 & $-0,03^{* *}$ & 0,02 & 98 \\
\hline $22 \mathrm{C}$ & $0,12^{\text {ns }}$ & 0,02 & 244 & $0,08^{* *}$ & 0,02 & 201 \\
\hline $22 \mathrm{~L}$ & $0,10^{\text {ns }}$ & 0,02 & 230 & $0,07^{* *}$ & 0,02 & 197 \\
\hline $24 \mathrm{C}$ & $0,23^{* *}$ & 0,05 & 223 & $0,09^{* *}$ & 0,02 & 196 \\
\hline $24 L$ & $0,29^{-\prime}$ & 0,05 & 231 & $0,11^{-}$ & 0,03 & 204 \\
\hline Média & $0,177^{\mathrm{B}}$ & 0,031 & 240 & $0,062^{B}$ & 0,022 & 188 \\
\hline
\end{tabular}


Tabela 22: Médias* das diferenças das medidas de comprimento (MComp) e de largura (MLarg), intervalos de confiança* $\left(\mathrm{IC}_{(1-0,01)}\right)$ e diferenças maiores do que zero* $\left(D_{i}>0\right)$, das diferenças de comprimento e largura estimadas pelo modelo do menor retângulo circunscrito em imagens de sementes de milho arranjadas na posição ordenada/ventral e digitalizadas com a resolução de 150 ppi, em relação às medidas correspondentes determinadas com o projetor de perfil em oito amostras . Dados em milímetros (mm).

\begin{tabular}{|c|c|c|c|c|c|c|}
\hline \multirow[t]{2}{*}{ Amostra } & \multicolumn{3}{|c|}{ Comprimento } & \multicolumn{3}{|c|}{ Largura } \\
\hline & $\begin{array}{c}\text { MComp } \\
(\mathrm{mm})\end{array}$ & $\begin{array}{c}\mathrm{IC}_{(1-0,01)} \\
(\mathrm{mm})\end{array}$ & $D_{p}>0$ & $\begin{array}{c}\text { MLarg } \\
(\mathrm{mm})\end{array}$ & $\begin{array}{c}\mathrm{IC}_{(1-0,01)} \\
(\mathrm{mm})\end{array}$ & $\mathrm{D}_{\mathrm{i}}>0$ \\
\hline $18 \mathrm{C}$ & $0,12^{n \mathrm{~s}}$ & 0,03 & 228 & $0,10^{\circ}$ & 0,02 & 232 \\
\hline $18 \mathrm{~L}$ & $0,07^{\text {ns }}$ & 0,02 & 224 & $0,04^{\mathrm{ns}}$ & 0,02 & 187 \\
\hline $20 \mathrm{C}$ & $0,06^{n s}$ & 0,01 & 223 & $0,06^{\mathrm{ns}}$ & 0,02 & 202 \\
\hline $20 \mathrm{~L}$ & $-0,01^{\mathrm{ns}}$ & 0,01 & 129 & $0,00^{\text {ns }}$ & 0,01 & 232 \\
\hline $22 \mathrm{C}$ & $0,03^{\text {ns }}$ & 0,02 & 184 & $0,04^{\mathrm{ns}}$ & 0,02 & 195 \\
\hline $22 L$ & $0,06^{\text {ns }}$ & 0,01 & 221 & $0,07^{* *}$ & 0,02 & 210 \\
\hline $24 \mathrm{C}$ & $0,03^{n s}$ & 0,02 & 198 & $-0,05^{* *}$ & 0,02 & 99 \\
\hline $24 \mathrm{~L}$ & $0,03^{\text {ns }}$ & 0,02 & 232 & $0,02^{\mathrm{ns}}$ & 0,02 & 198 \\
\hline Média & $0,048^{B}$ & 0,017 & 205 & $0,035^{B}$ & 0,018 & 194 \\
\hline
\end{tabular}


Tabela 23: Médias* das diferenças das medidas de comprimento (MComp) e de largura (MLarg), intervalos de confiança* $\left(\mathrm{IC}_{(1-0,01)}\right)$ e diferenças maiores do que zero* $\left(D_{i}>0\right)$, das diferenças de comprimento e largura estimadas pelo modelo do menor retângulo circunscrito em imagens de sementes de milho arranjadas na posição ordenada/ventral e digitalizadas com a resolução de 200 ppi, em relação às medidas correspondentes determinadas com o projetor de perfil em oito amostras. Dados em milímetros $(\mathrm{mm})$.

\begin{tabular}{|c|c|c|c|c|c|c|}
\hline \multirow[t]{2}{*}{ Amostra } & \multicolumn{3}{|c|}{ Comprimento } & \multicolumn{3}{|c|}{ Largura } \\
\hline & $\begin{array}{c}\text { MComp } \\
(\mathrm{mm})\end{array}$ & $\begin{array}{c}\mathrm{IC}_{(1-0,01)} \\
(\mathrm{mm})\end{array}$ & $\mathrm{D}_{\mathrm{i}}>0$ & $\begin{array}{c}\text { MLarg } \\
(\mathrm{mm})\end{array}$ & $\begin{array}{c}I_{(1-0,01)} \\
(\mathrm{mm})\end{array}$ & $\mathrm{D}_{\mathrm{i}}>0$ \\
\hline $18 \mathrm{C}$ & $-0,05^{n S}$ & 0,02 & 95 & $0,08^{\text {ns }}$ & 0,03 & 218 \\
\hline $18 \mathrm{~L}$ & $-0,11^{\text {ns }}$ & 0,01 & 32 & $0,02^{\text {ns }}$ & 0,02 & 161 \\
\hline $20 \mathrm{C}$ & $-0,10^{\text {ns }}$ & 0,01 & 45 & $0,03^{n s}$ & 0,02 & 198 \\
\hline $20 \mathrm{~L}$ & $0,01^{\mathrm{ns}}$ & 0,01 & 145 & $0,00^{\text {ns }}$ & 0,01 & 178 \\
\hline $22 \mathrm{C}$ & $-0,09^{\mathrm{ns}}$ & 0,02 & 55 & $0,03^{\text {ns }}$ & 0,02 & 180 \\
\hline $22 \mathrm{~L}$ & $-0,12^{\mathrm{ns}}$ & 0,01 & 23 & $0,04^{\mathrm{ns}}$ & 0,02 & 195 \\
\hline $24 C$ & $0,01^{\mathrm{ns}}$ & 0,01 & 104 & $-0,01^{\mathrm{ns}}$ & 0,01 & 143 \\
\hline $24 \mathrm{~L}$ & $0,01^{\mathrm{ns}}$ & 0,01 & 132 & $0,00^{\mathrm{ns}}$ & 0,01 & 189 \\
\hline Média & $-0,05^{A}$ & 0,012 & 79 & $0,023^{A}$ & 0,017 & 183 \\
\hline
\end{tabular}

ns $\rightarrow$ medidas nāo diferem significativamente a $1 \%$ pelo teste $t$ Student das medidas correspondentes determinadas com o projetor de perfil

$A \rightarrow$ as médias das amostras contidas na mesma coluna não diferem significativamente entre si a $1 \%$ pelo teste $t$ Student 
Tabela 24: Médias* das diferenças das medidas de comprimento (MComp) e de largura (MLarg), intervalos de confiança* $\left(\mathrm{IC}_{(1-0,01)}\right)$ e diferenças maiores do que zero* $\left(D_{i}>0\right)$, das diferenças de comprimento $e$ largura estimadas pelo modelo do menor retângulo circunscrito em imagens de sementes de milho arranjadas na posição ordenada/ventral e digitalizadas com a resolução de 250 ppi, em relação às medidas correspondentes determinadas com o projetor de perfil em oito amostras. Dados em milímetros $(\mathrm{mm})$.

\begin{tabular}{cccccccc}
\hline \hline Amostra & \multicolumn{3}{c}{ Comprimento } & & \multicolumn{3}{c}{ Largura } \\
\cline { 2 - 5 } \cline { 6 - 8 } & $\begin{array}{c}\text { MComp } \\
(\mathrm{mm})\end{array}$ & $\begin{array}{c}\mathrm{IC}_{(1-0,01)} \\
(\mathrm{mm})\end{array}$ & $\mathrm{D}_{\mathrm{i}>0}$ & & $\begin{array}{c}\text { MLarg } \\
(\mathrm{mm})\end{array}$ & $\begin{array}{c}\mathrm{IC}_{(1-0,01)} \\
(\mathrm{mm})\end{array}$ & $\mathrm{D}_{\mathrm{i}}>0$ \\
\hline \hline $18 \mathrm{C}$ & $0,09^{\text {ns }}$ & 0,02 & 246 & 0,11 & 0,03 & 242 \\
$18 \mathrm{~L}$ & $0,05^{\text {ns }}$ & 0,01 & 216 & $0,04^{\text {ns }}$ & 0,02 & 193 \\
$20 \mathrm{C}$ & $0,04^{\text {ns }}$ & 0,01 & 232 & $0,04^{\text {ns }}$ & 0,02 & 221 \\
$20 \mathrm{~L}$ & $-0,02^{\text {ns }}$ & 0,01 & 138 & $-0,02^{\text {ns }}$ & 0,02 & 145 \\
$22 \mathrm{C}$ & $0,05^{\text {ns }}$ & 0,01 & 216 & $0,04^{\text {ns }}$ & 0,02 & 199 \\
$22 \mathrm{~L}$ & $0,02^{\text {ns }}$ & 0,02 & 173 & $0,07^{*}$ & 0,02 & 225 \\
$24 \mathrm{C}$ & $-0,01^{\text {ns }}$ & 0,01 & 124 & $0,00^{\text {ns }}$ & 0,01 & 200 \\
$24 \mathrm{~L}$ & $0,04^{\text {ns }}$ & 0,02 & 179 & $0,06^{\text {** }}$ & 0,00 & 232 \\
\hline Média & $0,032^{\mathrm{A}}$ & 0,013 & 190 & $0,042^{\mathrm{B}}$ & 0,017 & 208 \\
\hline \hline
\end{tabular}

\footnotetext{
$\rightarrow \rightarrow$ referentes a 300 sementes

ns $\rightarrow$ medidas nâo diferem significativamente a $1 \%$ pelo teste $t$ Student das medidas correspondentes determinadas com o projetor de perfil

* $\rightarrow$ medidas diferem significativamente a $1 \%$ pelo teste $t$ Student das medidas correspondentes determinadas com o projetor de perfil

$A \rightarrow$ as médias das amostras contidas na mesma coluna não diferem significativamente entre si a $1 \%$ pelo teste $t$ Student

$B \rightarrow$ as médias das amostras contidas na mesma coluna diferem significativamente entre si a $1 \%$ pelo teste $t$ Student
} 
Tabela 25: Médias* das diferenças das medidas de comprimento (MComp) e de largura (MLarg), intervalos de confiança* $\left(\mathrm{IC}_{(1-0,01)}\right)$ e diferenças maiores do que zero* $\left(D_{i}>0\right)$, das diferenças de comprimento e largura estimadas pelo modelo do menor retângulo circunscrito em imagens de sementes de milho arranjadas na posição desordenada/dorsal e digitalizadas com a resolução de 100 ppi, em relação às medidas correspondentes determinadas com o projetor de perfil em oito amostras. Dados em milímetros $(\mathrm{mm})$.

\begin{tabular}{|c|c|c|c|c|c|c|}
\hline \multirow[t]{2}{*}{ Amostra } & \multicolumn{3}{|c|}{ Comprimento } & \multicolumn{3}{|c|}{ Largura } \\
\hline & $\begin{array}{l}\text { MComp } \\
(\mathrm{mm})\end{array}$ & $\begin{array}{c}\mathrm{IC}_{(1-0,01)} \\
(\mathrm{mm})\end{array}$ & $D_{i}>0$ & $\begin{array}{l}\text { MLarg } \\
(\mathrm{mm})\end{array}$ & $\begin{array}{c}\mathrm{IC}_{(1-0,01)} \\
(\mathrm{mm})\end{array}$ & $\overline{D_{i}>0}$ \\
\hline $18 \mathrm{C}$ & $0,21^{\mathrm{ns}}$ & $\overline{0,02}$ & 275 & 0,13 & 0,03 & 247 \\
\hline $18 \mathrm{~L}$ & $0,17^{* *}$ & 0,02 & 271 & $0,06^{* *}$ & 0,02 & 203 \\
\hline $20 \mathrm{C}$ & $0,19^{* *}$ & 0,02 & 245 & $0,09^{* *}$ & 0,02 & 254 \\
\hline $20 \mathrm{~L}$ & $0,08^{* *}$ & 0,02 & 235 & $0,03^{* *}$ & 0,02 & 214 \\
\hline $22 \mathrm{C}$ & $0,18^{\mathrm{ns}}$ & 0,02 & 270 & $0,09^{* *}$ & 0,03 & 215 \\
\hline $22 \mathrm{~L}$ & $0,15^{\mathrm{ns}}$ & 0,02 & 267 & $0,06^{* *}$ & 0,02 & 200 \\
\hline $24 \mathrm{C}$ & $0,11^{\mathrm{ns}}$ & 0,02 & 278 & $0,22^{* *}$ & 0,05 & 210 \\
\hline $24 \mathrm{~L}$ & $0,04^{\mathrm{ns}}$ & 0,02 & 245 & $0,14^{* *}$ & 0,02 & 200 \\
\hline Média & $0,141^{B}$ & 0,020 & 261 & $0,102^{B}$ & 0,026 & 218 \\
\hline
\end{tabular}

* $\rightarrow$ referentes a 300 sementes

ns $\rightarrow$ medidas não diferem significativamente a $1 \%$ pelo teste $t$ Student das medidas correspondentes determinadas com o projetor de perfil

* $\rightarrow$ medidas diferem significativamente a $1 \%$ pelo teste $t$ Student das medidas correspondentes determinadas com o projetor de perfil

$B \rightarrow$ as médias das amostras contidas na mesma coluna diferem significativamente entre si a $1 \%$ pelo teste $t$ Student 
Tabela 26: Médias* das diferenças das medidas de comprimento (MComp) e de largura (MLarg), intervalos de confiança* $\left(\mathrm{IC}_{(1-0,01)}\right)$ e diferenças maiores do que zero* $\left(D_{i}>0\right)$, das diferenças de comprimento e largura estimadas pelo modelo do menor retângulo circunscrito em imagens de sementes de milho arranjadas na posição desordenada/dorsal e digitalizadas com a resolução de 150 ppi, em relação às medidas correspondentes determinadas com o projetor de perfil em oito amostras . Dados em milimetros (mm).

\begin{tabular}{|c|c|c|c|c|c|c|}
\hline \multirow[t]{2}{*}{ Amostra } & \multicolumn{3}{|c|}{ Comprimento } & \multicolumn{3}{|c|}{ Largura } \\
\hline & $\begin{array}{c}\text { MComp } \\
(\mathrm{mm})\end{array}$ & $\begin{array}{c}\mathrm{IC}_{(1-0,01)} \\
(\mathrm{mm})\end{array}$ & $\mathrm{D}_{\mathrm{i}}>0$ & $\begin{array}{l}\text { MLarg } \\
(\mathrm{mm})\end{array}$ & $\begin{array}{c}\mathrm{IC}_{(1-0,01)} \\
(\mathrm{mm})\end{array}$ & $D_{i}>0$ \\
\hline $18 \mathrm{C}$ & $0,20^{15}$ & 0,02 & 268 & $\overline{0,09}$ & 0,03 & 230 \\
\hline $18 \mathrm{~L}$ & $0,16^{*}$ & 0,02 & 271 & $0,04^{\mathrm{ns}}$ & 0,02 & 183 \\
\hline $20 \mathrm{C}$ & $0,15^{\text {ns }}$ & 0,02 & 263 & $0,05^{\mathrm{ns}}$ & 0,02 & 223 \\
\hline $20 \mathrm{~L}$ & $0,00^{\text {ns }}$ & 0,01 & 227 & $-0,01^{\text {ns }}$ & 0,01 & 145 \\
\hline $22 \mathrm{C}$ & $0,14^{\mathrm{ns}}$ & 0,02 & 264 & $0,03^{\text {ns }}$ & 0,02 & 191 \\
\hline $22 \mathrm{~L}$ & $0,13^{\text {ns }}$ & 0,02 & 267 & $0,04^{\mathrm{ns}}$ & 0,02 & 196 \\
\hline $24 \mathrm{C}$ & $0,01^{\text {ns }}$ & 0,02 & 256 & $0,04^{\mathrm{ns}}$ & 0,02 & 199 \\
\hline $24 L$ & $0,02^{\mathrm{ns}}$ & 0,02 & 267 & $0,01^{\mathrm{ns}}$ & 0,01 & 167 \\
\hline Média & $0,101^{B}$ & 0,018 & 260 & $0,036^{\mathrm{B}}$ & 0,018 & 192 \\
\hline
\end{tabular}

\footnotetext{
$\rightarrow \rightarrow$ referentes a 300 sementes

ns $\rightarrow$ medidas näo diferem significativamente a $1 \%$ pelo teste $\mathbf{t}$ Student das medidas correspondentes determinadas com o projetor de perfil

* $\rightarrow$ medidas diferem significativamente a $1 \%$ pelo teste $t$ Student das medidas correspondentes determinadas com o projetor de perfil

$B \rightarrow$ as médias das amostras contidas na mesma coluna diferem significativamente entre si a $1 \%$ pelo teste $t$ Student
} 
Tabela 27: Médias* das diferenças das medidas de comprimento (MComp) e de largura (MLarg), intervalos de confiança* $\left(\mathrm{IC}_{(1-0,01)}\right)$ e diferenças maiores do que zero* $\left(D_{i}>0\right)$, das diferenças de comprimento e largura estimadas pelo modelo do menor retângulo circunscrito em imagens de sementes de milho arranjadas na posição desordenada/dorsal e digitalizadas com a resolução de 200 ppi, em relação às medidas correspondentes determinadas com o projetor de perfil em oito amostras. Dados em milímetros (mm).

\begin{tabular}{|c|c|c|c|c|c|c|}
\hline \multirow[t]{2}{*}{ Amostra } & \multicolumn{3}{|c|}{ Comprimento } & \multicolumn{3}{|c|}{ Largura } \\
\hline & $\begin{array}{c}\text { MComp } \\
(\mathrm{mm})\end{array}$ & $\begin{array}{c}\mathrm{IC}_{(1-0,01)} \\
(\mathrm{mm})\end{array}$ & $D_{i}>0$ & $\begin{array}{l}\text { MLarg } \\
(\mathrm{mm})\end{array}$ & $\begin{array}{c}\mathrm{IC}_{(1-0,01)} \\
(\mathrm{mm})\end{array}$ & $\mathrm{D}_{\mathrm{i}}>0$ \\
\hline $18 \mathrm{C}$ & $0,12^{\mathrm{ns}}$ & 0,03 & 235 & $0,03^{n s}$ & 0,03 & 183 \\
\hline $18 \mathrm{~L}$ & $0,06^{\text {ns }}$ & 0,02 & 193 & $-0,04^{\mathrm{ns}}$ & 0,02 & 108 \\
\hline $20 \mathrm{C}$ & $0,07^{n s}$ & 0,02 & 257 & $0,00^{\mathrm{ns}}$ & 0,01 & 221 \\
\hline $20 \mathrm{~L}$ & $0,00^{\mathrm{ns}}$ & 0,01 & 234 & $0,00^{n s}$ & 0,01 & 232 \\
\hline $22 \mathrm{C}$ & $0,04^{\mathrm{ns}}$ & 0,02 & 175 & $-0,03^{n s}$ & 0,02 & 127 \\
\hline $22 L$ & $0,04^{\mathrm{ns}}$ & 0,02 & 176 & $-0,05^{n s}$ & 0,02 & 95 \\
\hline $24 C$ & $0,01^{\mathrm{ns}}$ & 0,01 & 245 & $0,01^{\mathrm{ns}}$ & 0,01 & 232 \\
\hline $24 \mathrm{~L}$ & $0,01^{\text {ns }}$ & 0,01 & 256 & $0,01^{n s}$ & 0,01 & 245 \\
\hline Média & $0,043^{A}$ & 0,017 & 221 & $-0,008^{A}$ & 0,016 & 180 \\
\hline
\end{tabular}


Tabela 28: Médias* das diferenças das medidas de comprimento (MComp) e de largura (MLarg), intervalos de confiança* $\left(\mathrm{IC}_{(1-0,01)}\right)$ e diferenças maiores do que zero* $\left(D_{i}>0\right)$, das diferenças de comprimento e largura estimadas pelo modelo do menor retângulo circunscrito em imagens de sementes de milho arranjadas na posição desordenada/dorsal e digitalizadas com a resolução de 250 ppi, em relação às medidas correspondentes determinadas com o projetor de perfil em oito amostras. Dados em milimetros $(\mathrm{mm})$.

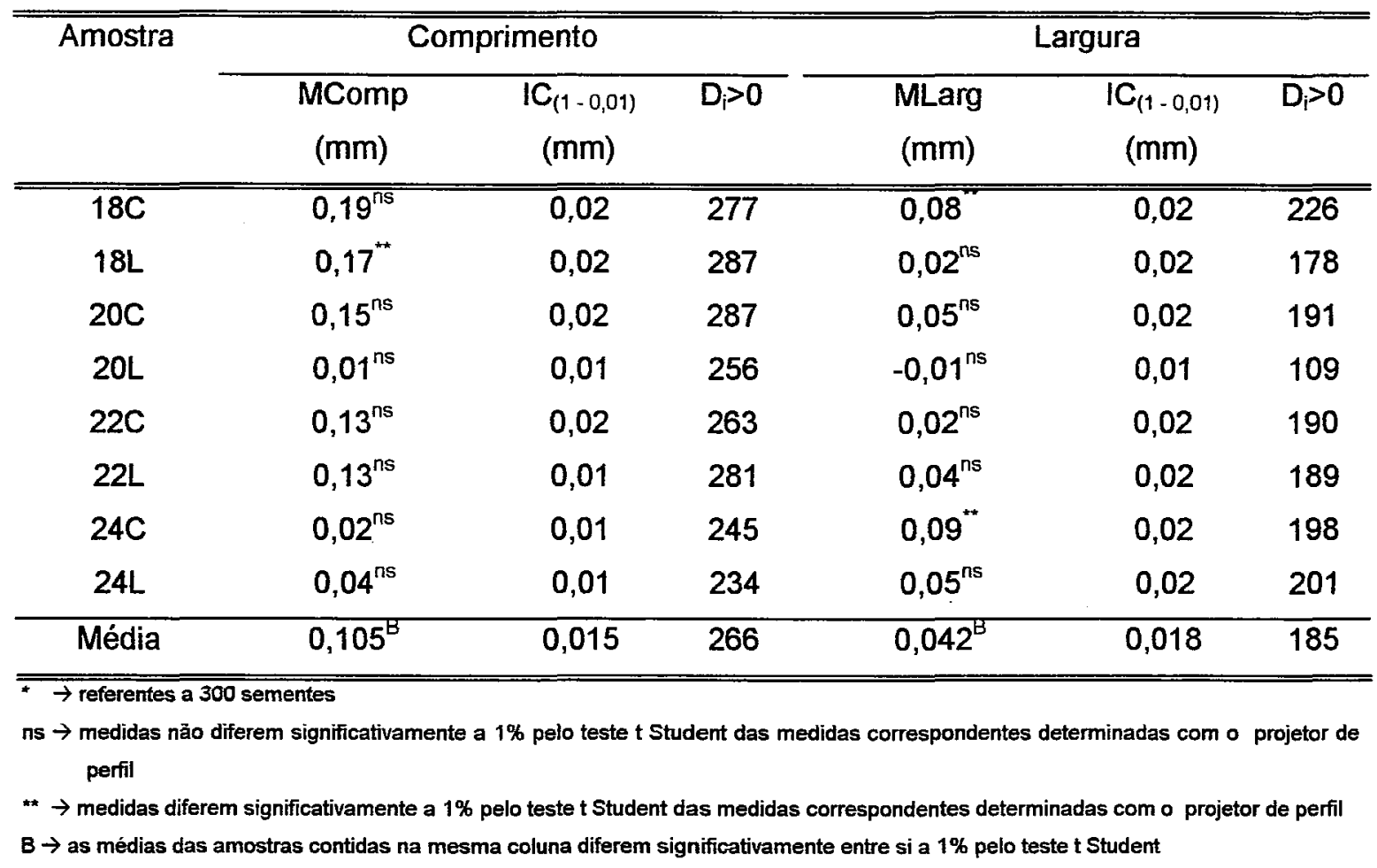


Tabela 29: Médias* das diferenças das medidas de comprimento (MComp) e de largura (MLarg), intervalos de confiança* $\left(\mathrm{IC}_{(1-0,01)}\right)$ e diferenças maiores do que zero* $\left(D_{i}>0\right)$, das diferenças de comprimento $e$ largura estimadas pelo modelo do menor retângulo circunscrito em imagens de sementes de milho arranjadas na posição desordenada/ventral e digitalizadas com a resolução de 100 ppi, em relação às medidas correspondentes determinadas com o projetor de perfil em oito amostras . Dados em milimetros $(\mathrm{mm})$.

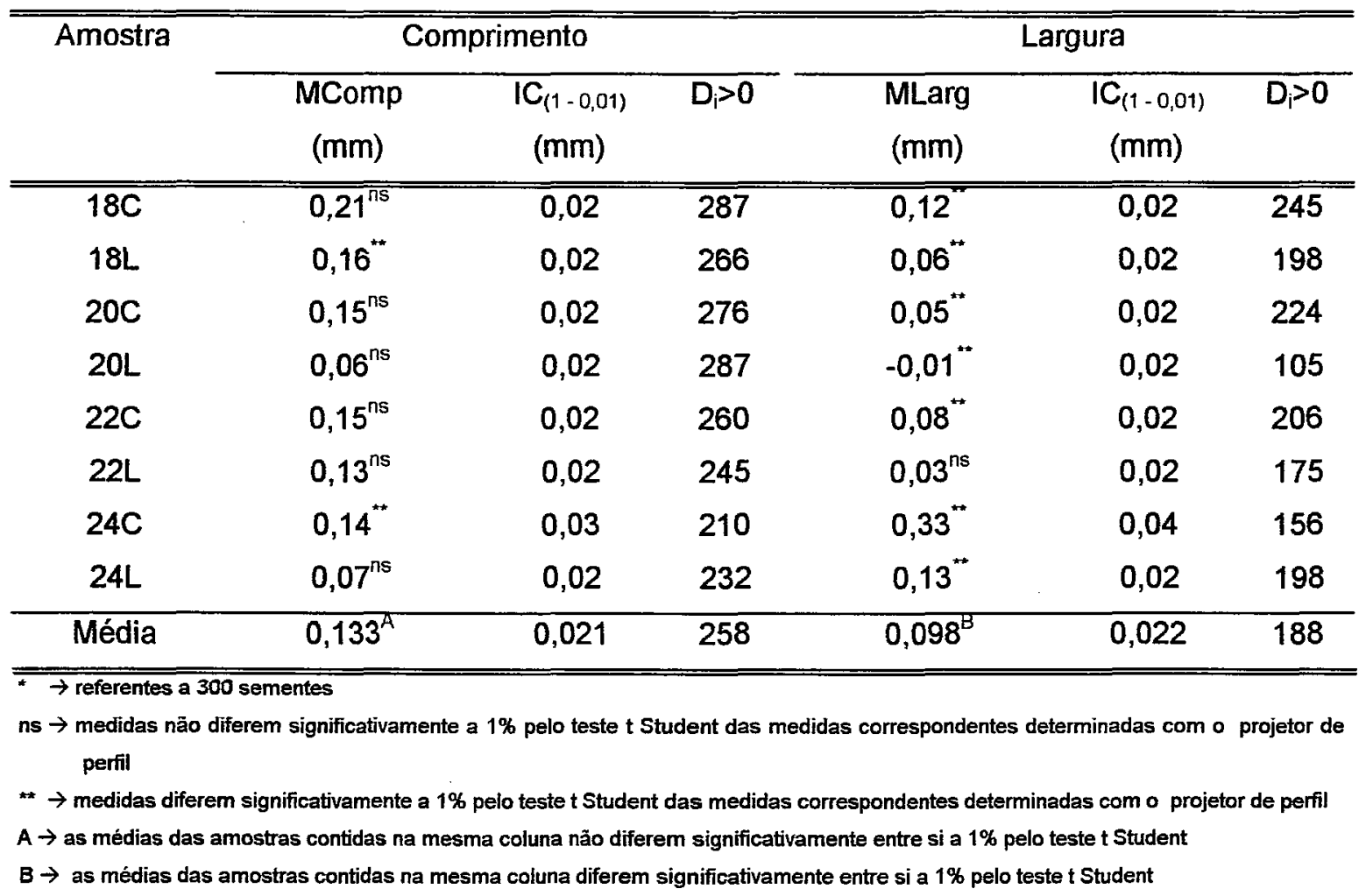


Tabela 30: Médias* das diferenças das medidas de comprimento (MComp) e de largura (MLarg), intervalos de confiança* $\left(\mathrm{IC}_{(1-0,01)}\right)$ e diferenças maiores do que zero* $\left(D_{i}>0\right)$, das diferenças de comprimento e largura estimadas pelo modelo do menor retângulo circunscrito em imagens de sementes de milho arranjadas na posição desordenada/ventral e digitalizadas com a resolução de 150 ppi, em relação às medidas correspondentes determinadas com o projetor de perfil em oito amostras . Dados em milímetros $(\mathrm{mm})$.

\begin{tabular}{|c|c|c|c|c|c|c|}
\hline \multirow[t]{2}{*}{$\overline{\text { Amostra }}$} & \multicolumn{3}{|c|}{ Comprimento } & \multicolumn{3}{|c|}{ Largura } \\
\hline & $\begin{array}{c}\text { MComp } \\
(\mathrm{mm})\end{array}$ & $\begin{array}{c}\mathrm{IC}_{(1-0,01)} \\
(\mathrm{mm})\end{array}$ & $\mathrm{D}_{\mathrm{i}}>0$ & $\begin{array}{c}\text { MLarg } \\
(\mathrm{mm})\end{array}$ & $\begin{array}{c}\mathrm{IC}_{(1-0,01)} \\
(\mathrm{mm})\end{array}$ & $\overline{D_{i}>0}$ \\
\hline$\overline{18 \mathrm{C}}$ & $0,18^{\text {ns }}$ & $\overline{\overline{0,02}}$ & 283 & 0,10 & $\overline{0,02}$ & $\overline{234}$ \\
\hline $18 \mathrm{~L}$ & $0,14^{\mathrm{ns}}$ & 0,02 & 268 & $0,03^{n s}$ & 0,02 & 180 \\
\hline $20 \mathrm{C}$ & $0,16^{\text {ns }}$ & 0,02 & 236 & $0,02^{\text {ns }}$ & 0,02 & 256 \\
\hline $20 \mathrm{~L}$ & $0,01^{\mathrm{ns}}$ & 0,02 & 256 & $-0,04^{\mathrm{ns}}$ & 0,02 & 134 \\
\hline $22 \mathrm{C}$ & $0,12^{\mathrm{ns}}$ & 0,02 & 257 & $0,04^{\mathrm{ns}}$ & 0,02 & 197 \\
\hline $22 \mathrm{~L}$ & $0,12^{\text {ns }}$ & 0,02 & 251 & $0,00^{\text {ns }}$ & 0,02 & 157 \\
\hline $24 \mathrm{C}$ & $0,02^{\text {ns }}$ & 0,01 & 287 & $0,04^{\mathrm{ns}}$ & 0,02 & 200 \\
\hline $24 \mathrm{~L}$ & $0,01^{\mathrm{ns}}$ & 0,01 & 267 & $0,02^{\text {ns }}$ & 0,02 & 145 \\
\hline Média & $0,095^{\mathrm{B}}$ & 0,012 & 263 & $0,026^{\mathrm{B}}$ & $\overline{0,02}$ & 188 \\
\hline
\end{tabular}

$\rightarrow$ referentes a 300 sementes

ns $\rightarrow$ medidas não diferem significativamente a $1 \%$ pelo teste $\mathbf{t}$ Student das medidas correspondentes determinadas com o projetor de perfil

*t $\rightarrow$ medidas diferem significativamente a 1\% pelo teste $t$ Student das medidas correspondentes determinadas com o projetor de perfil

$B \rightarrow$ as médias das amostras contidas na mesma coluna diferem significativamente entre si a $1 \%$ pelo teste $t$ Student 
Tabela 31: Médias* das diferenças das medidas de comprimento (MComp) e de largura (MLarg), intervalos de confiança* $\left(\mathrm{IC}_{(1-0,01)}\right)$ e diferenças maiores do que zero* $\left(D_{i}>0\right)$, das diferenças de comprimento e largura estimadas pelo modelo do menor retângulo circunscrito em imagens de sementes de milho arranjadas na posição desordenada/ventral e digitalizadas com a resolução de 200 ppi, em relação às medidas correspondentes determinadas com o projetor de perfil em oito amostras. Dados em milímetros $(\mathrm{mm})$.

\begin{tabular}{|c|c|c|c|c|c|c|}
\hline \multirow[t]{2}{*}{ Amostra } & \multicolumn{3}{|c|}{ "Comprimento } & \multicolumn{3}{|c|}{ Largura } \\
\hline & $\begin{array}{c}\text { MComp } \\
(\mathrm{mm})\end{array}$ & $\begin{array}{c}\mathrm{IC}_{(1-0,01)} \\
(\mathrm{mm})\end{array}$ & $D_{i}>0$ & $\begin{array}{c}\text { MLarg } \\
(\mathrm{mm})\end{array}$ & $\begin{array}{c}\mathrm{IC}_{(1-0,01)} \\
(\mathrm{mm})\end{array}$ & $D_{i}>0$ \\
\hline 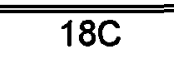 & $0,09^{n \mathbf{s}}$ & 0,02 & 217 & $0,02^{n S}$ & 0,02 & 166 \\
\hline $18 \mathrm{~L}$ & $0,06^{\text {ns }}$ & 0,02 & 191 & $-0,04^{n s}$ & 0,02 & 100 \\
\hline $20 \mathrm{C}$ & $0,03^{\text {ns }}$ & 0,02 & 202 & $-0,04^{\mathrm{ns}}$ & 0,02 & 99 \\
\hline $20 \mathrm{~L}$ & $0,00^{n s}$ & 0,01 & 145 & $0,00^{\text {ns }}$ & 0,02 & 178 \\
\hline $22 \mathrm{C}$ & $0,04^{\mathrm{ns}}$ & 0,02 & 174 & $-0,01^{\mathrm{ns}}$ & 0,02 & 138 \\
\hline $22 \mathrm{~L}$ & $0,06^{\mathrm{ns}}$ & 0,02 & 188 & $-0,05^{\text {ns }}$ & 0,02 & 99 \\
\hline $24 C$ & $0,01^{\mathrm{ns}}$ & 0,02 & 178 & $0,02^{n s}$ & 0,02 & 145 \\
\hline 24L & $0,01^{\mathrm{ns}}$ & 0,02 & 187 & $0,02^{n s}$ & 0,02 & 134 \\
\hline Média & $0,037^{A}$ & 0,018 & 185 & $-0,01^{A}$ & 0,020 & 132 \\
\hline
\end{tabular}


Tabela 32: Médias* das diferenças das medidas de comprimento (MComp) e de largura (MLarg), intervalos de confiança* $\left(\mathrm{IC}_{(1-0,01)}\right)$ e diferenças maiores do que zero* $\left(D_{i}>0\right)$, das diferenças de comprimento e largura estimadas pelo modelo do menor retângulo circunscrito em imagens de sementes de milho arranjadas na posição desordenada/ventral e digitalizadas com a resolução de 250 ppi, em relação às medidas correspondentes determinadas com o projetor de perfil em oito amostras . Dados em milímetros (mm).

\begin{tabular}{|c|c|c|c|c|c|c|}
\hline \multirow[t]{2}{*}{ Amostra } & \multicolumn{3}{|c|}{ Comprimento } & \multicolumn{3}{|c|}{ Largura } \\
\hline & $\begin{array}{c}\text { MComp } \\
(\mathrm{mm})\end{array}$ & $\begin{array}{c}1 \mathrm{IC}_{(1-0,01)} \\
(\mathrm{mm})\end{array}$ & $D_{i}>0$ & $\begin{array}{c}\text { MLarg } \\
\text { (mm) }\end{array}$ & $\begin{array}{c}I C_{(1-0,01)} \\
(m m)\end{array}$ & $\overline{D_{i}>0}$ \\
\hline $18 \mathrm{C}$ & $0,16^{\mathrm{nS}}$ & 0,02 & 277 & 0,07 & 0,02 & 223 \\
\hline $18 \mathrm{~L}$ & $0,14^{\mathrm{ns}}$ & 0,02 & 278 & $0,01^{\mathrm{ns}}$ & 0,02 & 162 \\
\hline $20 \mathrm{C}$ & $0,11^{\mathrm{ns}}$ & 0,02 & 287 & $0,01^{\mathrm{ns}}$ & 0,02 & 245 \\
\hline $20 \mathrm{~L}$ & $0,00^{\mathrm{ns}}$ & 0,01 & 267. & $-0,05^{* *}$ & 0,02 & 102 \\
\hline $22 \mathrm{C}$ & $0,13^{\mathrm{ns}}$ & 0,02 & 270 & $0,04^{\mathrm{ns}}$ & 0,02 & 202 \\
\hline $22 \mathrm{~L}$ & $0,14^{\mathrm{ns}}$ & 0,02 & 279 & $0,02^{\text {ns }}$ & 0,01 & 184 \\
\hline $24 C$ & $0,02^{\text {ns }}$ & 0,02 & 265 & $0,10^{*}$ & 0,02 & 176 \\
\hline $24 L$ & $0,01^{\mathrm{ns}}$ & 0,02 & 276 & $0,07^{* *}$ & 0,02 & 145 \\
\hline Média & $0,091^{A}$ & 0,018 & 275 & $0,033^{\mathrm{B}}$ & 0,018 & 180 \\
\hline
\end{tabular}

\footnotetext{
* $\rightarrow$ referentes a 300 sementes

$\mathrm{ns} \rightarrow$ medidas näo diferem significativamente a $1 \%$ pelo teste $\mathbf{t}$ Student das medidas correspondentes determinadas com o projetor de perfil

* $\rightarrow$ medidas diferem significativamente a $1 \%$ pelo teste $t$ Student das medidas correspondentes determinadas com o projetor de perfil

$A \rightarrow$ as médias das amostras contidas na mesma coluna não diferem significativamente entre si a $1 \%$ pelo teste $t$ Student

$B \rightarrow$ as médias das amostras contidas na mesma coluna diferem significativamente entre si a $1 \%$ pelo teste $t$ Student
} 
Tabela 33: Médias* das diferenças das medidas de comprimento (MComp) e de largura (MLarg), intervalos de confiança* $\left(\mathrm{IC}_{(1-0,01)}\right)$ e diferenças maiores do que zero* $\left(D_{i}>0\right)$, das diferenças de comprimento e largura estimadas pelo modelo da elipse que melhor representa o objeto em imagens de sementes de milho arranjadas na posição ordenada/dorsal e digitalizadas com a resolução de 100 ppi, em relação às medidas correspondentes determinadas com o projetor de perfil em oito amostras . Dados em milímetros (mm).

\begin{tabular}{|c|c|c|c|c|c|c|}
\hline \multirow[t]{2}{*}{ Amostra } & \multicolumn{3}{|c|}{ Comprimento } & \multicolumn{3}{|c|}{ Largura } \\
\hline & $\begin{array}{c}\text { MComp } \\
(\mathrm{mm})\end{array}$ & $\begin{array}{c}\mathrm{IC}_{(1-0,01)} \\
(\mathrm{mm})\end{array}$ & $D_{i}>0$ & $\begin{array}{c}\text { MLarg } \\
(\mathrm{mm})\end{array}$ & $\begin{array}{c}\mathrm{IC}_{(1-0,01)} \\
(\mathrm{mm})\end{array}$ & $D_{i}>0$ \\
\hline $18 \mathrm{C}$ & $-0,17^{\mathrm{ns}}$ & 0,05 & 99 & $0,03^{n S}$ & 0,03 & 180 \\
\hline $18 \mathrm{~L}$ & $-0,12^{\text {ns }}$ & 0,05 & 119 & $0,10^{* *}$ & 0,03 & 209 \\
\hline $20 \mathrm{C}$ & $0,82^{*}$ & 0,23 & 267 & $0,70^{* *}$ & 0,19 & 289 \\
\hline $20 \mathrm{~L}$ & $0,02^{\text {ns }}$ & 0,04 & 112 & $0,13^{* *}$ & 0,04 & 267 \\
\hline $22 \mathrm{C}$ & $-0,18^{\text {ns }}$ & 0,05 & 84 & $0,08^{* *}$ & 0,03 & 198 \\
\hline $22 \mathrm{~L}$ & $-0,24^{\star \star}$ & 0,06 & 80 & $0,16^{* *}$ & 0,03 & 248 \\
\hline $24 \mathrm{C}$ & $1,47^{* *}$ & 0,34 & 145 & $-0,31^{* *}$ & 0,15 & 99 \\
\hline $24 \mathrm{~L}$ & $1,43^{\star \star}$ & 0,45 & 156 & $-0,09^{* *}$ & 0,04 & 143 \\
\hline Média & $0,378^{B}$ & 0,060 & 132 & $0,100^{B}$ & 0,060 & 204 \\
\hline
\end{tabular}


Tabela 34: Médias* das diferenças das medidas de comprimento (MComp) e de largura (MLarg), intervalos de confiança* $\left(\mathrm{IC}_{(1-0,01)}\right)$ e diferenças maiores do que zero* $\left(D_{i}>0\right)$, das diferenças de comprimento e largura estimadas pelo modelo da elipse que melhor representa o objeto em imagens de sementes de milho arranjadas na posição ordenada/dorsal e digitalizadas com a resolução de 150 ppi, em relação às medidas correspondentes determinadas com o projetor de perfil em oito amostras . Dados em milímetros (mm).

\begin{tabular}{|c|c|c|c|c|c|c|}
\hline \multirow[t]{2}{*}{ Amostra } & \multicolumn{3}{|c|}{ Comprimento } & \multicolumn{3}{|c|}{ Largura } \\
\hline & $\begin{array}{c}\text { MComp } \\
\text { (mm) }\end{array}$ & $\begin{array}{c}\mathrm{IC}_{(1-0,01)} \\
(\mathrm{mm})\end{array}$ & $D_{i}>0$ & $\begin{array}{l}\text { MLarg } \\
(\mathrm{mm})\end{array}$ & $\begin{array}{c}\mathrm{IC}_{(1-0,01)} \\
(\mathrm{mm})\end{array}$ & $D_{i}>0$ \\
\hline $18 \mathrm{C}$ & $-0,19^{n \mathrm{~s}}$ & 0,05 & 74 & $0,05^{n \mathrm{~S}}$ & 0,03 & 189 \\
\hline $18 \mathrm{~L}$ & $-0,15^{\mathrm{ns}}$ & 0,05 & 101 & $0,11^{* *}$ & 0,03 & 221 \\
\hline $20 \mathrm{C}$ & $-0,17^{\mathrm{ns}}$ & 0,05 & 112 & $0,01^{\text {ns }}$ & 0,03 & 178 \\
\hline $20 \mathrm{~L}$ & $-0,03^{n s}$ & 0,03 & 67 & $0,16^{* *}$ & 0,04 & 232 \\
\hline $22 \mathrm{C}$ & $-0,26^{* *}$ & 0,05 & 58 & $0,08^{\prime *}$ & 0,03 & 192 \\
\hline $22 \mathrm{~L}$ & $-0,31^{\star *}$ & 0,06 & 56 & $0,15^{*}$ & 0,03 & 243 \\
\hline $24 C$ & $0,86^{* *}$ & 0,12 & 156 & $-0,16^{* *}$ & 0,03 & 123 \\
\hline $24 \mathrm{~L}$ & $0,87^{* *}$ & 0,14 & 178 & $0,06^{-}$ & 0,02 & 178 \\
\hline Média & $0,077^{\mathrm{B}}$ & 0,068 & 100 & $0,057^{8}$ & 0,030 & 194 \\
\hline
\end{tabular}


Tabela 35: Médias* das diferenças das medidas de comprimento (MComp) e de largura (MLarg), intervalos de confiança* $\left(\mathrm{IC}_{(1-0,01)}\right)$ e diferenças maiores do que zero* $\left(D_{i}>0\right)$, das diferenças de comprimento e largura estimadas pelo modelo da elipse que melhor representa o objeto em imagens de sementes de milho arranjadas na posição ordenada/dorsal e digitalizadas com a resolução de 200 ppi, em relação às medidas correspondentes determinadas com o projetor de perfil em oito amostras. Dados em milímetros $(\mathrm{mm})$.

\begin{tabular}{|c|c|c|c|c|c|c|}
\hline \multirow[t]{2}{*}{ Amostra } & \multicolumn{3}{|c|}{ Comprimento } & \multicolumn{3}{|c|}{ Largura } \\
\hline & $\begin{array}{c}\text { MComp } \\
(\mathrm{mm})\end{array}$ & $\begin{array}{c}\mathrm{IC}_{(1-0,01)} \\
(\mathrm{mm})\end{array}$ & $D_{i}>0$ & $\begin{array}{c}\text { MLarg } \\
(\mathrm{mm})\end{array}$ & $\begin{array}{c}\mathrm{IC}_{(1-0,01)} \\
(\mathrm{mm})\end{array}$ & $D_{i}>0$ \\
\hline 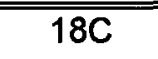 & $-\overline{-0,32}$ & 0,05 & $\overline{31}$ & $0,03^{\text {ns }}$ & 0,03 & 184 \\
\hline $18 \mathrm{~L}$ & $-0,35^{\star *}$ & 0,05 & 35 & $0,07^{* *}$ & 0,03 & 189 \\
\hline $20 \mathrm{C}$ & $-0,34^{* *}$ & 0,05 & 43 & $-0,02^{* *}$ & 0,03 & 123 \\
\hline $20 \mathrm{~L}$ & $0,01^{\prime *}$ & 0,02 & 145 & $0,01^{\mathrm{ns}}$ & 0,02 & 167 \\
\hline $22 \mathrm{C}$ & $-0,43^{* *}$ & 0,05 & 15 & $0,04^{\mathrm{ns}}$ & 0,03 & 175 \\
\hline $22 \mathrm{~L}$ & $-0,50^{* *}$ & 0,06 & 17 & $0,13^{* *}$ & 0,03 & 229 \\
\hline $24 \mathrm{C}$ & $0,65^{*}$ & 0,07 & 132 & $-0,24^{* *}$ & 0,05 & 121 \\
\hline $24 \mathrm{~L}$ & $0,64^{-}$ & 0,07 & 156 & $-0,02^{\mathrm{ns}}$ & 0,02 & 134 \\
\hline Média & $-0,080^{B}$ & 0,052 & 72 & $0,000^{B}$ & 0,030 & 165 \\
\hline
\end{tabular}

$\rightarrow$ referentes a 300 sementes

ns $\rightarrow$ medidas nāo diferem significativamente a $1 \%$ pelo teste $t$ Student das medidas correspondentes determinadas com o projetor de periil

** $\rightarrow$ medidas diferem significativamente a $1 \%$ pelo teste $t$ Student das medidas correspondentes determinadas com o projetor de perfil $B \rightarrow$ as médias das amostras contidas na mesma coluna diferem significativamente entre si a $1 \%$ pelo teste $t$ Student 
Tabela 36: Médias* das diferenças das medidas de comprimento (MComp) e de largura (MLarg), intervalos de confiança* $\left(\mathrm{IC}_{(1-0,01)}\right)$ e diferenças maiores do que zero* $\left(D_{i}>0\right)$, das diferenças de comprimento e largura estimadas pelo modelo da elipse que melhor representa 0 objeto em imagens de sementes de milho arranjadas na posição ordenada/dorsal e digitalizadas com a resolução de 250 ppi, em relação às medidas correspondentes determinadas com o projetor de perfil em oito amostras . Dados em milímetros $(\mathrm{mm})$.

\begin{tabular}{|c|c|c|c|c|c|c|}
\hline \multirow[t]{2}{*}{ Amostra } & \multicolumn{3}{|c|}{ Comprimento } & \multicolumn{3}{|c|}{ Largura } \\
\hline & $\begin{array}{c}\text { MComp } \\
(\mathrm{mm})\end{array}$ & $\begin{array}{c}\mathrm{IC}_{(1-0,01)} \\
(\mathrm{mm})\end{array}$ & $D_{i}>0$ & $\begin{array}{c}\text { MLarg } \\
(\mathrm{mm})\end{array}$ & $\begin{array}{c}\mathrm{IC}_{(1-0,01)} \\
(\mathrm{mm})\end{array}$ & $D_{i}>0$ \\
\hline $18 \mathrm{C}$ & $\overline{-0,24}$ & 0,05 & $\overline{52}$ & $0,01^{15}$ & $\overline{0,03}$ & 164 \\
\hline $18 \mathrm{~L}$ & $-0,19^{* *}$ & 0,05 & 79 & $0,08^{* *}$ & 0,03 & 188 \\
\hline $20 \mathrm{C}$ & $-0,19^{* * *}$ & 0,05 & 85 & $-0,01^{\mathrm{ns}}$ & 0,03 & 134 \\
\hline $20 \mathrm{~L}$ & $0,04^{* \prime}$ & 0,05 & 201 & $0,01^{\mathrm{ns}}$ & 0,03 & 234 \\
\hline $22 \mathrm{C}$ & $-0,28^{* *}$ & 0,05 & 49 & $0,05^{*}$ & 0,03 & 182 \\
\hline $22 \mathrm{~L}$ & $-0,35^{* *}$ & 0,06 & 49 & $0,15^{\prime \prime}$ & 0,03 & 235 \\
\hline $24 \mathrm{C}$ & $0,54^{*}$ & 0,07 & 167 & $-0,26$ & 0,03 & 121 \\
\hline $24 \mathrm{~L}$ & 0,54 & 0,07 & 145 & $-0,04^{*}$ & 0,02 & 145 \\
\hline Média & $-0,016^{B}$ & 0,056 & 103 & $-0,001^{\mathrm{B}}$ & 0,028 & 175 \\
\hline
\end{tabular}

$\rightarrow \rightarrow$ referentes a 300 sementes

ns $\rightarrow$ medidas nāo diferem significativamente a $1 \%$ pelo teste $t$ Student das medidas correspondentes determinadas com o projetor de perfil

** $\rightarrow$ medidas diferem significativamente a $1 \%$ pelo teste $t$ Student das medidas correspondentes determinadas com o projetor de perfil

$B \rightarrow$ as médias das amostras contidas na mesma coluna diferem significativamente entre si a $1 \%$ pelo teste $t$ Student 
Tabela 37: Médias* das diferenças das medidas de comprimento (MComp) e de largura (MLarg), intervalos de confiança* $\left(\mathrm{IC}_{(1-0,01)}\right)$ e diferenças maiores do que zero* $\left(D_{i}>0\right)$, das diferenças de comprimento e largura estimadas pelo modelo da elipse que melhor representa o objeto em imagens de sementes de milho arranjadas na posição ordenada/ventral e digitalizadas com a resolução de 100 ppi, em relação às medidas correspondentes determinadas com o projetor de perfil em oito amostras . Dados em milímetros $(\mathrm{mm})$.

\begin{tabular}{|c|c|c|c|c|c|c|}
\hline \multirow[t]{2}{*}{ Amostra } & \multicolumn{3}{|c|}{ Comprimento } & \multicolumn{3}{|c|}{ Largura } \\
\hline & $\begin{array}{l}\text { MComp } \\
(\mathrm{mm})\end{array}$ & $\begin{array}{c}\mathrm{IC}_{(1-0,01)} \\
(\mathrm{mm})\end{array}$ & $D_{i}>0$ & $\begin{array}{c}\text { MLarg } \\
(\mathrm{mm})\end{array}$ & $\begin{array}{c}\mathrm{IC}_{(1-0,01)} \\
(\mathrm{mm})\end{array}$ & $D_{i}>0$ \\
\hline $18 \mathrm{C}$ & $-0,12^{\text {ns }}$ & 0,04 & $\overline{90}$ & $0,02^{n s}$ & $\overline{0,03}$ & 169 \\
\hline $18 \mathrm{~L}$ & $-0,07^{n s}$ & 0,04 & 134 & $0,11^{-}$ & 0,03 & 220 \\
\hline $20 \mathrm{C}$ & $-0,16^{\text {ns }}$ & 0,04 & 92 & $-0,01^{\mathrm{ns}}$ & 0,02 & 123 \\
\hline $20 \mathrm{~L}$ & $0,01^{\mathrm{ns}}$ & 0,02 & 234 & $-0,03^{* *}$ & 0,03 & 98 \\
\hline $22 \mathrm{C}$ & $-0,20^{\text {ns }}$ & 0,04 & 64 & $0,07^{* *}$ & 0,03 & 208 \\
\hline $22 \mathrm{~L}$ & $-0,22$ & 0,05 & 74 & $0,15^{*}$ & 0,02 & 249 \\
\hline $24 \mathrm{C}$ & $1,50^{* *}$ & 0,23 & 154 & $-0,15^{*}$ & 0,03 & 123 \\
\hline $24 \mathrm{~L}$ & $1,56^{* *}$ & 0,31 & 156 & $0,06^{* *}$ & 0,02 & 199 \\
\hline Média & $0,287^{8}$ & 0,096 & 125 & $0,025^{\mathrm{B}}$ & 0,026 & 175 \\
\hline
\end{tabular}

\footnotetext{
* $\rightarrow$ referentes a 300 sementes

$\mathrm{ns} \rightarrow$ medidas não diferem significativamente a $1 \%$ pelo teste t Student das medidas correspondentes determinadas com o projetor de perfil

* $\rightarrow$ medidas diferem significativamente a $1 \%$ pelo teste $t$ Student das medidas correspondentes determinadas com o projetor de perfil

$B \rightarrow$ as médias das amostras contidas na mesma coluna diferem significativamente entre si a $1 \%$ pelo teste t Student
} 
Tabela 38: Médias* das diferenças das medidas de comprimento (MComp) e de largura (MLarg), intervalos de confiança* $\left(\mathrm{IC}_{(1-0,01)}\right)$ e diferenças maiores do que zero* $\left(D_{i}>0\right)$, das diferenças de comprimento e largura estimadas pelo modelo da elipse que melhor representa 0 objeto em imagens de sementes de milho arranjadas na posição ordenada/ventral e digitalizadas com a resolução de 150 ppi, em relação às medidas correspondentes determinadas com o projetor de perfil em oito amostras. Dados em milimetros $(\mathrm{mm})$.

\begin{tabular}{|c|c|c|c|c|c|c|}
\hline \multirow[t]{2}{*}{ Amostra } & \multicolumn{3}{|c|}{ Comprimento } & \multicolumn{3}{|c|}{ Largura } \\
\hline & $\begin{array}{c}\text { MComp } \\
(\mathrm{mm})\end{array}$ & $\begin{array}{c}\mathrm{IC}_{(1-0,01)} \\
(\mathrm{mm})\end{array}$ & $\mathrm{D}_{\mathrm{i}}>0$ & $\begin{array}{c}\text { MLarg } \\
(\mathrm{mm})\end{array}$ & $\begin{array}{c}\mathrm{IC}_{(1-0,01)} \\
(\mathrm{mm})\end{array}$ & $D_{i}>0$ \\
\hline $18 \mathrm{C}$ & $-0,15^{\text {ns }}$ & 0,05 & 79 & $0,02^{\text {ns }}$ & 0,03 & 167 \\
\hline $18 \mathrm{~L}$ & $-0,11^{\text {ns }}$ & 0,04 & 105 & $0,11^{m *}$ & 0,03 & 222 \\
\hline $20 \mathrm{C}$ & $-0,21^{* *}$ & 0,05 & 89 & $0,00^{\text {ns }}$ & 0,02 & 245 \\
\hline $20 \mathrm{~L}$ & $0,00^{n s}$ & 0,02 & 167 & $-0,06^{*}$ & 0,03 & 123 \\
\hline $22 \mathrm{C}$ & $-0,28^{* *}$ & 0,04 & 38 & $0,06^{* *}$ & 0,03 & 194 \\
\hline $22 \mathrm{~L}$ & $-0,27^{* *}$ & 0,05 & 54 & $0,15^{-}$ & 0,03 & 247 \\
\hline $24 \mathrm{C}$ & $0,88^{* *}$ & 0,12 & 156 & $0,10^{*}$ & 0,03 & 145 \\
\hline $24 \mathrm{~L}$ & $0,87^{*-}$ & 0,21 & 178 & $0,29^{\prime \prime}$ & 0,03 & 165 \\
\hline Média & $0,091^{B}$ & 0,072 & 108 & $0,083^{B}$ & 0,028 & 188 \\
\hline
\end{tabular}

$\rightarrow$ referentes a 300 sementes

ns $\rightarrow$ medidas nāo diferem significativamente a $1 \%$ pelo teste $t$ Student das medidas correspondentes determinadas com o projetor de perfil

** $\rightarrow$ medidas diferem significativamente a $1 \%$ pelo teste $t$ Student das medidas correspondentes determinadas com o projetor de perfil

$B \rightarrow$ as médias das amostras contidas na mesma coluna diferem significativamente entre si a $1 \%$ pelo teste t Student 
Tabela 39: Médias* das diferenças das medidas de comprimento (MComp) e de largura (MLarg), intervalos de confiança* $\left(\mathrm{IC}_{(1-0,01)}\right)$ e diferenças maiores do que zero* $\left(D_{i}>0\right)$, das diferenças de comprimento e largura estimadas pelo modelo da elipse que melhor representa 0 objeto em imagens de sementes de milho arranjadas na posição ordenada/ventral e digitalizadas com a resolução de 200 ppi, em relação às medidas correspondentes determinadas com o projetor de perfil em oito amostras. Dados em milímetros $(\mathrm{mm})$.

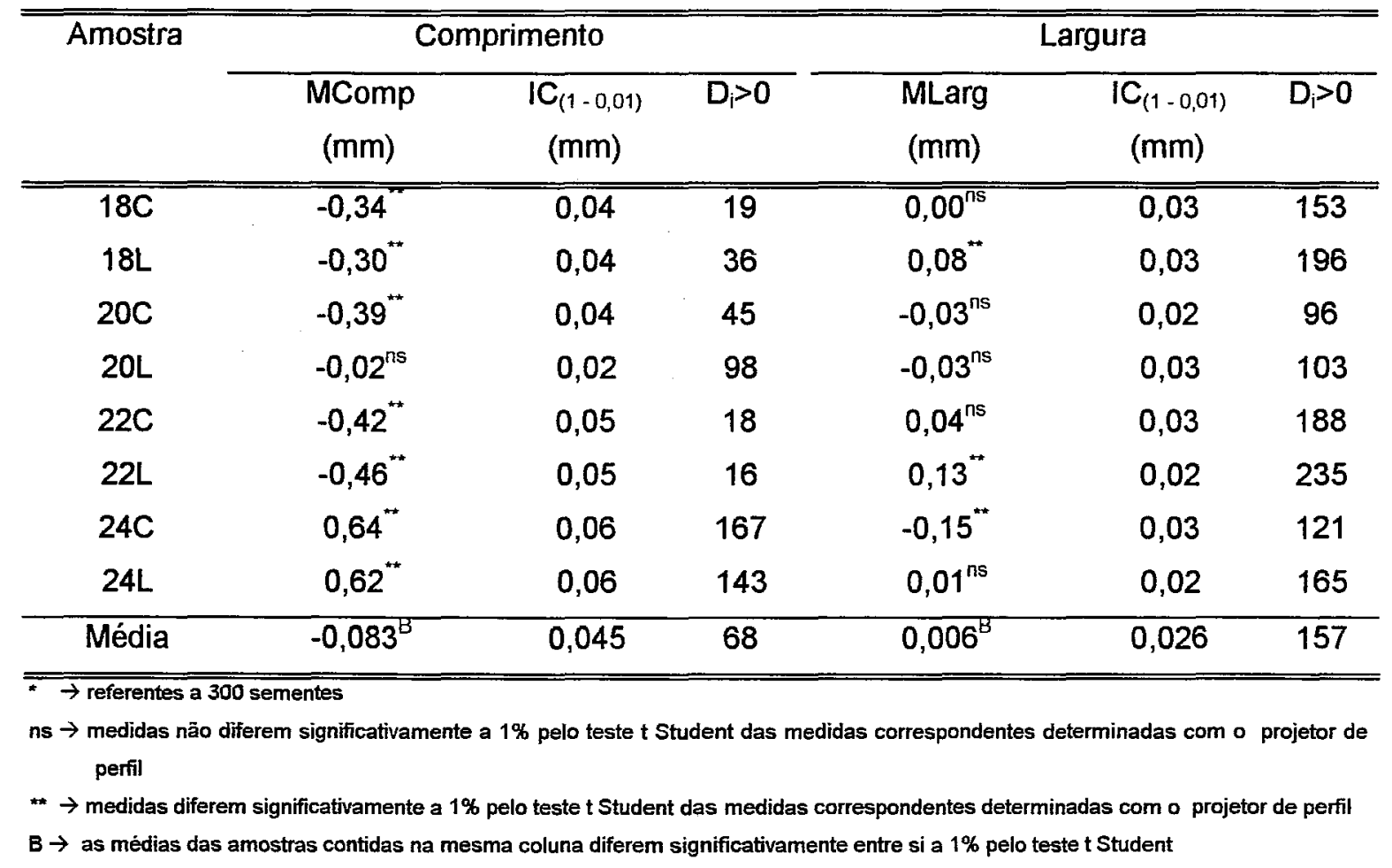


Tabela 40: Médias* das diferenças das medidas de comprimento (MComp) e de largura (MLarg), intervalos de confiança* $\left(\mathrm{IC}_{(1-0,01)}\right)$ e diferenças maiores do que zero* $\left(D_{i}>0\right)$, das diferenças de comprimento e largura estimadas pelo modelo da elipse que melhor representa 0 objeto em imagens de sementes de milho arranjadas na posição ordenada/ventral e digitalizadas com a resolução de 250 ppi, em relação às medidas correspondentes determinadas com o projetor de perfil em oito amostras. Dados em milímetros (mm).

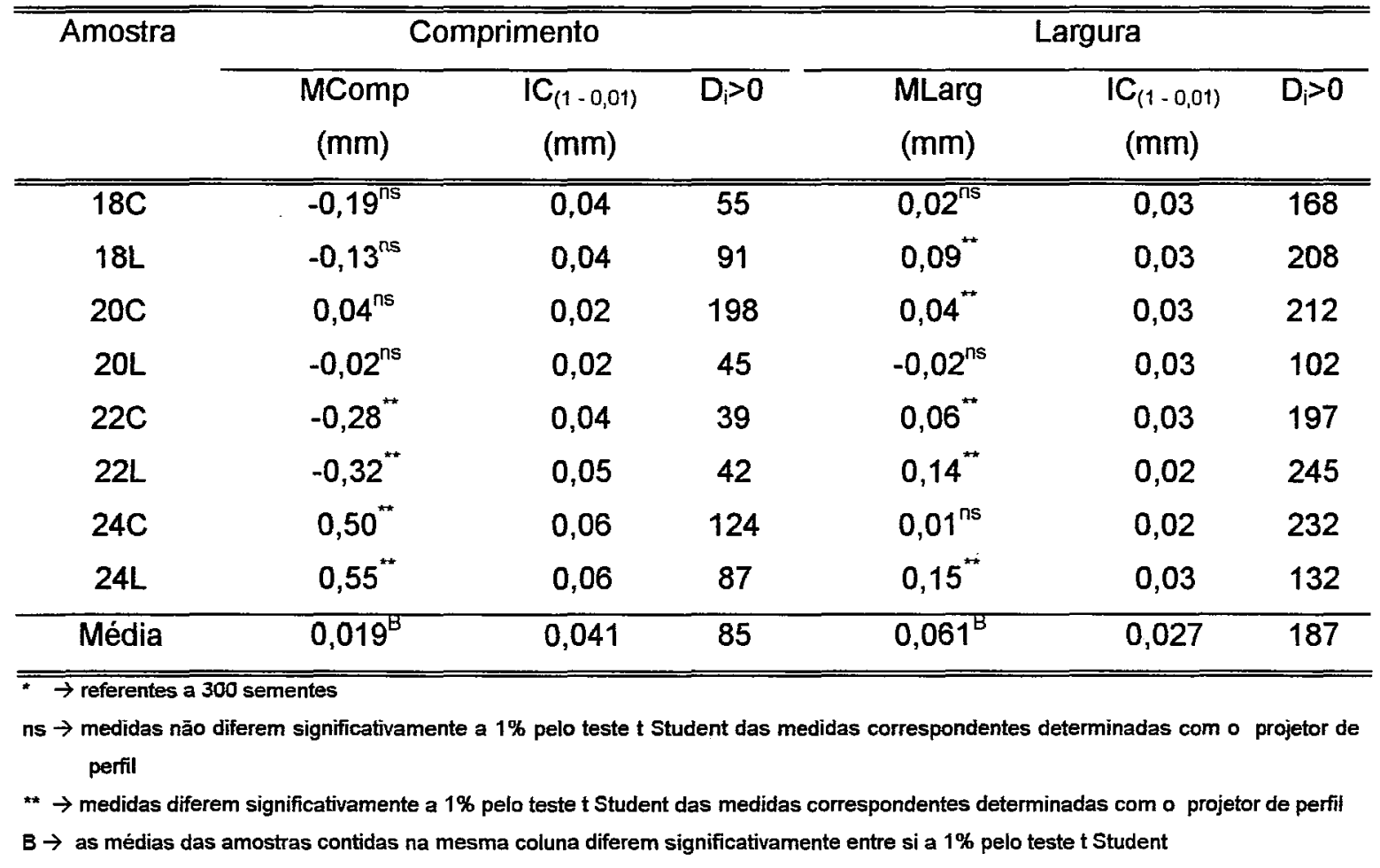


Tabela 41: Médias* das diferenças das medidas de comprimento (MComp) e de largura (MLarg), intervalos de confiança* $\left(\mathrm{IC}_{(1-0,01)}\right)$ e diferenças maiores do que zero* $\left(D_{i}>0\right)$, das diferenças de comprimento e largura estimadas pelo modelo da elipse que melhor representa o objeto em imagens de sementes de milho arranjadas na posição desordenada/dorsal e digitalizadas com a resolução de 100 ppi, em relação às medidas correspondentes determinadas com o projetor de perfil em oito amostras. Dados em milímetros $(\mathrm{mm})$.

\begin{tabular}{|c|c|c|c|c|c|c|}
\hline \multirow[t]{2}{*}{ Amostra } & \multicolumn{3}{|c|}{ Comprimento } & \multicolumn{3}{|c|}{ Largura } \\
\hline & $\begin{array}{l}\text { MComp } \\
(\mathrm{mm})\end{array}$ & $\begin{array}{c}\mathrm{IC}_{(1-0,01)} \\
(\mathrm{mm})\end{array}$ & $D_{i}>0$ & $\begin{array}{l}\text { MLarg } \\
(\mathrm{mm})\end{array}$ & $\begin{array}{c}\mathrm{IC}_{(1-0,01)} \\
(\mathrm{mm})\end{array}$ & $\overline{D_{i}}>0$ \\
\hline $18 \mathrm{C}$ & $-1,17$ & 0,16 & 27 & 0,30 & 0,05 & 242 \\
\hline $18 \mathrm{~L}$ & $-1,53^{* *}$ & 0,24 & 45 & $0,43^{-\infty}$ & 0,07 & 258 \\
\hline $20 \mathrm{C}$ & $-1,04^{*-}$ & 0,15 & 32 & $0,26^{*}$ & 0,05 & 242 \\
\hline $20 \mathrm{~L}$ & $-2,85^{* *}$ & 0,67 & 2 & $0,25^{* *}$ & 0,05 & 232 \\
\hline $22 \mathrm{C}$ & $-0,99^{* *}$ & 0,15 & 29 & $0,31^{+}$ & 0,05 & 246 \\
\hline $22 \mathrm{~L}$ & $-1,35^{* *}$ & 0,17 & 19 & $0,42^{* *}$ & 0,05 & 275 \\
\hline $24 \mathrm{C}$ & $1,38^{* *}$ & 0,34 & 131 & $0,61^{* *}$ & 0,06 & 232 \\
\hline $24 \mathrm{~L}$ & $1,31^{* *}$ & 0,22 & 99 & $0,25^{* *}$ & 0,04 & 199 \\
\hline Média & $-0,780^{B}$ & 0,262 & 48 & $0,353^{8}$ & 0,05 & 241 \\
\hline
\end{tabular}


Tabela 42: Médias* das diferenças das medidas de comprimento (MComp) e de largura (MLarg), intervalos de confiança* $\left(\mathrm{IC}_{(1-0,01)}\right)$ e diferenças maiores do que zero* $\left(D_{i}>0\right)$, das diferenças de comprimento e largura estimadas pelo modelo da elipse que melhor representa o objeto em imagens de sementes de milho arranjadas na posição desordenada/dorsal e digitalizadas com a resolução de 150 ppi, em relação às medidas correspondentes determinadas com o projetor de perfil em oito amostras . Dados em milímetros (mm).

\begin{tabular}{|c|c|c|c|c|c|c|}
\hline \multirow[t]{2}{*}{ Amostra } & \multicolumn{3}{|c|}{ Comprimento } & \multicolumn{3}{|c|}{ Largura } \\
\hline & $\begin{array}{c}\text { MComp } \\
(\mathrm{mm})\end{array}$ & $\begin{array}{c}I_{(1-0,01)} \\
(\mathrm{mm})\end{array}$ & $\mathrm{D}_{\mathrm{i}}>0$ & $\begin{array}{c}\text { MLarg } \\
(\mathrm{mm})\end{array}$ & $\begin{array}{c}\mathrm{IC}_{(1-0,01)} \\
(\mathrm{mm})\end{array}$ & $D_{i}>0$ \\
\hline $18 \mathrm{C}$ & $-1,21$ & 0,16 & 16 & 0,25 & 0,05 & 222 \\
\hline $18 \mathrm{~L}$ & $-1,54^{* *}$ & 0,24 & 39 & $0,41^{* *}$ & 0,07 & 246 \\
\hline $20 \mathrm{C}$ & $-1,08^{* *}$ & 0,15 & 39 & $0,22^{* *}$ & 0,05 & 232 \\
\hline $20 \mathrm{~L}$ & $-3,41^{* \star}$ & 0,78 & 1 & $0,20^{* *}$ & 0,05 & 243 \\
\hline $22 \mathrm{C}$ & $-1,03^{* *}$ & 0,15 & 21 & $0,27^{* *}$ & 0,05 & 228 \\
\hline $22 \mathrm{~L}$ & $-1,36^{* *}$ & 0,17 & 21 & $0,40^{* *}$ & 0,05 & 267 \\
\hline $24 C$ & $0,86^{* *}$ & 0,15 & 121 & $0,82^{* *}$ & 0,09 & 121 \\
\hline $24 \mathrm{~L}$ & $0,86^{* *}$ & 0,15 & 143 & $0,70^{*}$ & 0,09 & 143 \\
\hline Média & $-0,988^{\mathrm{B}}$ & 0,244 & 50 & $0,409^{B}$ & 0,060 & 213 \\
\hline
\end{tabular}


Tabela 43: Médias* das diferenças das medidas de comprimento (MComp) e de largura (MLarg), intervalos de confiança* $\left(\mathrm{IC}_{(1-0,01)}\right)$ e diferenças maiores do que zero* $\left(D_{i}>0\right)$, das diferenças de comprimento e largura estimadas pelo modelo da elipse que melhor representa o objeto em imagens de sementes de milho arranjadas na posição desordenada/dorsal e digitalizadas com a resolução de 200 ppi, em relação às medidas correspondentes determinadas com o projetor de perfil em oito amostras. Dados em milímetros $(\mathrm{mm})$.

\begin{tabular}{|c|c|c|c|c|c|c|}
\hline \multirow[t]{2}{*}{ Amostra } & \multicolumn{3}{|c|}{ Comprimento } & \multicolumn{3}{|c|}{ Largura } \\
\hline & $\begin{array}{c}\text { MComp } \\
(\mathrm{mm})\end{array}$ & $\begin{array}{c}\mathrm{IC}_{(1-0,01)} \\
(\mathrm{mm})\end{array}$ & $\mathrm{D}_{\mathrm{i}}>0$ & $\begin{array}{l}\text { MLarg } \\
(\mathrm{mm})\end{array}$ & $\begin{array}{c}\mathrm{IC}_{(1-0,01)} \\
(\mathrm{mm})\end{array}$ & $D_{i}>0$ \\
\hline $18 \mathrm{C}$ & $-1,28$ & 0,16 & 9 & $0,19^{\prime \prime}$ & 0,05 & 203 \\
\hline $18 \mathrm{~L}$ & $-1,63$ & 0,24 & 27 & $0,33^{* *}$ & 0,06 & 227 \\
\hline $20 \mathrm{C}$ & $-1,17^{* *}$ & 0,15 & 32 & 0,16 & 0,05 & 245 \\
\hline $20 \mathrm{~L}$ & $-0,63^{* *}$ & 0,04 & 67 & $0,16^{-}$ & 0,05 & 234 \\
\hline $22 \mathrm{C}$ & $-1,13^{*}$ & 0,15 & 13 & $0,20^{* *}$ & 0,05 & 203 \\
\hline $22 \mathrm{~L}$ & $-1,47^{* *}$ & 0,17 & 10 & $0,30^{*}$ & 0,05 & 235 \\
\hline $24 C$ & $0,65^{*}$ & 0,11 & 132 & $0,10^{* *}$ & 0,05 & 221 \\
\hline $24 L$ & $0,65^{* *}$ & 0,11 & 101 & $0,21^{*}$ & 0,05 & 198 \\
\hline Média & $-0,751^{B}$ & 0,141 & 49 & $0,206^{\mathrm{B}}$ & 0,050 & 221 \\
\hline
\end{tabular}


Tabela 44: Médias* das diferenças das medidas de comprimento (MComp) e de largura (MLarg), intervalos de confiança* $\left(\mathrm{IC}_{(1-0,01)}\right)$ e diferenças maiores do que zero* $\left(D_{i}>0\right)$, das diferenças de comprimento e largura estimadas pelo modelo da elipse que melhor representa 0 objeto em imagens de sementes de milho arranjadas na posição desordenada/dorsal e digitalizadas com a resolução de 250 ppi, em relação às medidas correspondentes determinadas com o projetor de perfil em oito amostras . Dados em milímetros (mm).

\begin{tabular}{|c|c|c|c|c|c|c|}
\hline \multirow[t]{2}{*}{ Amostra } & \multicolumn{3}{|c|}{ Comprimento } & \multicolumn{3}{|c|}{ Largura } \\
\hline & $\begin{array}{c}\text { MComp } \\
(\mathrm{mm})\end{array}$ & $\begin{array}{c}\mathrm{IC}_{(1-0,01)} \\
(\mathrm{mm})\end{array}$ & $D_{i}>0$ & $\begin{array}{c}\text { MLarg } \\
(\mathrm{mm})\end{array}$ & $\begin{array}{c}\mathrm{IC}_{(1-0,01)} \\
(\mathrm{mm})\end{array}$ & $D_{i}>0$ \\
\hline $18 \mathrm{C}$ & $-1,22$ & 0,16 & 14 & 0,25 & 0,05 & 219 \\
\hline $18 \mathrm{~L}$ & $-1,55^{\prime \prime}$ & 0,24 & 41 & $0,40^{-m}$ & 0,07 & 244 \\
\hline $20 \mathrm{C}$ & $-1,10^{* *}$ & 0,15 & 23 & $0,21^{-m}$ & 0,05 & 256 \\
\hline $20 \mathrm{~L}$ & $-3,41^{* *}$ & 0,67 & 3 & $0,23^{*}$ & 0,05 & 213 \\
\hline $22 \mathrm{C}$ & $-1,05^{* *}$ & 0,15 & 19 & $0,25^{*}$ & 0,05 & 222 \\
\hline $22 L$ & $-1,38^{* *}$ & 0,18 & 24 & $0,39^{* *}$ & 0,05 & 259 \\
\hline $24 C$ & $0,52^{\text {t* }}$ & 0,11 & 87 & $0,10^{* *}$ & 0,04 & 201 \\
\hline $24 \mathrm{~L}$ & $0,55^{* *}$ & 0,11 & 67 & $0,18^{* *}$ & 0,05 & 219 \\
\hline Média & $-1,080^{B}$ & 0,221 & 35 & $0,251^{B}$ & 0,050 & 229 \\
\hline
\end{tabular}


Tabela 45: Médias* das diferenças das medidas de comprimento (MComp) e de largura (MLarg), intervalos de confiança* $\left(\mathrm{IC}_{(1-0,01)}\right)$ e diferenças maiores do que zero* $\left(D_{i}>0\right)$, das diferenças de comprimento e largura estimadas pelo modelo da elipse que melhor representa o objeto em imagens de sementes de milho arranjadas na posição desordenada/ventral e digitalizadas com a resolução de 100 ppi, em relação às medidas correspondentes determinadas com o projetor de perfil em oito amostras. Dados em milímetros $(\mathrm{mm})$.

\begin{tabular}{|c|c|c|c|c|c|c|}
\hline \multirow[t]{2}{*}{ Amostra } & \multicolumn{3}{|c|}{ Comprimento } & \multicolumn{3}{|c|}{ Largura } \\
\hline & $\begin{array}{l}\text { MComp } \\
(\mathrm{mm})\end{array}$ & $\begin{array}{c}\mathrm{IC}_{(1-0,01)} \\
(\mathrm{mm})\end{array}$ & $D_{i}>0$ & $\begin{array}{c}\text { MLarg } \\
(\mathrm{mm})\end{array}$ & $\begin{array}{c}\mathrm{IC}_{(1-0,01)} \\
(\mathrm{mm})\end{array}$ & $D_{i}>0$ \\
\hline $18 \mathrm{C}$ & $-1,14$ & 0,16 & 36 & $\overline{0,31}$ & 0,05 & $\overline{254}$ \\
\hline $18 \mathrm{~L}$ & $-1,43^{+*}$ & 0,24 & 50 & $0,41^{-}$ & 0,06 & 262 \\
\hline $20 \mathrm{C}$ & $-1,17^{* *}$ & 0,16 & 36 & 0,26 & 0,04 & 245 \\
\hline $20 \mathrm{~L}$ & $-2,41^{* *}$ & 0,34 & 23 & $0,22^{*}$ & 0,04 & 267 \\
\hline $22 \mathrm{C}$ & $-1,06^{* *}$ & 0,16 & 29 & $0,33^{*}$ & 0,05 & 249 \\
\hline $22 \mathrm{~L}$ & $-1,24^{* *}$ & 0,17 & 32 & $0,37^{* *}$ & 0,05 & 265 \\
\hline $24 \mathrm{C}$ & $1,41^{* *}$ & 0,20 & 134 & $0,61^{* *}$ & 0,06 & 231 \\
\hline $24 \mathrm{~L}$ & $1,34^{* *}$ & 0,18 & 156 & $0,37^{* *}$ & 0,05 & 152 \\
\hline Média & $-0,712^{B}$ & 0,201 & 62 & $0,360^{B}$ & 0,050 & 241 \\
\hline
\end{tabular}

\footnotetext{
$\rightarrow \rightarrow$ referentes a 300 sementes

* $\rightarrow$ medidas diferem significativamente a $1 \%$ pelo teste $t$ Student das medidas correspondentes determinadas com o projetor de peril

$B \rightarrow$ as médias das amostras contidas na mesma coluna diferem significativamente entre si a $1 \%$ pelo teste $t$ Student
} 
Tabela 46: Médias* das diferenças das medidas de comprimento (MComp) e de largura (MLarg), intervalos de confiança* $\left(\mathrm{IC}_{(1-0,01)}\right)$ e diferenças maiores do que zero* $\left(D_{i}>0\right)$, das diferenças de comprimento e largura estimadas pelo modelo da elipse que melhor representa 0 objeto em imagens de sementes de milho arranjadas na posição desordenada/ventral e digitalizadas com a resolução de 150 ppi, em relação às medidas correspondentes determinadas com o projetor de perfil em oito amostras. Dados em milimetros (mm).

\begin{tabular}{|c|c|c|c|c|c|c|}
\hline \multirow[t]{2}{*}{ Amostra } & \multicolumn{3}{|c|}{ Comprimento } & \multicolumn{3}{|c|}{ Largura } \\
\hline & $\begin{array}{c}\text { MComp } \\
(\mathrm{mm})\end{array}$ & $\begin{array}{c}\mathrm{IC}_{(1-0,01)} \\
(\mathrm{mm})\end{array}$ & $D_{i}>0$ & $\begin{array}{l}\text { MLarg } \\
(\mathrm{mm})\end{array}$ & $\begin{array}{c}\mathrm{IC}_{(1-0,01)} \\
(\mathrm{mm})\end{array}$ & $D_{i}>0$ \\
\hline $18 \mathrm{C}$ & $-1,18$ & $\overline{0,16}$ & 29 & 0,27 & 0,05 & 239 \\
\hline $18 \mathrm{~L}$ & $-1,46^{* *}$ & 0,24 & 47 & $0,39^{* *}$ & 0,06 & 259 \\
\hline $20 \mathrm{C}$ & $-1,18^{* *}$ & 0,16 & 45 & $0,22^{* *}$ & 0,05 & 245 \\
\hline $20 \mathrm{~L}$ & $-3,50^{* *}$ & 0,78 & 12 & $0,18^{* *}$ & 0,05 & 256 \\
\hline $22 \mathrm{C}$ & $-1,11^{* *}$ & 0,16 & 25 & $0,29^{* *}$ & 0,05 & 235 \\
\hline $22 \mathrm{~L}$ & $-1,27^{*}$ & 0,17 & 30 & $0,33^{* *}$ & 0,05 & 256 \\
\hline $24 \mathrm{C}$ & $0,87^{*}$ & 0,16 & 99 & $1,11^{* *}$ & 0,65 & 123 \\
\hline $24 \mathrm{~L}$ & $0,86^{*}$ & 0,16 & 102 & $0,17^{* *}$ & 0,05 & 221 \\
\hline Média & $-0,996^{B}$ & 0,248 & 49 & $0,370^{B}$ & 0,126 & 229 \\
\hline
\end{tabular}

$\rightarrow \rightarrow$ referentes a 300 sementes

** $\rightarrow$ medidas diferem significativamente a $1 \%$ pelo teste $t$ Student das medidas correspondentes determinadas com o projetor de perfil

$B \rightarrow$ as médias das amostras contidas na mesma coluna diferem significativamente entre si a $1 \%$ pelo teste $t$ Student 
Tabela 47: Médias* das diferenças das medidas de comprimento (MComp) e de largura (MLarg), intervalos de confiança* $\left(\mathrm{IC}_{(1-0,01)}\right)$ e diferenças maiores do que zero* $\left(D_{i}>0\right)$, das diferenças de comprimento e largura estimadas pelo modelo da elipse que melhor representa o objeto em imagens de sementes de milho arranjadas na posição desordenada/ventral e digitalizadas com a resolução de 200 ppi, em relação às medidas correspondentes determinadas com o projetor de perfil em oito amostras. Dados em milimetros (mm).

\begin{tabular}{|c|c|c|c|c|c|c|}
\hline \multirow[t]{2}{*}{ Amostra } & \multicolumn{3}{|c|}{ Comprimento } & \multicolumn{3}{|c|}{ Largura } \\
\hline & $\begin{array}{c}\text { MComp } \\
(\mathrm{mm})\end{array}$ & $\begin{array}{c}\mathrm{IC}_{(1-0,01)} \\
(\mathrm{mm})\end{array}$ & $D_{i}>0$ & $\begin{array}{c}\text { MLarg } \\
(\mathrm{mm})\end{array}$ & $\begin{array}{c}\mathrm{IC}_{(1-0,01)} \\
(\mathrm{mm})\end{array}$ & $\overline{D_{i}}>0$ \\
\hline $18 \mathrm{C}$ & $-1,28$ & 0,16 & 16 & $0,20^{\circ}$ & 0,05 & 212 \\
\hline $18 \mathrm{~L}$ & $-1,53^{* *}$ & 0,24 & 40 & $0,32^{* *}$ & 0,06 & 243 \\
\hline $20 \mathrm{C}$ & $-1,29^{* *}$ & 0,16 & 23 & $0,16^{*}$ & 0,05 & 232 \\
\hline $20 \mathrm{~L}$ & $-0,42^{* *}$ & 0,06 & 67 & $0,11^{*}$ & 0,04 & 265 \\
\hline $22 \mathrm{C}$ & $-1,19^{* *}$ & 0,16 & 16 & $0,24^{* *}$ & 0,05 & 220 \\
\hline $22 \mathrm{~L}$ & $-1,33^{* *}$ & 0,17 & 22 & $0,29^{* *}$ & 0,05 & 236 \\
\hline $24 \mathrm{C}$ & $0,64^{* *}$ & 0,12 & 145 & $0,49^{* *}$ & 0,06 & 245 \\
\hline $24 \mathrm{~L}$ & 0,64 & 0,12 & 167 & $0,31^{* *}$ & 0,05 & 199 \\
\hline Média & $-0,720^{B}$ & 0,148 & 62 & $0,265^{B}$ & 0,050 & 231 \\
\hline
\end{tabular}

\footnotetext{
$\rightarrow$ referentes a 300 sementes

* $\rightarrow$ medidas diferem significativamente a $1 \%$ pelo teste $t$ Student das medidas correspondentes determinadas com o projetor de perfil $B \rightarrow$ as médias das amostras contidas na mesma coluna diferem significativamente entre si a $1 \%$ pelo teste $t$ Student
} 
Tabela 48: Médias* das diferenças das medidas de comprimento (MComp) e de largura (MLarg), intervalos de confiança* $\left(\mathrm{IC}_{(1-0,01)}\right)$ e diferenças maiores do que zero* $\left(D_{i}>0\right)$, das diferenças de comprimento e largura estimadas pelo modelo da elipse que melhor representa o objeto em imagens de sementes de milho arranjadas na posição desordenada/ventral e digitalizadas com a resolução de 250 ppi, em relação às medidas correspondentes determinadas com o projetor de perfil em oito amostras. Dados em milímetros $(\mathrm{mm})$.

\begin{tabular}{|c|c|c|c|c|c|c|}
\hline \multirow[t]{2}{*}{ Amostra } & \multicolumn{3}{|c|}{ Comprimento } & \multicolumn{3}{|c|}{ Largura } \\
\hline & $\begin{array}{c}\text { MComp } \\
(\mathrm{mm})\end{array}$ & $\begin{array}{c}\mathrm{IC}_{(\uparrow-0,01)} \\
(\mathrm{mm})\end{array}$ & $D_{i}>0$ & $\begin{array}{c}\text { MLarg } \\
(\mathrm{mm})\end{array}$ & $\begin{array}{c}\mathrm{IC}_{(1-0,01)} \\
(\mathrm{mm})\end{array}$ & $D_{i}>0$ \\
\hline $18 \mathrm{C}$ & $-1,21$ & 0,16 & 22 & 0,24 & 0,05 & 229 \\
\hline $18 \mathrm{~L}$ & $-1,46^{\star *}$ & 0,24 & 49 & $0,36^{*}$ & 0,06 & 253 \\
\hline $20 \mathrm{C}$ & $-1,23^{* *}$ & 0,16 & 26 & $0,21^{-*}$ & 0,05 & 232 \\
\hline $20 \mathrm{~L}$ & $-2,98^{* *}$ & 0,56 & 2 & $0,18^{* *}$ & 0,05 & 243 \\
\hline $22 \mathrm{C}$ & $-1,12^{* *}$ & 0,16 & 25 & $0,28^{* *}$ & 0,05 & 236 \\
\hline $22 \mathrm{~L}$ & $-1,26^{* *}$ & 0,17 & 35 & $0,35^{* *}$ & 0,05 & 256 \\
\hline $24 C$ & $0,53^{* *}$ & 0,15 & 156 & $0,31^{\star \star}$ & 0,05 & 234 \\
\hline $24 L$ & $0,52^{* *}$ & 0,16 & 167 & $0,20^{* *}$ & 0,05 & 245 \\
\hline Média & $-1,026^{B}$ & 0,220 & 60 & $0,266^{B}$ & 0,051 & 241 \\
\hline
\end{tabular}


Com relação às medidas estimadas pelo modelo do menor retângulo circunscrito e a ordenação das sementes (ordenadas e desordenadas), comparando-se a exatidão das medidas, arquivos com diferença de medida significativa $\left(^{\star \star}\right)$ e não significativa (ns), apresentados nas Tabelas 17 a 24 com as respectivas exatidões de medidas apresentadas nas Tabelas 25 a 32, nas quais o fator alterado é a ordenação das sementes, verifica-se que a ordenação não afeta a exatidão das medidas, ou seja, os arquivos não tem a significância alterada em função da ordenação das sementes, principalmente em imagens digitalizadas com resoluções entre 150 e 200 ppi. Portanto, medidas estimadas com emprego do modelo do menor retângulo circunscrito em imagens digitais contendo sementes de milho, são indiferentes a ordenação das sementes; é preferível optar por digitalizar imagens de sementes desordenadas em razão da maior praticidade em não ordenar as mesmas.

Com relação às medidas estimadas pelo modelo da elipse que melhor representa o objeto e a ordenação das sementes (ordenadas e desordenadas) comparando a exatidão das medidas (ț) e as médias das diferenças de medidas apresentados nas Tabelas 33 a 40 com as respectivas exatidões e médias apresentadas nas Tabelas 41 a 48 , nas quais o fator 
alterado é a ordenação das sementes, verifica-se que a ordenação afeta a exatidão e a média das diferenças das medidas, principalmente com relação a medida de comprimento. As médias das diferenças das medidas de comprimento apresentam valores superiores a um milimetro quando as imagens contem sementes desordenadas. Esta alta incerteza de medida em imagens contendo sementes desordenadas é devida ao modelo considerar o maior eixo da imagem para orientação da elipse, alocando as elipses com o maior eixo no mesmo sentido do eixo $\underline{x}$ da imagem. A estimativa de momentos superiores, como as dimensões de um objeto contido na imagem, são todas derivadas da equação (6)

$$
m_{p q}=\sum \sum_{i, j \in R} I^{p} J^{q}
$$

que define o momento 0.0 , ou momento básico.

Para a estimativa de momentos superiores de um objeto contido na imagem, deve-se isolar o objeto da imagem, assumindo como referência seus eixos e centro de gravidade e não os referidos parâmetros da imagem. Os erros observados para o modelo da elipse que melhor representa o objeto sugerem que o modelo considera os parâmetros, eixos e centro de gravidade, da imagem como referência. Assim, sementes com o eixo do comprimento transversal ao eixo $\underline{x}$ da imagem são representadas por elipses em que 0 menor eixo da elipse (ê) corresponde ao eixo do comprimento da semente, ou seja, estas sementes são representadas por elipses super dimensionadas. 
Em razão do comentário acima a respeito do modelo da elipse que melhor representa o objeto e como o sistema SIARCS $3.0^{\circledR}$ oferece a possibilidade dos momentos serem estimados por um ou outro, ou ambos os modelos, o modelo da elipse que melhor representa o objeto não deve ser considerado quando estimar medidas em sementes de milho.

Comparando a exatidão das medidas determinadas pelo teste $\mathrm{t}$ Student, apresentados nas Tabelas 17 a 20, 25 a 28, 33 a 36 e 41 a 45 com as respectivas exatidões e médias apresentadas nas Tabelas 21 a 24, 29 a 32, 37 a 40 e 46 a 49, nas quais o fator alterado é a posição da face da semente em relação ao vidro do scanner, verifica-se que a exatidão da medida estimada não foi afetada significativamente com relação à posição da face dorsal ou ventral da semente voltada para o vidro do scanner, principalmente em imagens digitalizadas nas resoluções acima de 150 ppi. Portanto, é indiferente a posição da face da semente em relação ao vidro do scanner durante a digitalização da imagem, podendo a imagem ser digitalizada com as sementes em uma ou outra, ou ainda em ambas as posições. É importante considerar que a posição ventral ou dorsal da semente não afeta os resultados, pois permite que as sementes sejam distribuídas aleatoriamente sobre o vidro do scanner, permitindo maior agilidade durante a digitalização das imagens.

Com relação a resolução em que a imagem foi digitalizada $e$ observando os 32 resultados referentes as imagens digitalizadas com a 
resolução de 100 ppi contidos nas Tabelas 17, 21, 25 e 29, verifica-se que 31 amostras apresentaram incerteza da medida de largura e/ou comprimento altamente significativa, principalmente para as medidas de largura, não sendo adequada esta resolução para digitalizar imagens de sementes de milho com o objetivo de estimar medidas de comprimento e largura.

Observando os resultados contidos nas Tabelas 18, 22, 26 e 30, referentes a 32 imagens digitalizadas com a resolução de 150 ppi, verifica-se que os casos de incerteza de medida significativa totalizaram 13, portanto, menos freqüentes quando comparados às imagens digitalizadas com a resolução de 100 ppi, confirmando as afirmações que o aumento da resolução de digitalização permite melhor definição da imagem e, conseqüentemente, menor erro ao estimar atributos da imagem. Entretanto, como a resolução de 150 ppi também apresentou casos de incerteza de medida significativa, principalmente com relação à largura da amostra $18 \mathrm{C}$, esta resolução também não é adequada para digitalizar imagens de sementes de milho com o objetivo de estimar medidas de comprimento e largura.

Observando os resultados contidos nas Tabelas 19, 23, 27 e 31, referentes as imagens digitalizadas com a resolução de 200 ppi, verifica-se que em todos os casos, a incerteza de medida não foi significativa, sendo esta resolução adequada para digitalizar imagens de sementes de milho com o objetivo de estimar medidas de comprimento e largura. Ainda, verifica-se que 
em todos os casos estudados, as médias das diferenças de medida não diferiram entre si a $1 \%$ de probabilidade, significando que as medidas estimadas pelo modelo do retângulo em imagens digitalizadas com 200 ppi são precisas e é possivel empregar a média geral das diferenças, bem como o intervalo de confiança como fator de correção.

Observando os resultados contidos nas Tabelas $20,24,28$ e 32 , referentes as imagens digitalizadas com a resolução de 250 ppi, verifica-se que em 13 casos, a incerteza de medida foi altamente significativa contrariando as afirmações de que o aumento da resolução de digitalização permite estimar medidas mais exatas. Provavelmente, o fato é devido a presença de sombras, efeito que tende a ser pronunciado com o aumento da resolução de digitalização e pode ser confirmado com estudo específico.

É importante o estudo de sombras pois os efeitos sobre a incerteza de medida devem ser mais pronunciados quando tratamos de sementes com formato mais esférico, a exemplo das sementes classificadas com largura superior a 14/64", denominadas redondas. Não é recomendável a análise de imagens contendo sementes redondas digitalizadas como descrito no presente trabalho. Observou-se durante a digitalização das imagens, ser possivel minimizar o efeito das sombras com emprego de iluminação sobre o scanner, devendo ser conduzido um trabalho especifico para avaliar a sugestão. 


\subsection{Tamanho da amostra}

O tamanho da amostra empregada, 300 sementes, foi adequado para representar as diferenças de medida determinadas com o paquímetro (Tabela 50) e estimadas em imagens de sementes digitalizadas com as resoluções de 100, 150, 200 e 250 ppi contendo sementes nas posições ordenada/dorsal, ordenada/ventral, desordenada/dorsal e desordenada/ventral em relação às medidas correspondentes determinadas com o projetor de perfil com precisões requeridas iguais a 0,05 e $0,1 \mathrm{~mm}$ a $1 \%$ de significância. Para a precisão de $0,01 \mathrm{~mm}$, em todos os casos a amostra contendo 300 sementes foi insuficiente.

O número de sementes necessário para representar as diferenças de medida no caso do longuímetro e da peneira não foram consideradas em razão de que o tamanho da amostra é estimado levando em consideração o desvio padrão; como nestes casos o desvio padrão das diferenças de medida não deve ser considerado, pois as medidas para estes instrumentos foram agrupadas em maiores e menores do que $11,11 \mathrm{~mm}$ e não medidas, o tamanho da amostra necessária não foi determinado.

Observando as Tabelas 51 a 54, nas quais são apresentados os resultados estimados, com emprego da equação (1), do número de sementes 
necessário para medidas determinadas com o paquímetro e estimadas em imagens de sementes digitalizadas com a resolução de 200 ppi, contendo sementes arranjadas nas posições ordenada/dorsal, ordenada/ventral, desordenada/dorsal e desordenada/ventral, com precisões requeridas iguais a 0,$01 ; 0,05$ e $0,1 \mathrm{~mm}$ a $1 \%$ de significância, verifica-se que para a precisão proposta inicialmente igual a 0,05 uma amostra contendo 100 sementes é suficiente para estimar as medidas de comprimento e largura.

É importante observar que as médias do número de sementes contidas nas Tabelas 50 a 54 são apresentadas com a finalidade de ilustrar a magnitude da variação do tamanho da amostra em função da precisão requerida $(p)$. Para medidas com a precisão de $0,01 \mathrm{~mm}$ há a necessidade de um número de sementes superior a 700, o que dificulta a aplicação prática de qualquer método de medição para a avaliação da classificação de sementes de milho. Embora a precisão de $0,05 \mathrm{~mm}$ tenha sido adotada com base em relatos empíricos, não se dispondo na literatura de dados que justifiquem esta precisão, a inviabilidade prática da adoção de uma precisão de $0,01 \mathrm{~mm}$, justifica a não aplicação desta precisão para avaliar a classificação de sementes de milho até que estudos específicos venham a determinar a precisão ideal.

Quando empregadas amostras menores do que 100 sementes, considerar o número de sementes indicado para a amostra em cada situação 
em que as sementes foram digitalizadas, ou o maior tamanho de amostra destacado em negrito nas tabelas.

Observa-se que as amostras $18 \mathrm{C}$ e $22 \mathrm{C}$ requerem os maiores tamanhos de amostra, em função do desvio padrão elevado decorrente das formas irregulares das sementes que propiciam o inconveniente de sombras durante a digitalização da imagem.

Tabela 50: Número de sementes necessário $(n)$ para medidas com precisões (p) de 0,01; 0,05 e 0,1 mm, considerando as diferenças de comprimento e largura determinadas com o paquímetro em relação às medidas correspondentes, determinadas com o projetor de perfil em oito amostras de sementes de milho. Dados em milímetros $(\mathrm{mm})$.

\begin{tabular}{ccccccc}
\hline \hline Amostra & \multicolumn{7}{c}{$\mathrm{n}$} \\
\cline { 2 - 8 } & \multicolumn{7}{c}{ Comprimento } & \multicolumn{5}{c}{ Largura } \\
\cline { 2 - 7 } \cline { 2 - 7 } & 0,10 & 0,05 & 0,01 & 0,10 & 0,05 & 0,01 \\
\hline & 8 & 33 & 847 & 10 & 38 & 978 \\
$18 \mathrm{C}$ & 4 & 15 & 403 & 7 & 28 & 723 \\
$20 \mathrm{C}$ & 8 & 37 & 787 & 9 & 35 & 789 \\
$20 \mathrm{~L}$ & 5 & 23 & 489 & 6 & 28 & 887 \\
$22 \mathrm{C}$ & 11 & 41 & 1.069 & 9 & 35 & 917 \\
$22 \mathrm{~L}$ & 7 & 27 & 696 & 5 & 18 & 471 \\
$24 \mathrm{C}$ & 9 & 40 & 501 & 10 & 38 & 876 \\
$24 \mathrm{~L}$ & 6 & 25 & 598 & 7 & 25 & 499 \\
\hline Média & 8 & 30 & 674 & 8 & 31 & 768 \\
\hline \hline
\end{tabular}


Tabela 51: Número de sementes necessário $(n)$ para medidas com precisões (p) de 0,$01 ; 0,05$ e 0,1 mm, considerando as diferenças de comprimento estimadas pelo modelo do menor retângulo circunscrito em imagens de sementes de milho arranjadas na posição ordenada/dorsal e digitalizadas com a resolução de 200 ppi, em relação às medidas correspondentes determinadas com o projetor de perfil em oito amostras. Dados em milímetros (mm).

\begin{tabular}{|c|c|c|c|c|c|c|}
\hline \multirow[t]{4}{*}{ Amostra } & \multicolumn{6}{|c|}{ n } \\
\hline & \multicolumn{3}{|c|}{ Comprimento } & \multicolumn{3}{|c|}{ Largura } \\
\hline & \multicolumn{6}{|c|}{$\overline{p(m m)}$} \\
\hline & 0,10 & 0,05 & 0,01 & 0,10 & 0,05 & 0,01 \\
\hline $18 C$ & 15 & 59 & 1.545 & 18 & 68 & 1.767 \\
\hline $18 \mathrm{~L}$ & 8 & 29 & 753 & 14 & 52 & 1.358 \\
\hline $20 \mathrm{C}$ & 14 & 46 & 1.234 & 19 & 56 & 1.234 \\
\hline $20 \mathrm{~L}$ & 7 & 30 & 634 & 15 & 57 & 1.528 \\
\hline $22 \mathrm{C}$ & 11 & 42 & 1.099 & 17 & 64 & 1.661 \\
\hline $22 L$ & 6 & 24 & 613 & 13 & 49 & 1.273 \\
\hline $24 C$ & 10 & 36 & 976 & 18 & 56 & 1.230 \\
\hline $24 L$ & 6 & 38 & 421 & 16 & 67 & 1.567 \\
\hline Média & 10 & 38 & 909 & 16 & 59 & 1.453 \\
\hline
\end{tabular}


Tabela 52: Número de sementes necessário $(n)$ para medidas com precisões (p) de 0,01; 0,05 e 0,1 mm, considerando as diferenças de comprimento estimadas pelo modelo do menor retângulo circunscrito em imagens de sementes de milho arranjadas na posição ordenada/ventral e digitalizadas com a resolução de 200 ppi, em relação às medidas correspondentes determinadas com o projetor de perfil em oito amostras. Dados em milimetros (mm).

\begin{tabular}{|c|c|c|c|c|c|c|}
\hline \multirow[t]{4}{*}{ Amostra } & \multicolumn{6}{|c|}{$\overline{\mathrm{n}}$} \\
\hline & \multicolumn{3}{|c|}{ Comprimento } & \multicolumn{3}{|c|}{ Largura } \\
\hline & \multicolumn{6}{|c|}{$p(m m)$} \\
\hline & 0,10 & 0,05 & 0,01 & 0,10 & 0,05 & 0,01 \\
\hline $18 \mathrm{C}$ & 11 & 42 & 1.088 & 20 & 77 & 1.994 \\
\hline 18L & 6 & 23 & 591 & 11 & 42 & 1.094 \\
\hline $20 \mathrm{C}$ & 10 & 42 & 899 & 15 & 67 & 1.232 \\
\hline $20 \mathrm{~L}$ & 5 & 34 & 376 & 10 & 40 & 999 \\
\hline $22 \mathrm{C}$ & 8 & 33 & 850 & 16 & 62 & 1.618 \\
\hline $22 \mathrm{~L}$ & 5 & 21 & 540 & 10 & 38 & 986 \\
\hline $24 \mathrm{C}$ & 7 & 31 & 811 & 12 & 56 & 1.213 \\
\hline $24 \mathrm{~L}$ & 5 & 21 & 434 & 11 & 28 & 867 \\
\hline Média & 7 & 31 & 699 & 13 & 51 & 1.250 \\
\hline
\end{tabular}


Tabela 53: Número de sementes necessário $(n)$ para medidas com precisões (p) de 0,01; 0,05 e 0,1 mm, considerando as diferenças de comprimento estimadas pelo modelo do menor retângulo circunscrito em imagens de sementes de milho arranjadas na posição desordenada/dorsal e digitalizadas com a resolução de 200 ppi, em relação às medidas correspondentes determinadas com o projetor de perfil em oito amostras . Dados em milímetros $(\mathrm{mm})$.

\begin{tabular}{|c|c|c|c|c|c|c|}
\hline \multirow[t]{4}{*}{ Amostra } & \multicolumn{6}{|c|}{$\bar{n}$} \\
\hline & \multicolumn{3}{|c|}{ Comprimento } & \multicolumn{3}{|c|}{ Largura } \\
\hline & \multicolumn{6}{|c|}{$p(m m)$} \\
\hline & 0,10 & 0,05 & 0,01 & 0,10 & 0,05 & 0,01 \\
\hline $18 \mathrm{C}$ & 20 & 75 & 1.954 & 20 & 76 & 1.978 \\
\hline $18 \mathrm{~L}$ & 17 & 65 & 1.686 & 15 & 57 & 1.473 \\
\hline $20 \mathrm{C}$ & 15 & 65 & 1.589 & 18 & 65 & 1.567 \\
\hline $20 \mathrm{~L}$ & 13 & 54 & 1.236 & 12 & 47 & 1.234 \\
\hline $22 \mathrm{C}$ & 16 & 62 & 1.605 & 16 & 63 & 1.637 \\
\hline $22 \mathrm{~L}$ & 10 & 38 & 998 & 11 & 41 & 1.064 \\
\hline $24 \mathrm{C}$ & 10 & 56 & 1.019 & 14 & 57 & 1.457 \\
\hline $24 \mathrm{~L}$ & 8 & 28 & 789 & 9 & 39 & 987 \\
\hline Média & 14 & 55 & 1.360 & 14 & 56 & 1.425 \\
\hline
\end{tabular}


Tabela 54: Número de sementes necessário $(n)$ para medidas com precisões (p) de 0,01; 0,05 e 0,1 mm, considerando as diferenças de comprimento estimadas pelo modelo do menor retângulo circunscrito em imagens de sementes de milho arranjadas na posição desordenada/ventral e digitalizadas com a resolução de 200 ppi, em relação às medidas correspondentes determinadas com o projetor de perfil em oito amostras. Dados em milímetros (mm).

\begin{tabular}{|c|c|c|c|c|c|c|}
\hline \multirow[t]{4}{*}{ Amostra } & \multicolumn{6}{|c|}{$\overline{\mathrm{n}}$} \\
\hline & \multicolumn{3}{|c|}{ Comprimento } & \multicolumn{3}{|c|}{ Largura } \\
\hline & \multicolumn{6}{|c|}{$\overline{p(m m)}$} \\
\hline & 0,10 & 0,05 & 0,01 & 0,10 & 0,05 & 0,01 \\
\hline $18 \mathrm{C}$ & 14 & 52 & 1.362 & 12 & 46 & 1.193 \\
\hline $18 \mathrm{~L}$ & 12 & 47 & 1.219 & 11 & 42 & 1.090 \\
\hline $20 \mathrm{C}$ & 13 & 50 & 1.078 & 9 & 44 & 1.099 \\
\hline $20 \mathrm{~L}$ & 12 & 34 & 998 & 11 & 37 & 1.002 \\
\hline $22 \mathrm{C}$ & 16 & 60 & 1.563 & 13 & 51 & 1.325 \\
\hline $22 L$ & 15 & 58 & 1.505 & 10 & 38 & 988 \\
\hline $24 \mathrm{C}$ & 14 & 56 & 1.326 & 9 & 53 & 1.001 \\
\hline $24 \mathrm{~L}$ & 15 & 55 & 1.311 & 11 & 29 & 788 \\
\hline Média & 14 & 51 & 1.295 & 11 & 42 & 1.061 \\
\hline
\end{tabular}




\subsection{Considerações finais}

"É preciso ter coragem para modificar o que pode ser modificado, inteligência para aceitar o que não pode, e sabedoria para entender a diferença" R.D..

\subsubsection{Adequação dos parâmetros e procedimentos}

Considerando os resultados obtidos no presente trabalho, é possível sugerir, para a determinação das dimensões de comprimento e largura em sementes de milho com emprego da técnica de análise de imagens, os seguinte parâmetros e procedimentos:

- resolução de digitalização $\quad \rightarrow 200$ ppi em 24 bits;

- ordenação das sementes $\quad \rightarrow$ desordenadas, em razão da facilidade no manuseio das mesmas;

- posição das sementes

$\rightarrow$ ventral elou dorsal; 
- tamanho da amostra

- procedimento computacional $\rightarrow 100$ sementes (precisão de 0,05mm);

$\rightarrow$ método do retângulo circunscrito, no caso de ser empregado o sistema SIARCS $3.0^{\circledR}$.

\subsubsection{Sistema de classificação de sementes}

A técnica de análise de imagens apresenta as vantagens adicionais de permitir automatizar o sistema de classificação de sementes, possibilitando a obtenção das seguintes informações:

- valores médios das dimensões de comprimento e largura das sementes;

- distribuição de freqüência das dimensões de comprimento e largura das sementes;

- aferição da classificação comercial.

Sugere-se o emprego da técnica de análise de imagens para avaliação dos seguintes atributos de um lote de sementes:

- físicos $\rightarrow$ teor de material inerte, sementes de outras espécies e/ou outras cultivares, e o indice de sementes danificadas por insetos; 
- fisiológicos $\rightarrow$ índice de danos mecânicos, interpretação do teste de tetrazólio e avaliação do teste de germinação;

- sanidade $\rightarrow$ avaliação do índice de sementes com a presença de patógenos que afetem as características morfológicas da semente, a exemplo de Cercocpora kikushi em sementes de soja.

As sugestões acima citadas são apenas alguns exemplos de aplicações práticas possiveis da técnica de análise de imagens para a produção de sementes. Entretanto, é possivel sugerir o desenvolvimento de uma infinidade de novas aplicações práticas para a análise de imagens na produção de sementes ao considerarmos técnicas não destrutivas de aquisição de imagens, a exemplo de tomografia de resolução micrométrica e ressonancia nuclear magnética, que permitam obter imagens de estruturas vitais das sementes como as estruturas do embrião. Outra aplicação a ser considerada é a interpretação de testes sobre a constituição genética, a exemplo da eletroforese e outras técnicas afims, campo que deverá apresentar grande demanda de tecnologia com a recente promulgação da lei de proteção de cultivares e recentes avanços em engenharia genética e biotecnologia. 


\section{CONCLUSÃO}

Em função da adequação dos parâmetros e dos procedimentos estudados, conclui-se que o emprego da técnica de análise de imagens é viável para determinar o comprimento e a largura de sementes de milho, apresentando alta precisão e exatidão satisfatória, bem como vantagens adicionais em relação aos métodos tradicionais. 


\section{REFERÊNCIAS BIBLIOGRÁFICAS}

ASSAD, E.D.; SANO, E.E. Sistema de informação geográfica: aplicações na agricultura. Planaltina: EMBRAPA -CPAC, 1993. 1v.

BALASTREIRE, L.A. Semeadura convencional. In: BALASTREIRE, L.A. Máquinas Agricolas. São Paulo: Manole, 1990. p.146-207.

BARMMIGTON, R.D. The relation of seed, cell size, and speed to beet planter performance. Agricultural Engineering, v. 29, n. 12, p. 530-532, 1948.

BERNDT, G. Medida y medicion. In: COMPANY, M. Manual del ingeniero de taller. Tomo I. Barcelona: Editorial Gustavo Gili S.A., 1961. p.515-542

BEWLEY, J.D.; BLACK, M. Seeds: physiology of development and germination. $2^{\circ}$ ed. New York : Plenun Press, 1994. p.199-267. 
BRASIL. Ministério da Agricultura e Reforma Agrária. Regras para análise de sementes. Brasília: MARA, SNAD, LANARV,1992. 365p.

CASILLAS, A. TECNOLOGIA DA MEDIÇÃO. $4^{\circ}$ ed. São Paulo: Editora Mestre Jou, 1979. 100p.

CHINNAN, M.S.; YONG, J.H. ROHRBACK, R.P. Accuracy of seed spacing in peanuts planter. Transactions of the ASAE, v. 18, n. 5, p. 828-831, 1975.

COCHRAN, W.G. Técnicas de amostragem. $2^{\circ}$ ed. Trad. F. M. Barbosa. Rio de Janeiro: USAID, 1965. 555p.

COMPAIN, L. METROLOGIA DE TALLER. Bilbao: Urmo S.A. de Ediciones, 1974, 303p.

CRESTANA, S.; GUIMARÃES, M.F.; JORGE, L.A.C.; RALISCH, R.; TOZZI, C.L.; TORRE, A.; VAZ, C.M. Avaliação da distribuição de raízes no solo auxiliada por processamento de imagens digitais. Revista Brasileira de Ciência do Solo. v.18, n.3, p.365-372, 1994. 
CRUVINEL, P.E.; CRESTANA, S.; JORGE, L.A.C. Métodos e aplicações do processamento de imagens digitais. In: CRESTANA, S.; CRUVINEL, P.E.; MASCARENHAS, S.; BISCEGLI, C.I.; MARTIN-NETO, L.; COLNAGO, L.A. (Ed). Instrumentação Agropecuária: Contribuições no limiar do novo século. Brasília: EMBRAPA - SPI, 1996. p.91-151.

DAY, J.B. Color scanning handbook. Upper Saddle River: Prentice Hall PTR, 1997. 267p.

DUNCAN, W.G. Maize. In: EVANS, L.T. (Ed). Crop physiology: some case histories. Cambridge: University Press, 1975. p.23-50.

EMBRAPA - CNPMS. Tecnologia para produção de sementes de milho. Sete Lagoas: EMBRAPA - CNPMS, 1993. 61 p. (Circular Técnica, 19).

EMBRAPA - SPSB. Manual de normas técnicas para produção e execução do controle de qualidade dos híbridos duplos BR-210, BR-205 e BR206 da EMBRAPA. Brasília: EMBRAPA - SPSB, 1994. 29 p.

ETAC MERCADOS. Análise quinzenal sobre a tendência dos preços e cultura do milho no Brasil. Mercado de Milho, v. 9, n. 193, p. 1-4, 1993. 
FACON, J. Oportunidades do processamento de imagens na pesquisa agropecuária. In: SIMPÓSIO NACIONAL DE INSTRUMENTAÇÃO AGROPECUÁRIA - SIAGRO, 1996, São Carlos. CRUVINEL, P.E.; CRESTANA, S.; MARTIN-NETO, L.; COLNAGO, L.A.; MATTOSO, L.H.C. (Eds). Anais. Brasília: EMBRAPA - SPI, 1997. p.31-38.

FANCELLI, A.L.; DOURADO-NETO, D. Milho: Fisiologia da produção. In: FACELLI, A.L.; DOURADO-NETO, D. (coord.) Seminário sobre Fisiologia e Manejo de Água e de Nutrientes na Cultura do Milho de Alta Produtividade. Piracicaba: POTAFOS, 1996. p.9-20.

FONSECA, J.S.; MARTINS, G.A. Curso de estatística. $5^{\circ}$ ed. São Paulo: Editora Atlas S.A., 1995. 317p.

FRANÇA, G.E.; RESENDE, M.; ALVES, V.M.C.; ALBUQUERQUE, P.E.P. Comportamento de cultivares de milho sob irrigação com diferentes densidades de plantio e doses de nitrogênio. EMCAPA, 1990, p.106. (Documentos EMCAPA, 65).

FREIRE, J.M. INSTRUMENTOS E FERRAMENTAS MANUAIS. Rio de Janeiro: Livros Técnicos e Científicos Editora S.A., 1984. 184p. 
GAZZOLA, O. Produção e avaliação de um sistema dosador para semeadora de tração animal. Campinas, Faculdade de Engenharia Agrícola. Piracicaba, 1989. 130 p. Dissertação (Mestrado) - Escola Superior de Agricultura "Luiz de Queiroz", Universidade de São Paulo.

GONZALEZ, R.C.; WINTZ, P.A. Digital Image Processing. Reading: AddisonWesley Publishing Company Inc, 1987. 431p.

GOMES, F.P. Curso de estatística experimental. 13ed. São Paulo: Nobel, 1990. 468p.

GOODMAN, M.M. História e origem do milho. In: PATERNIANI, E. Melhoramento e produção do milho no Brasil. Piracicaba: ESALQ, 1978, p. $1-18$.

GUNASEKARAN, S.; COOPER, T.M.; BERLAGE, A.G. Soybean seed coat and cotyledon crack detection by image processing. Journal of Agricultural Engineering Research, v.41, p.139-148, 1988a.

GUNASEKARAN, S.; COOPER, T.M.; BERLAGE, A.G. Evaluating quality factors of corn and soybeans using a computer vision system. Transactions of the ASAE, v.31, n.4, p.1264-1271, 1988b. 
HEGRON, G. Image synthesis. Cambridge: MIT Press, 1988. p.18-28.

HEIBERGER, R.M. Computation for the Analysis of Designed Experiments. New York: John Wiley \& Sons, 1989. 683p.

HOWARTH, M.S.; STANWOOD, P.C. Tetrazolium staining viability seed test using color image processing. Transactions of the ASAE, v.36, n.6, p.1937-1940, 1993.

HUME, K.J. Metrologia Industrial. $2^{\circ}$ ed. Madrid: Editorial River S.A., 1962. $379 p$.

IHRIG, S.; IHRIG, E. Scanning: the professional way. Berkeley: Osborne McGraw-Hill, 1997. 148p.

JORGE, L.A.C.; CRESTANA, S. SIARCS 3.0: novo aplicativo para análise de imagens digitais aplicado a ciência do solo. In: CONGRESSO LATINO DE CIÊNCIA DO SOLO, 13., Águas de Lindóia, 1996. Solo Suelo 96. Campinas: Sociedade Brasileira de Ciência do solo, 1996. p.5.

KENNEDY, C.W. INSPECCION Y CALIBRADO. Bilbao: Urmo S.A. de Ediciones, 1973. 573p. 
KEPNER, R.A.; BAYNER, R.; BARGER, E.L. Principles of farm machinery. New York: John Valey, 1978. 571 p.

KRANZIER, G.A. Applyning digital image processing in agriculture. Agricultural Engineering, v.66, n.3, p.11-13, 1985.

LENZI, E.A; MACHADO, J.R. Influência de espaçamento e distribuições espaciais de plantas nas características e agronômicas do milho. In: Congresso Nacional de Milho e sorgo, 21., Londrina, 1996. Produtividade, qualidade, integração; resumos. Londrina: ABMS/IAPAR, 1996a. p.194.

LENZI, E.A.; MACHADO, J.R. Componentes de produção em combinações espaciais de plantas de milho. In: Congresso Nacional de Milho e sorgo, 21., Londrina, 1996. Produtividade, qualidade, integração; resumos. Londrina: ABMS/IAPAR, 1996b. p.195.

MANTOVANI, E.C.; BERTAUX, S.; MANTOVANI, B.H.M. Uso de câmara de vídeo VHS em bancada de teste para semeadora. In: Congresso Brasileiro de Engenharia Agrícola, 1991, Londrina. Anais. Londrina: ABEA/EMBRAPA, 1991. p.1386. 
McCUEN, R.H. Statistical Methods for Engineers. Englewood Cliffs: PrenticeHall Inc., 1985. 439p.

MCDONALD, T.; CHEN, Y.R. Application of morphological image processing in agriculture. Transactions of the ASAE, v.33, n.4, p.1345-1352, 1990.

MEROTTO JR., A.; ALMEIDA, M. FUCHS, O. Aumento do rendimento de grãos de milho proporcionado pelo aumento da população de plantas. In: Congresso Nacional de Milho e sorgo, 21., Londrina, 1996. Produtividade, qualidade, integração; resumos. Londrina: ABMS/IAPAR, 1996. p. 193.

PRATT, W.K. Digital image processing. New York: John Wiley \& Sons, 1978. $750 p$.

ROSSMANN, E.C.; COOK, R.I.L. Soil preparation and rate and pattern of planting. In: PIERRE, W.H.; ALDRICH, S.A.; MARTIN, W.P. (Eds). Advances in corn production, principles and pratices. lowa State University Press, 1966. p. 53-101.

SAS. STAT USER'S GUIDE: version 6. $4^{\circ}$ ed. SAS Institute Inc., 1990. 890p. 
SHATADAL, P.; JAYAS, D.S.; BULLEY, N.R. Digital image analysis for software separation and classification of touching grains: disconnect algorithm. Transactions of the ASAE, v.38, n.2, p.635-643, 1995.

SEARS, F.W.; ZEMANSKYM.W. Física: mecânica - hidrodinâmica. Rio de Janeiro: Livros Técnicos e Científicos Editora, 1980. 207p. v.3.

SOUZA, J. Sementes: produção, distribuição e comercialização. In: OSUNA, J.A.; MORO, J.R. (Eds). Produção e melhoramento do milho. Jaboticabal: FUNEP, 1995. p.99-108.

SPIEGEL, M. Probabilidade e estatística. Trad. Alfredo Alves de Faria. São Paulo: McGraw-Hill do Brasil, 1978. 518p.

SUPHOT, P.; KITIMA, M. Effects of nitrogen fertilizer on nitrate reductase grain yield and some agronomic characteristicas in corn (Zea mays L.). Kasetsart Journal, v. 11, n. 1-2, p. 33-49, 1977.

TANAKA, A.; YAMAGUCHI, J. Producción de materia seca, componentes del redimiento y rendimiento del grano en maíz. Chapingo: Colégio de Postgraduados, 1977. 124p. 
TOLEDO, F.F.; MARCOS FILHO, J. Manual das sementes: tecnologia da produção. São Paulo: Editora Agronômica Ceres, 1977. 224 p.

VAUGHAN, C.E.; GREGG, B.R.; DELOUCHE, J.C. Beneficiamento e manuseio de sementes. Brasília: AGIPLAN, 1976. 195 p.

VIEGAS, G.P. Práticas culturais. In: PATERNIANI, E. Melhoramento e produção do milho no Brasil. Piracicaba: ESALQ, 1978. p. 398-405.

VOOREN, J.G.; POLDER, G.; HEIJDEN, G.W.A.M. Identification of mushroom cultivars using image analysis. Transactions of the ASAE, v.35, n.1, p.347-350, 1992.

VOOREN, J.G.; HEIJDEN, G.W.A.M. Measuring the size of French beans with image analysis. Plant Varieties and Seeds, v.6, n.47, p.47-353, 1993.

VOSSEPOEL, A.M.; SMEUDERS, A.W.M. Vector code probability and metrication error in the representation of stright lines of finite lenght. Computer Graphics and Image, v.20, p.347-364, 1982.

WAYNER, P. How microchips shok the world. Byte, v.21, n.12, p.68-74, 1996. 
WELCH, G. B. Beneficiamento de sementes no Brasil. $2^{\circ}$ ed. Brasilia: AGIPLAN, 1974. $205 \mathrm{p}$.

WESTERLIND, E. Seed scanner, a computer-based device for determinations of other seeds by nunber in cereal seed. Seed Science and Technology, v.16, p.289-297, 1988.

ZAYAS, I.; CONVERSE, H.; STEELE, J. Discrimination of whole from broken corn kernels with image analysis. Transactions of the ASAE, v.33, n.5, p. 1642-1646, 1990. 